Provided for non-commercial research and education use. Not for reproduction, distribution or commercial use.

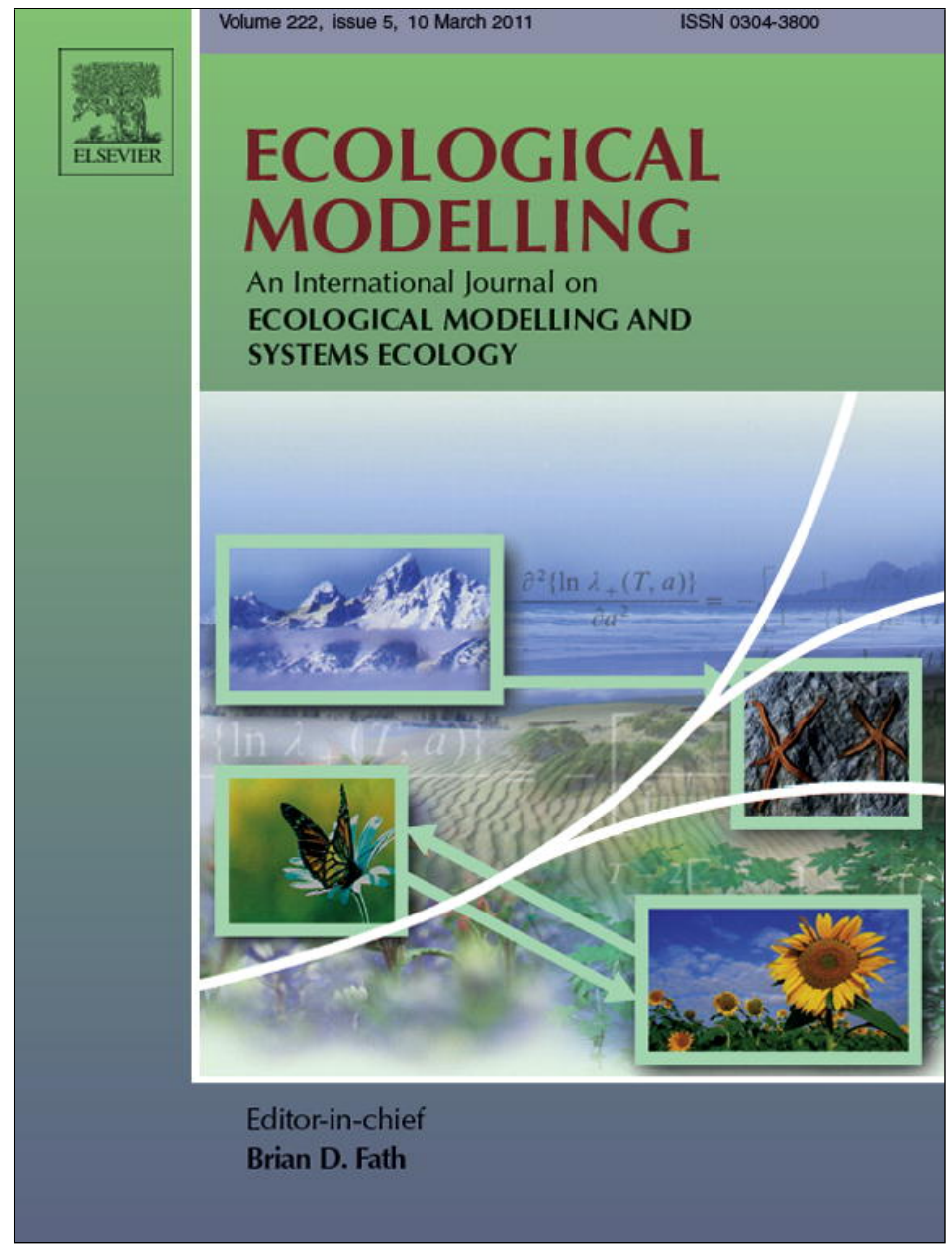

This article appeared in a journal published by Elsevier. The attached copy is furnished to the author for internal non-commercial research and education use, including for instruction at the authors institution and sharing with colleagues.

Other uses, including reproduction and distribution, or selling or licensing copies, or posting to personal, institutional or third party websites are prohibited.

In most cases authors are permitted to post their version of the article (e.g. in Word or Tex form) to their personal website or institutional repository. Authors requiring further information regarding Elsevier's archiving and manuscript policies are encouraged to visit:

http://www.elsevier.com/copyright 


\title{
Modeling the seasonal autochthonous sources of dissolved organic carbon and nitrogen in the upper Chesapeake Bay
}

\author{
David P. Keller*, Raleigh R. Hood \\ Horn Point Laboratory, University of Maryland Center for Environmental Science, P.O. Box 775, Cambridge, MD 21613, USA
}

\section{A R T I C L E I N F O}

\section{Article history:}

Received 27 August 2010

Received in revised form

10 December 2010

Accepted 16 December 2010

Available online 15 January 2011

\section{Keywords:}

Dissolved organic matter (DOM) cycling

Dissolved organic nitrogen (DON) cycling

Dissolved organic carbon (DOC) cycling

Marine biogeochemical ecosystem model

\begin{abstract}
A B S T R A C T
In this paper we investigate the seasonal autochthonous sources of dissolved organic carbon (DOC) and nitrogen (DON) in the euphotic zone at a station in the upper Chesapeake Bay using a new mass-based ecosystem model. Important features of the model are: (1) carbon and nitrogen are incorporated by means of a set of fixed and varying C:N ratios; (2) dissolved organic matter (DOM) is separated into labile, semi-labile, and refractory pools for both $\mathrm{C}$ and $\mathrm{N}$; (3) the production and consumption of DOM is treated in detail; and (4) seasonal observations of light, temperature, nutrients, and surface layer circulation are used to physically force the model. The model reasonably reproduces the mean observed seasonal concentrations of nutrients, DOM, plankton biomass, and chlorophyll $a$. The results suggest that estuarine DOM production is intricately tied to the biomass concentration, ratio, and productivity of phytoplankton, zooplankton, viruses, and bacteria. During peak spring productivity phytoplankton exudation and zooplankton sloppy feeding are the most important autochthonous sources of DOM. In the summer when productivity peaks again, autochthonous sources of DOM are more diverse and, in addition to phytoplankton exudation, important ones include viral lysis and the decay of detritus. The potential importance of viral decay as a source of bioavailable DOM from within the bulk DOM pool is also discussed. The results also highlight the importance of some poorly constrained processes and parameters. Some potential improvements and remedies are suggested. Sensitivity studies on selected parameters are also reported and discussed.
\end{abstract}

(C) 2011 Elsevier B.V. All rights reserved.

\section{Introduction}

In many mid-Atlantic estuaries, the biochemical composition and isotopic signature of DOM changes across the salinity gradient with biomarkers and carbon isotopes indicating that a significant amount of DOM production and modification occurs within the estuary (Loh et al., 2006; Mannino and Harvey, 2000; Raymond and Bauer, 2001). In the largest of these estuaries, Chesapeake Bay, DOC exhibits a non-conservative distribution at certain times of the year, suggesting that seasonal autochthonous DOM production can be significant (Fisher et al., 1998; Rochelle-Newall and Fisher, 2002). Fisher et al. (1998) estimated that this DOC accumulation was greater than atmospheric or terrestrial organic carbon inputs and was equivalent to $\sim 10 \%$ of estuarine primary production. Dissolved organic nitrogen (DON) has also been suggested to accumulate seasonally in estuaries (Bronk, 2002; Bronk et al., 1998; Lomas et al., 2002). Radiocarbon measurements of

\footnotetext{
* Corresponding author. Present address: IFM-GEOMAR, Leibniz-Institut für Meereswissenschaften, Düsternbrooker Weg 20, 24105 Kiel, Germany. Tel.: +490431600 4513.

E-mail address: dkeller@ifm-geomar.de (D.P. Keller).
}

estuarine, continental shelf, and slope DOM indicate that the large pool of $>10 \mathrm{kDa}$ DOM is relatively young and has a residence time of 1-30 days, whereas the smaller pool of $1-10 \mathrm{kDa}$ DOM is between 380 and 4500 years old (Santschi et al., 1995). These observations suggest that autochthonous estuarine DOM production plays an important role in estuarine biogeochemistry. An understanding of these sources and their effect on the DOM cycle is critical for constraining local carbon and nitrogen budgets and for evaluating the role of estuaries in the global carbon cycle.

In the euphotic zone of the Chesapeake Bay estuary, the site of this study, several sources and processes control DOM cycling. The major allochthonous source of DOM is the Susquehanna river (Fisher et al., 1998). Smaller rivers (sub-estuaries), atmospheric deposition (Seitzinger and Sanders, 1999), wetland discharge (Tzortziou et al., 2008), and terrestrial runoff and leaching (Berman and Bronk, 2003) also add significant amounts of DOM to the estuary. Internal sources of DOM include benthic fluxes (Burdige and Zheng, 1998), extracellular release by phytoplankton, grazer-mediated release and excretion, release via cell lysis (both viral and bacterial), solubilization of particles, and bacterial transformation and release (Carlson, 2002). Free-living heterotrophic bacterioplankton are the dominant consumers of DOM (Nagata, 
2000). Some phytoplankton also have the ability to take up DOM to supplement their metabolic needs (Mulholland et al., 2003). Photochemical processes, through UV excitation, directly and indirectly remove and transform DOM (Mopper and Kieber, 2002). DOM can also potentially form gels that may aggregate to form particulate organic matter (POC) (Verdugo et al., 2004) which may sink out of surface waters. As in other temperate systems, the rate and magnitude of these sources and sinks varies on a seasonal basis as changes in light, temperature, and freshwater flow affect the environment (Apple et al., 2006; Bronk et al., 1998; Jonas and Tuttle, 1990; Lomas et al., 2002; Malone et al., 1991; Mulholland et al., 2003; Shiah and Ducklow, 1994b; Wommack et al., 1992).

Quantifying the role of these sources and sinks in Chesapeake Bay DOM cycling has proven difficult. Most of the research has focused on characterizing the composition of DOM and understanding the individual role of different functional groups (i.e., primary producers, secondary consumers, predators, etc.) and species in DOM cycling. Few studies have quantified the amounts of $\mathrm{C}$ or $\mathrm{N}$ that flux into, and out, of the DOM pool relative to the other major $\mathrm{C}$ and $\mathrm{N}$ pools. Those that have provide an incomplete picture of DOM cycling as they often cannot distinguish between the individual sources and sinks of DOM (Bronk et al., 1994, 1998). Additionally, as far as we are aware, there are no long-term time series measurements of the $\mathrm{C}$ and $\mathrm{N}$ flux through the DOM pool that adequately describe the annual DOM cycle.

Models can be a powerful tool for integrating data and running long term simulations. They are also valuable for determining the magnitude and importance of processes that are difficult to measure and observe in the field. Many recent coastal and open ocean biogeochemical ecosystem models have included DOM (Anderson and Pondaven, 2003; Anderson et al., 2007; Anderson and Williams, 1998, 1999; Aumont et al., 2003; Baklouti et al., 2006a,b; Druon et al., 2010; Faure et al., 2006; Grégoire and Soetaert, 2010; Llebot et al., 2010; Luo et al., 2010; Nakata and Doi, 2006; Pahlow and Vézina, 2003; Pahlow et al., 2008; Polimene et al., 2006, 2007; Ruardij et al., 2005; Salihoglu et al., 2008; Schmittner et al., 2005; Vichi et al., 2007) in order to better simulate and understand biogeochemical cycles. Carbon and nitrogen are typically accounted for in these models, although a few include phosphorus as well. Most of these models are quite complex and typically have state variables that describe the lability of DOM and multiple size classes or functional types of phytoplankton and zooplankton. Bacteria are also often, but not always, included as state variables. Sources and sinks of DOM such as phytoplankton exudation, zooplankton grazing processes, the breakdown of detritus, and uptake by bacteria are almost always accounted for in these models. However, other processes that play a role in DOM cycling, like viral lysis and photochemical reactions, are often implicitly accounted for, if at all. Despite the recognized importance of DOM cycling in these and many other studies, few estuarine biogeochemical models have included DOM cycling.

In this paper we describe a modeling study of the DOM cycle in the surface waters of Chesapeake Bay. Our objective is to elucidate the seasonal autochthonous sources of DOC and DON in the upper bay. We specifically focus on the roles that phytoplankton extra-cellular release, non-grazing mortality, bacterial and phytoplankton viral lysis, and grazer-mediated sloppy feeding, egestion, and excretion play in the production of DOM. In addition, we explore how seasonal variability affects the physical, chemical, and biological processes that drive DOM cycling. Observations are used to evaluate the model performance. Through comparisons with observations we show that the model is capable of reproducing the seasonal patterns in plankton biomass and productivity. This then allows us to examine how biologically mediated DOM production, transformation, and consumption change in response to seasonal forcing. These comparisons also highlight the importance of some

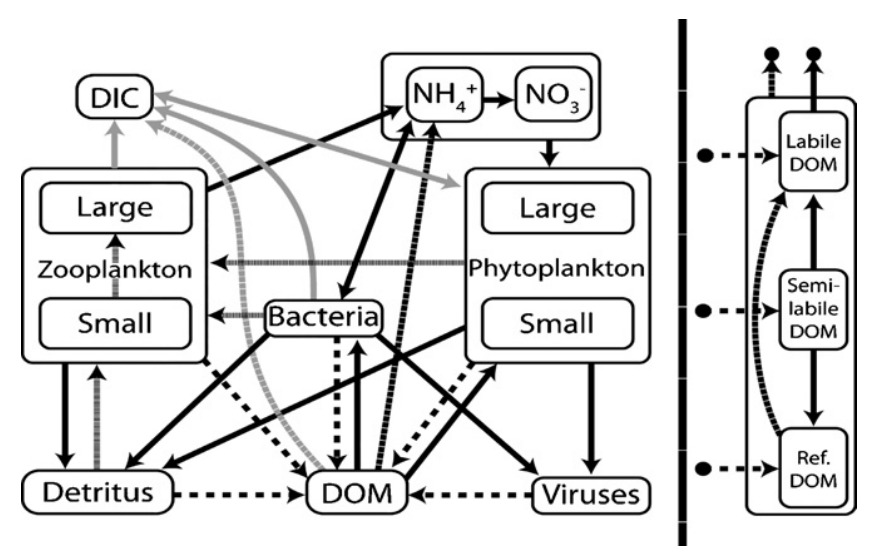

Fig. 1. A schematic diagram of the ecosystem model. Grey lines indicate the flow of carbon only. Segmented lines indicate photochemical reactions. Dashed lines indicate sources of DOM. Hatched lines indicate zooplankton grazing. Processes within the DOM pool are shown on the right.

poorly constrained processes that require additional research or more complex numerical approaches.

\section{Model description}

The model of Anderson and Williams (1998) provided the basic structure for our biogeochemical model. However, we modified their model in several significant ways to explicitly account for specific sources of DOM and photochemical reactions that effect DOM. Important modifications include: (1) dividing DOM into labile, semi-labile, and refractory pools, (2) dividing zooplankton and phytoplankton into two size classes, (3) removing sedimentation, (4) including phytoplankton and bacterial viruses as state variables, and (5) including dissolved inorganic carbon (DIC) as a state variable. A complete list of the model equations can be found in the Appendix (Section A.2). Tables 1 and 2 give lists of parameters and variables used in the model. Fig. 1 is a schematic diagram that shows the flow of nitrogen, and in some instances carbon, between the model compartments.

The model includes 18 state variables that span the herbivorous and microbial food webs, with compartments for large phytoplankton $\left(P_{L}\right)$, small phytoplankton $\left(P_{S}\right)$, large zooplankton $\left(Z_{L}\right)$, small zooplankton $\left(Z_{S}\right)$, bacteria $(B)$, phytoplankton viruses $\left(V_{P}\right)$, bacteriophages $\left(V_{B}\right)$, ammonium $(A)$, nitrate $\left(N_{n}\right)$, detritus $\left(D_{N}\right.$ and $\left.D_{C}\right)$, dissolved inorganic carbon (DIC), and labile $\left(L_{C}\right.$ and $\left.L_{N}\right)$, semi-labile $\left(S_{C}\right.$ and $\left.S_{N}\right)$, and refractory $\left(R_{C}\right.$ and $\left.R_{N}\right)$ DOC and DON. Nitrogen is the basic unit for simulation and mass balance. However, carbon has been accounted for by allowing the state variables to have fixed or varying C: $\mathrm{N}$ ratios. Close attention has been paid to the formulation of the interactions between these two elements. Thus, both the carbon and nitrogen cycles have been constrained. Phosphorus was not included in the model.

\subsection{Station description and data availability}

The model was formulated to simulate the mean seasonal cycling of dissolved organic matter in the surface layer at the Chesapeake Bay Program's (CBP) station CB3.3C $\left(38.9960^{\circ} \mathrm{N}, 76.3597^{\circ} \mathrm{W}\right)$ which is located in the main channel of the upper Chesapeake Bay near the bay bridge (Fig. 2). The mean water depth at this station from 1997 to 2007 was $25 \mathrm{~m}$ with a mixed layer depth that ranged seasonally between 3.25 and $7.37 \mathrm{~m}$. Due to physical circulation and the influence of Susquehanna River flow the mixed layer was deeper during in the summer than at other times of year. Mean surface salinities at this station ranged between 5.05 and 11.86 with the highest salinities occurring in the summer. The mean seasonal 
Table 1

Model parameters.

\begin{tabular}{|c|c|c|c|}
\hline Description & Symbol & Value & Units \\
\hline Phytoplankton light saturation parameter & $I_{P}$ & 40 & $\mathrm{Wm}^{-2}$ \\
\hline Phytoplankton photoinhibition parameter & $I_{\beta}$ & 400 & $W m^{-2}$ \\
\hline Partitioning of phytoplankton production & $\alpha$ & 0.95 & Dimensionless \\
\hline Phytoplankton excretion parameter & $\varpi_{2}$ & 0.26 & Dimensionless \\
\hline Phytoplankton C:N ratio & $\lambda_{P}$ & 7.5 & $\mathrm{~mol} \mathrm{~mol}^{-1}$ \\
\hline Half-sat. const. for $N_{n}$ uptake by $P_{L}$ & $K_{P_{L} N_{n}}$ & 20 & $\mu \mathrm{M}$ \\
\hline Half-sat. const. for $A$ uptake by $P_{L}$ & $K_{P_{L} A}$ & 15 & $\mu \mathrm{M}$ \\
\hline Half-sat. const. for $N_{n}$ uptake by $P_{S}$ & $K_{P_{S} N_{n}}$ & 20 & $\mu \mathrm{M}$ \\
\hline Half-sat. const for $A$ uptake by $P_{S}$ & $K_{P_{S} A}$ & 10 & $\mu \mathrm{M}$ \\
\hline Half-sat. const for DON uptake by phytoplankton & $K_{P_{L \text { or } S} L_{N}}$ & 20 & $\mu \mathrm{M}$ \\
\hline Large zooplankton maximum consumption rate & $C_{Z_{L}}$ & 1.0 & $\mathrm{~d}^{-1}$ \\
\hline Small zooplankton maximum consumption rate & $C_{Z_{S}}$ & 2.0 & $\mathrm{~d}^{-1}$ \\
\hline Zooplankton assimilation efficiency $(\mathrm{N})$ & $\beta_{N_{Z}}$ & 0.77 & Dimensionless \\
\hline Zooplankton assimilation efficiency (C) & $\beta_{C_{Z}}$ & 0.64 & Dimensionless \\
\hline Large zooplankton growth coefficient & $g e_{Z_{L}}$ & 0.75 & Dimensionless \\
\hline Small zooplankton growth coefficient & $\begin{array}{ll}g L_{L} \\
g Z_{S}\end{array}$ & 0.40 & Dimensionless \\
\hline Half-sat. const. for zooplankton grazing & $K_{Z}$ & 0.75 & $\mu \mathrm{M}$ \\
\hline Large zooplankton preference for $P_{L}$ & $\Phi_{P_{L}}$ & 0.20 & Dimensionless \\
\hline Large zooplankton preference for $P_{S}$ & $\Phi_{P_{S}}$ & 0.15 & Dimensionless \\
\hline Large zooplankton preference for $D$ & $\Phi_{D}$ & 0.20 & Dimensionless \\
\hline Large zooplankton preference for $Z_{L}$ & $\Phi_{Z_{L}}$ & 0.20 & Dimensionless \\
\hline Large zooplankton preference for $Z_{S}$ & $\Phi_{Z_{S}}$ & 0.20 & Dimensionless \\
\hline Large zooplankton preference for $B$ & $\Phi_{B}$ & 0.05 & Dimensionless \\
\hline Small zooplankton preference for $P_{L}$ & $\varphi_{P_{L}}$ & 0.15 & Dimensionless \\
\hline Small zooplankton preference for $P_{S}$ & $\varphi_{P_{S}}$ & 0.25 & Dimensionless \\
\hline Small zooplankton preference for $D$ & $\varphi_{D}$ & 0.20 & Dimensionless \\
\hline Small zooplankton preference for $Z_{S}$ & $\varphi_{Z_{S}}$ & 0.20 & Dimensionless \\
\hline Small zooplankton preference for $B$ & $\varphi_{B}$ & 0.20 & Dimensionless \\
\hline Zooplankton C:N ratio & $\lambda_{z}$ & 5.5 & $\mathrm{~mol} \mathrm{~mol}^{-1}$ \\
\hline Bacterial gross growth efficiency & $\operatorname{gge}_{B}$ & 0.30 & $\operatorname{molC}(\mathrm{molC})^{-1}$ \\
\hline Maximum bacterial growth rate & $\mu_{B}$ & 13.3 & $d^{-1}$ \\
\hline Half-sat. const. for ammonium uptake by bacteria & $K_{B A}$ & 0.50 & $\mu \mathrm{M}$ \\
\hline Half-sat. const. for labile DOC uptake by bacteria & $K_{L_{C}}$ & 25 & $\mu \mathrm{M}$ \\
\hline Bacteria C: $\mathrm{N}$ ratio & $\lambda_{B}$ & 5.1 & $\mathrm{~mol} \mathrm{~mol}^{-1}$ \\
\hline Viral decay rate & $v$ & 0.60 & $\mathrm{~h}^{-1}$ \\
\hline Virus $\mathrm{C}: \mathrm{N}$ ratio & $\lambda_{V}$ & 3.26 & $\mathrm{~mol} \mathrm{~mol}^{-1}$ \\
\hline Production of new viruses from lysis & $\varepsilon_{V}$ & 0.50 & Dimensionless \\
\hline Partitioning of sloppy feeding on lrg. zooplankton & $\omega_{Z_{L}}$ & 0.69 & Dimensionless \\
\hline Partitioning of sloppy feeding on detritus & $\omega_{D}$ & 0.24 & Dimensionless \\
\hline Partitioning of sloppy feeding on lrg. phytoplankton & $\omega_{P_{L}}$ & 0.26 & Dimensionless \\
\hline Partitioning of mortality to detritus and DOM & $\beta_{1}$ & 0.66 & Dimensionless \\
\hline Partitioning of "extra C" from lysis to LC & $\beta_{2}$ & 0.025 & Dimensionless \\
\hline Partitioning of "extra C" from lysis to SC & $\beta_{3}$ & 0.224 & Dimensionless \\
\hline Partitioning of "extra C" from lysis to RC & $\beta_{4}$ & 0.001 & Dimensionless \\
\hline Partitioning of "extra C" from lysis to detritus & $\beta_{5}$ & 0.75 & Dimensionless \\
\hline Partitioning of sloppy feeding and B mort to detritus & $\rho_{D}$ & 0.25 & Dimensionless \\
\hline Partitioning of sloppy feeding and B mort. to labile DOM & $\rho_{L}$ & 0.40 & Dimensionless \\
\hline Partitioning of sloppy feeding and B mort. to semi-labile DOM & $\rho_{S}$ & 0.34 & Dimensionless \\
\hline Partitioning of sloppy feeding and B mort. to refractory DOM & $\rho_{R}$ & 0.01 & Dimensionless \\
\hline Labile fraction of DOM from detritus decay & $\delta_{1}$ & 0.50 & Dimensionless \\
\hline Semi-labile fraction of DOM from detritus decay & $\delta_{2}$ & 0.49 & Dimensionless \\
\hline Refractory fraction of DOM from detritus decay & $\delta_{3}$ & 0.01 & Dimensionless \\
\hline Maximum rate of semi-labile DOM hydrolysis & $\mu_{S}$ & 4.0 & $\mathrm{~d}^{-1}$ \\
\hline Half-sat. const. for DOM hydrolysis & $K_{S}$ & 417 & $\mu \mathrm{MC}$ \\
\hline Partitioning of phytoplankton DOM leakage and plankton mortality to labile DOM & $O_{L}$ & 0.40 & Dimensionless \\
\hline Partitioning of phytoplankton DOM leakage and plankton mortality to semi-labile DOM & $O_{S}$ & 0.59 & Dimensionless \\
\hline Partitioning of phytoplankton DOM leakage and plankton mortality to refractory DOM & $O_{R}$ & 0.01 & Dimensionless \\
\hline Partitioning of lysis product to D & $\varepsilon_{D}$ & 0.375 & Dimensionless \\
\hline Partitioning of lysis product to labile DOM & $\varepsilon_{L}$ & 0.062 & Dimensionless \\
\hline Partitioning of lysis product to semi-labile DOM & $\varepsilon_{S}$ & 0.062 & Dimensionless \\
\hline Partitioning of lysis product to refractory DOM & $\varepsilon_{R}$ & 0.001 & Dimensionless \\
\hline Breakdown of N detritus to DOM & $\chi_{D_{N}}$ & 0.055 & $\mathrm{~d}^{-1}$ \\
\hline Breakdown of $\mathrm{C}$ detritus to DOM & $\chi_{D_{C}}$ & 0.040 & $\mathrm{~d}^{-1}$ \\
\hline Partitioning of viral decay to DOM & $\eta$ & 0.10 & Dimensionless \\
\hline UV photooxidation of refractory DOM & $\zeta$ & 0.0015 & $\mathrm{~d}^{-1}$ \\
\hline Partitioning of zooplankton excretion to DON and ammonium & $\kappa_{Z}$ & 0.68 & Dimensionless \\
\hline Partitioning of zooplankton DOM excretion to labile and semi-labile pools & $\mathrm{O}_{Z}$ & 0.70 & Dimensionless \\
\hline Partitioning of zooplankton metabolized carbon to DIC and DOC & $\sigma_{Z}$ & 0.69 & Dimensionless \\
\hline Rate of DOC photooxidation to DIC & $\chi_{U v_{C}}$ & 0.004 & $\mathrm{~d}^{-1}$ \\
\hline Rate of DON photooxidation to ammonium & $\chi_{U V_{N}}$ & 0.0005 & $\mathrm{~d}^{-1}$ \\
\hline
\end{tabular}


Table 2

List of model variables.

\begin{tabular}{|c|c|c|}
\hline Variable & Symbol & Units \\
\hline Ammonium & $A$ & $\mu \mathrm{MN}$ \\
\hline Bacteria & $B$ & $\mu \mathrm{MN}$ \\
\hline Bacteriophages & $V_{B}$ & $\mu \mathrm{MN}$ \\
\hline Detritus & $D_{N}$ & $\mu \mathrm{MN}$ \\
\hline Detritus & $D_{C}$ & $\mu \mathrm{MC}$ \\
\hline Dissolved inorganic carbon & DIC & $\mu \mathrm{MC}$ \\
\hline Labile DOC & $L_{C}$ & $\mu \mathrm{MC}$ \\
\hline Labile DON & $L_{N}$ & $\mu \mathrm{MN}$ \\
\hline Large phytoplankton & $P_{L}$ & $\mu \mathrm{MN}$ \\
\hline Large zooplankton & $Z_{L}$ & $\mu \mathrm{MN}$ \\
\hline Nitrate & $N_{n}$ & $\mu \mathrm{MN}$ \\
\hline Phytoplankton viruses & $V_{P}$ & $\mu \mathrm{MN}$ \\
\hline Refractory DOC & $R_{C}$ & $\mu \mathrm{MC}$ \\
\hline Refractory DON & $R_{N}$ & $\mu \mathrm{MN}$ \\
\hline Semi-labile DOC & $S_{C}$ & $\mu \mathrm{MC}$ \\
\hline Semi-labile DON & $S_{N}$ & $\mu \mathrm{MN}$ \\
\hline Small phytoplankton & $P_{S}$ & $\mu \mathrm{MN}$ \\
\hline Small zooplankton & $Z_{S}$ & $\mu \mathrm{MN}$ \\
\hline Irradiance & $I$ & $\mathrm{~W} \mathrm{~m}^{-2}$ \\
\hline Vertical light attenuation coefficient & $K_{d}$ & $\mathrm{~m}^{-1}$ \\
\hline Mortality of plankton $\left(i=B, P_{L}, P_{S}, Z_{L}\right.$, or $\left.Z_{S}\right)$ & $S_{i}$ & $\mathrm{~d}^{-1}$ \\
\hline Biomass from mortality not exported & $m$ & $\mathrm{~d}^{-1}$ \\
\hline Maximum phytoplankton growth rate & $\mu_{P}$ & $\mathrm{~d}^{-1}$ \\
\hline Light-limited phytoplankton growth & $J_{P_{L \text { orS }}}$ & $\mathrm{d}^{-1}$ \\
\hline Nutrient limitation of phytoplankton & $\begin{array}{l}\text { LorS } \\
Q_{P_{L \text { orS }}}\end{array}$ & None \\
\hline Ammonium limitation of phytoplankton & $Q_{P_{L o r S}}^{1}$ & None \\
\hline Labile DON limitation of phytoplankton & $Q_{P_{L}}^{2}$ & None \\
\hline Nitrate limitation of phytoplankton & $Q_{P_{L}}^{3}$ & None \\
\hline Extra photosynthetic carbon exudation & $E_{P_{L \text { orS }}}$ & $\mu \mathrm{MCd}^{-1}$ \\
\hline Viral infection rate $\left(i=B, P_{L}\right.$, or $\left.P_{S}\right)$ & $\Psi_{i}$ & $\mu \mathrm{M}^{-1} \mathrm{Nd}^{-1}$ \\
\hline Zooplankton production & $F_{Z_{L o r S}}$ & $\mu \mathrm{MN} \mathrm{d}^{-1}$ \\
\hline Zooplankton grazing on bacteria & $G_{Z_{L o r} P_{L}}$ & $\mu \mathrm{MNd}^{-1}$ \\
\hline Zooplankton grazing on large phytoplankton & $G_{Z_{L o r} P_{L}}$ & $\mu \mathrm{MNd}^{-1}$ \\
\hline Zooplankton grazing on small phytoplankton & $G_{Z_{L o r S} P_{S}}$ & $\mu \mathrm{MNd}^{-1}$ \\
\hline Zooplankton grazing on small zooplankton & $G_{Z_{L \text { or } S} Z_{S}}$ & $\mu \mathrm{MNd}^{-1}$ \\
\hline $\mathrm{Z}_{\mathrm{L}}$ grazing on other $\mathrm{Z}_{\mathrm{L}}$ & $G_{Z_{L} Z_{L}}$ & $\mu \mathrm{MNd}^{-1}$ \\
\hline Zooplankton grazing on nitrogenous detritus & $G_{Z_{L o r} D_{N}}$ & $\mu \mathrm{MN} \mathrm{d}^{-1}$ \\
\hline Zooplankton grazing on carbon detritus & $G_{Z_{L O r S} D_{C}}$ & $\mu \mathrm{MCd}^{-1}$ \\
\hline Zooplankton respiration & $R_{Z_{\text {LorS }}}$ & $\mu \mathrm{MCd}^{-1}$ \\
\hline Zooplankton excretion & $E_{Z_{L o r S}}$ & $\mu \mathrm{MNd}^{-1}$ \\
\hline Bacterial production & $B_{\text {growth }}$ & $\mu \mathrm{MN} \mathrm{d}^{-1}$ \\
\hline Uptake of DOC by bacteria & $U_{C}$ & $\mu \mathrm{MCd}^{-1}$ \\
\hline Uptake of DON by bacteria & $U_{N}$ & $\mu \mathrm{MNd}^{-1}$ \\
\hline Potential uptake of A by bacteria & $U_{A}^{*}$ & $\mu \mathrm{MNd}^{-1}$ \\
\hline Realized uptake of A by bacteria & $U_{A}^{A}$ & $\mu \mathrm{MNd}^{-1}$ \\
\hline Bacterial respiration & $R_{B}$ & $\mu \mathrm{MCd}^{-1}$ \\
\hline Bacterial excretion & $b_{\chi}$ & $\mu \mathrm{MNd}^{-1}$ \\
\hline Nitrification rate & $\bar{\varpi}_{1}$ & $\mathrm{~d}^{-1}$ \\
\hline Total suspended solids & TSS & $\mathrm{mg} \mathrm{l}^{-1}$ \\
\hline Temperature & $T$ & Degrees C \\
\hline Chlorophyll $a$ & Chl & $\mu g l^{-1}$ \\
\hline Salinity & $S$ & None \\
\hline Mixed layer depth & $Z$ & $\mathrm{~m}$ \\
\hline Rate of turbidostat flow & $h$ & $\mathrm{~s}^{-1}$ \\
\hline Susquehanna river flow & $F_{\text {river }}$ & $\mathrm{m}^{3} \mathrm{~s}^{-1}$ \\
\hline Turbidostat equation area (i.e., vessel area) & Carea & $\mathrm{m}^{2}$ \\
\hline Amount of state variable $(i)$ entering the system & $i^{0}$ & $\mu \mathrm{MC}$ or $\mathrm{N}$ \\
\hline
\end{tabular}

water temperatures ranged between 3 and $27^{\circ} \mathrm{C}$. Station CB3.2 $\left(39.1637^{\circ} \mathrm{N}, 76.3063^{\circ} \mathrm{W}\right)$ located to the north of station CB3.3C provided boundary condition data for our model runs.

Chemical, physical, and biological data from stations CB3.3C and CB3.2 were downloaded from the Chesapeake Bay Program website (CBP, online database) for forcing and model validation. At each station, ammonium, nitrate, chlorophyll, primary production, total suspended solids (TSS), vertical light attenuation, DON, DOC, particulate carbon and nitrogen, temperature, salinity, surface layer depth, and biological (phytoplankton and zooplankton species and abundance) data were measured once or twice every month. We calculated mean seasonal values for these parameters by averaging the surface layer data on a monthly or bi-monthly basis from

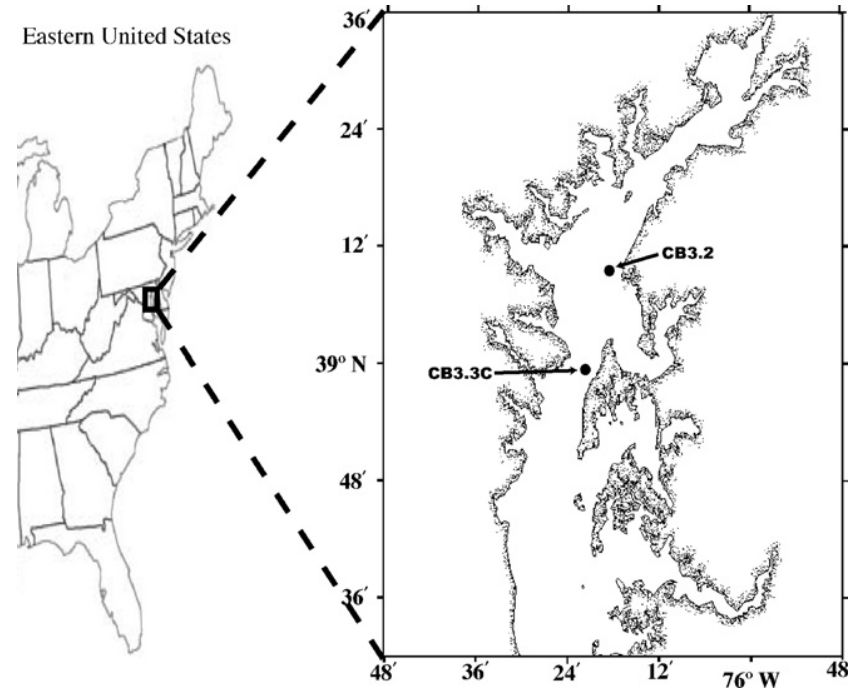

Fig. 2. Chesapeake Bay Program monitoring station locations

1997 to 2007, except for DOC data, which were only available from 1987 to 1997 . Biological data on phytoplankton and zooplankton species and numerical abundance were also only available up to 2002. The chlorophyll $a$ data that we used are based on the maximum chlorophyll $a$ concentration in the water column and not just surface layer data. We did this because in the spring dinoflagellates, which migrate to the surface during the day and to just above or in the pycnocline at night, are often present and can represent most of the chlorophyll in the water column (Adolf et al., 2006; Keller, personal observation in 2007 and 2008). As CBP sampling at this station often occurred early in the morning when the dinoflagellates were just starting to migrate from above the pycnocline, surface measurements underestimate the amount of chlorophyll that will be present in upper water column throughout most of the day (i.e., the chlorophyll $a$ maximum is just above the pycnocline early in the morning and moves up toward the surface as the day progresses). Photosynthetically available radiation (PAR) data used in the model were the monthly seasonal average from a 17-yr time series taken near the Chesapeake Bay $\left(38.6^{\circ} \mathrm{N}, 78.2^{\circ} \mathrm{W}\right.$ ) (Fisher et al., 2003). Monthly virus and bacterial abundance and production data from 2002 to 2007 were provided by the Microbial Observatory for Virioplankton Ecology (MOVE) research group. Whenever possible we calculated means for MOVE data. However, samples were not taken for all months every year resulting in an incomplete data set (data availability: Feb.: 2005, 2007; Mar.: 2004-2006; Apr.: 2003-2005; May: 2004, 2005; June: 2003, 2004; July: 2004-2006; Aug.: 2003-2005; Sept.: 2002; Oct.: 2003-2005; Nov.: 2006). Daily mean Susquehanna river flow data (1997-2007) from a station at Conowingo, MD were downloaded from the U.S. Geological Survey website (U.S.G.S.) and averaged to calculate monthly mean flow.

\subsection{Physical parameterization}

\subsubsection{Model circulation}

A turbidostat formulation was used to simulate circulation in the upper layer at station CB3.3C (see Appendix A.1-A.3). We used this formulation because circulation in the main channel of the Chesapeake Bay is two-layered with a fresher layer flowing seaward at the surface and a saltier layer flowing landward at the bottom (Schubel and Pritchard, 1986). Strong stratification exists between these layers at this station throughout much of the year and limits the exchange of nutrients and plankton. Therefore, we felt that this formulation would allow us to simulate the inflow and outflow of nutrients, plankton, detritus, and DOM caused by 
Table 3

Seasonally variable parameters.

\begin{tabular}{|c|c|c|c|c|c|c|c|}
\hline \multirow[t]{2}{*}{ Day } & \multirow{2}{*}{$\begin{array}{l}\text { Phytoplankton Chl a } \\
\text { ratio (\% small) }\end{array}$} & \multirow{2}{*}{$\begin{array}{l}\text { Extra ammonium addition } \\
\left(\mu \mathrm{mol} \mathrm{N} \mathrm{d}^{-1}\right)\end{array}$} & \multicolumn{5}{|c|}{ Mortality $\left(\mathrm{d}^{-1}\right)$} \\
\hline & & & $P_{L}$ & $P_{S}$ & $Z_{L}$ & $Z_{S}$ & $B$ \\
\hline 0 & 0.10 & 0 & 0.04 & 0.04 & 0.01 & 0.10 & 0.15 \\
\hline 15 & 0.10 & 0 & 0.02 & 0.04 & 0.01 & 0.08 & 0.15 \\
\hline 45 & 0.20 & 0 & 0.02 & 0.04 & 0.01 & 0.08 & 0.15 \\
\hline 74 & 0.23 & 0 & 0.02 & 0.04 & 0.02 & 0.08 & 0.15 \\
\hline 97 & 0.25 & 0 & 0.02 & 0.04 & 0.02 & 0.08 & 0.15 \\
\hline 115 & 0.25 & 0 & 0.02 & 0.04 & 0.02 & 0.08 & 0.15 \\
\hline 127 & 0.25 & 0 & 0.50 & 0.50 & 0.02 & 0.08 & 0.15 \\
\hline 145 & 0.25 & 0 & 0.50 & 0.50 & 0.30 & 0.80 & 0.15 \\
\hline 166 & 0.30 & 0 & 0.50 & 0.50 & 0.20 & 0.80 & 0.08 \\
\hline 188 & 0.40 & 0 & 0.10 & 0.08 & 0.20 & 0.80 & 0.08 \\
\hline 206 & 0.50 & 31 & 0.02 & 0 & 0.30 & 0.80 & 0.08 \\
\hline 219 & 0.50 & 67 & 0.02 & 0 & 0.30 & 0.80 & 0.08 \\
\hline 237 & 0.50 & 8 & 0.02 & 0 & 0.30 & 0.80 & 0.08 \\
\hline 258 & 0.40 & 0 & 0.10 & 0.01 & 0.30 & 0.80 & 0.15 \\
\hline 288 & 0.25 & 0 & 0.25 & 0.35 & 0.25 & 0.80 & 0.15 \\
\hline 319 & 0.10 & 0 & 0.15 & 0.10 & 0.15 & 0.80 & 0.15 \\
\hline 349 & 0.10 & 0 & 0.10 & 0.06 & 0.01 & 0.10 & 0.15 \\
\hline 365 & 0.10 & 0 & 0.04 & 0.04 & 0.01 & 0.10 & 0.15 \\
\hline
\end{tabular}

this circulation pattern without invoking a more complex hydrodynamic model. Additions and losses to state variables caused by other processes such as sinking, vertical migration, higher trophic level predation, advection, and diffusion have been accounted for by having additional loss terms (see Section 2.3 .5 below) or by adjusting the inflowing state variable mass.

\subsubsection{Light}

Underwater light forcing was calculated using a simple model (see Appendix A.4) that derives the average irradiance of the surface layer from PAR, the surface layer depth, and a calculated diffuse attenuation coefficient $\left(K_{d}\right) . K_{d}$ was calculated (see Appendix A.5) using an empirical optical model that was derived specifically for the Chesapeake Bay (Xu et al., 2005).

\subsection{Biological parameterization}

\subsubsection{Phytoplankton}

The light- and nitrogen-dependant growth rate of phytoplankton (see Appendix A.6-A.18) is described by an exponential saturation function with photoinhibition for light dependence (Platt et al., 1980) and a non-dimensional Michaelis-Menten hyperbolic saturation function is used to describe nitrogen (ammonium, nitrate, and labile DON) dependence. This formulation allows phytoplankton cells to take up ammonium and labile DON preferentially, with nitrate uptake inhibited in the presence of significant concentrations of ammonium (Christian et al., 2002; Harrison et al., 1996) and labile DON. DON uptake by phytoplankton was included in this model because recent research has shown that DON can be a significant nitrogen source (up to 50\%) for phytoplankton (Fan et al., 2003; Mulholland et al., 2002, 2003). The maximum attainable daily growth rate of large phytoplankton, $\mu_{P}$, was calculated using an exponential temperature function (Bissinger et al., 2008; Eppley, 1972). Based on allometric theory (Raven and Kübler, 2002) the maximum growth rate of small phytoplankton was set to be $30 \%$ higher than that of large phytoplankton. The half saturation constants for the uptake of ammonium and nitrate by phytoplankton were used to tune (optimize) the model. Thus they were set at values, which fall within the ranges reported for the uptake of ammonium and nitrate by phytoplankton at high nutrient concentrations (Collos et al., 2005; Eppley et al., 1969), reflecting the high nitrate and ammonium concentrations found at station CB3.3C throughout much of the year. The half saturation constants were also set so that the uptake affinity for ammonium of small phyto- plankton is stronger than that of large phytoplankton (Stolte et al., 1994).

The uptake of DON by phytoplankton is poorly understood (Mulholland et al., 2003) so we set the half saturation constant for uptake by phytoplankton at $20 \mu \mathrm{M}$, which allows phytoplankton to take up some DON but restricts it from being their dominant nitrogen source. Phytoplankton use DIC in combination with nutrients at a fixed C:N ratio for production (Anderson and Pondaven, 2003). A constant fraction of phytoplankton production is exuded as DOM, and "extra" DOC is also excreted in proportion to production (Anderson and Williams, 1998) (see Appendix A.17). The amount of DOC excreted can range between 5 and $70 \%$ of total primary production (Connolly et al., 1992). The factors that control this excretion are not fully understood (Flynn et al., 2008) so we chose to follow the simple parameterization of Anderson and Williams (1998) where extra DOC excretion is set at a mid-range value of 0.26 .

The addition of phytoplankton to the system (see Section 2.2.1) is based on upstream CBP chlorophyll $a$ data, which does not differentiate between large and small phytoplankton. Therefore, we split (Table 3) inflowing chlorophyll between large and small phytoplankton based on research which shows that larger phytoplankton (mostly diatoms and large dinoflagellates) dominate both biomass and productivity in the winter, early spring, and late fall and that smaller phytoplankton (cyanobacteria, cryptophytes, flagellates and small diatoms) dominate production, but not necessarily biomass, in the summer (Adolf et al., 2006; Malone, 1980; Malone et al., 1996). The phytoplankton chlorophyll to carbon ratio is modeled (see Appendix A.18) as a function of temperature, light, and nutrient availability (Cloern et al., 1995).

\subsubsection{Zooplankton}

Use of food by zooplankton for growth is based on a stoichiometric model (Anderson and Hessen, 1995) that operates on the basis of a food-threshold elemental ratio, below which $C$ limits growth and above which $\mathrm{N}$ limits growth (see Appendix A.19-A.56). This formulation accounts for the respiration of DIC, the egestion of feces to detritus, and the excretion of ammonium and DOM. The maximum grazing rate, $C_{L_{Z \text { or }}}$, was set at $2.0 \mathrm{~d}^{-1}$ for small zooplankton and $1.0 \mathrm{~d}^{-1}$ for large zooplankton, reflecting the ability of nanoand micro-zooplankton to grow faster than mesozooplankton (i.e., copepods vs. protists) (Tillmann, 2004). The carbon production efficiencies, $g e_{L_{Z \text { or } S}}$, were set at 0.75 for large zooplankton and 0.40 for small zooplankton reflecting measured growth efficiencies for 
Acartia tonsa (Kiørboe et al., 1985), a copepod common at this station, and general protozoan growth efficiencies (Caron et al., 1990). The model also allows for the assignment of "preferences" for different forms of organic nitrogen (i.e., prey) (Hood et al., 2001). Large zooplankton were assigned preferences (see Table 1) that describe the diverse diet they have been shown to have (Kleppel, 1993). Note that the preference assigned to them for grazing on bacteria was selected to account for inadvertently ingesting particle-attached bacteria rather than actual selective grazing on bacteria. Small zooplankton grazing preferences (see Table 1 ) were assigned to reflect known preferences for small phytoplankton, other small zooplankton, and bacteria (Boenigk and Arndt, 2002; Calbet and Landry, 2004; Tillmann, 2004).

The production of DOM and detritus as a result of large zooplankton sloppy feeding is based on a predator-to-prey size ratio (Møller, 2005) that determines the amount of DOM and detritus produced (see Appendix A.57). Zooplankton excretion of ammonium and DON was set so that $68 \%$ of the nitrogen excreted is in the form of ammonium with the remaining 32\% in the form of DON (Steinberg et al., 2002). Excretion of DOC by zooplankton was set so that $31 \%$ of the carbon released (including respiration) was in the form of DOC (Steinberg et al., 2000).

The inflow of zooplankton to the system (see Section 2.2.1) was based on mean monthly abundance of mesozooplankton and microzooplankton at station CB3.3C (zooplankton data for station CB3.2 was unavailable). Large zooplankton inflow was based on the abundance of the copepods Acartia tonsa and Eurytemora affinis because these species dominate the Chesapeake Bay mesozooplankton community (Kimmel and Roman, 2004). We used a conversion factor of $2.5 \mu \mathrm{g}$ carbon per copepod (Huntley and Lopez, 1992) to convert the number of adult copepods and copepodites to carbon biomass. Then, we increased the calculated carbon biomass by $10 \%$ to account for the presence of other mesozooplankton and higher up-bay copepod abundances (Zhang et al., 2006). Small zooplankton biomass inflow was calculated by first estimating nano/microflagellate abundances from CBP microzooplankton data, which only reported microzooplankton abundances for cells larger than $44 \mu \mathrm{m}$ (mostly copepod nauplii, rotifers, and large ciliates). The nano/microflagellate to ciliate ratio of 500 that we used was based on a study of seasonal abundances of ciliates and microflagellates in Chesapeake Bay (Dolan and Coats, 1990). The abundances of nano/microzooplankton were then converted to carbon using conversion factors of $0.22 \mathrm{pg} C$ times cell volume $\left(\mu \mathrm{m}^{3}\right)$ for nano/microflagellates (Børsheim and Bratbak, 1987) and $0.154 \mathrm{pg} C$ times cell volume $\left(\mu \mathrm{m}^{3}\right)$ for ciliates (Müller and Geller, 1993). In these calculations we assumed an average cell volume of $200 \mu \mathrm{m}^{3}$ for nano/microflagellates and $100,000 \mu \mathrm{m}^{3}$ for ciliates and other microzooplankton.

\subsubsection{Bacteria}

The cycling of $\mathrm{C}$ and $\mathrm{N}$ by bacteria is described and parameterized following Anderson and Williams' stoichiometric model (Anderson and Williams, 1998). This formulation (see Appendix A.58-A.67) describes the adaptive capability of bacteria and assumes that labile DOC and DON are the primary growth substrates, with ammonium uptake supplementing DOM only when the C: $\mathrm{N}$ of DOM is high. Thus, bacteria act as either remineralizers or consumers of ammonium, depending on the relationship between their fixed C:N ratio and that of the DOM they consume. Bacterial growth efficiency was set at 0.30 to reflect measured estuarine growth efficiencies (del Giorgio and Cole, 1998).

The addition of bacteria to the system (see Section 2.2.1) was based on monthly mean MOVE data from station CB3.3C as data from a more northern station, which showed similar abundance trends, was only partially available for one year. This data set was not as complete as the CBP data sets used for other state vari- ables but provides us with information that we would otherwise be without. In addition, we are confident that this data set reflects the general pattern of bacterioplankton seasonal abundance as it shows a trend similar to mid-bay seasonal bacterioplankton measurements made in 1990 and 1991 (Shiah and Ducklow, 1994a). A conversion factor of $30.2 \mathrm{fg}$ of $\mathrm{C}$ per cell (Fukuda et al., 1998) was used to convert bacterioplankton abundance to biomass.

\subsubsection{Viruses}

Viruses that infect phytoplankton and bacteria are considered to be a component of DOM even though they were treated as separate state variables for the purpose of this model. In our model viral infection and subsequent lysis of the host produced new viruses, detritus, and DOM. The infection of phytoplankton and bacteria by viruses was modeled so that $40 \%$ of bacteria, $7 \%$ of small phytoplankton, and 3\% of large phytoplankton were lysed per day (see Appendix A.82-A.84). These infection rates are within the wide range of reported infection rates that are based on calculations of the abundance of viruses and how many need to be produced daily to sustain that abundance given calculated decay rates (Fuhrman, 1999; MOVE; Weinbauer, 2004; Wommack and Colwell, 2000). To calculate the production of new viruses from lysis we used averaged burst size data which shows that the number of viruses produced per lysis event averages 24 phages per cell lysed for bacteria and up to 400-500 viruses per lysed cell for large phytoplankton like Emiliania huxleyi (Wommack and Colwell, 2000). Based on these burst sizes and our calculations of viral biomass (see below), 50\% of the mass of a lysed cell is converted to new viruses $\left(\varepsilon_{V}\right)$ with the remaining cellular contents entering the detritus (37.5\%) and DOM pools (12.5\%). Viral decay or loss was formulated using a power function (Fischer et al., 2004), to prevent viral biomass from oscillating uncontrollably, with destroyed viral material returning to the DOM pool. Because viral decay rates are poorly constrained and a large range is reported in the literature (Weinbauer, 2004) we used the decay rate to tune the model.

Since virus data is typically reported in terms of abundance we needed to convert viral abundance to biomass. In order to do this we assumed that roughly half of a virus's mass was DNA and half protein (Szybalski, 1974). Since virus data often includes the genome size (kb) we were able to calculate the amount of nitrogen and carbon for different sized viruses based on the amount of carbon and nitrogen in DNA (assuming viral DNA is 35\% guanine and cytosine and $65 \%$ adenine and thymine). The amount of nitrogen and carbon in our viral protein was based on the amount of nitrogen and carbon in a 15,484 Da T4 bacteriophage capsid protein which contained 176 nitrogen atoms and 682 carbon atoms (Mazzone, 1998). So, according to our calculations the virus $\mathrm{C}: \mathrm{N}$ ratio is 3.26 and a $40 \mathrm{~kb}$ virus (bacteriophage) has $3.11 \times 10^{-11} \mu \mathrm{MC}$, a $175 \mathrm{~kb}$ virus (small phytoplankton virus) has $1.36 \times 10^{-10} \mu \mathrm{MC}$, and a $225 \mathrm{~kb}$ virus (large phytoplankton virus) has $1.75 \times 10^{-10} \mu \mathrm{MC}$.

As with bacteria, the inflow of viruses to the system (see Section 2.2.1) was based on monthly mean MOVE abundance data from station CB3.3C as data from a more northern station, which showed similar abundance trends, was only partially available for one year. Because the data set does not differentiate between different types of viruses we estimated that $80 \%$ are bacteriophages (assuming an average size of $40 \mathrm{~kb}$ ), $9 \%$ are small phytoplankton viruses (assuming an average size of $175 \mathrm{~kb}$ ), and $9 \%$ are large phytoplankton viruses (assuming an average size of $225 \mathrm{~kb}$ ) based on data that supports the hypothesis that most aquatic viruses are bacteriophages (Wommack and Colwell, 2000).

\subsubsection{Mortality}

Mortality terms (Table 3) were set to account for biomass losses and export due to natural mortality, sinking, advection, diffusion, and higher trophic level predation. Our formulation (see Appendix 
A.85) allows some of the biomass from mortality, determined by $m$, to stay in the system (up to $2 \%$ for all plankton except large zooplankton who have an in system loss of up to $1 \%$ ) and become detritus and DOM. Any biomass loss in excess of $2 \%$ (1\% from large zooplankton) is exported from the model.

In order to reproduce the seasonal patterns observed in plankton biomass at this station it is necessary to vary the mortality terms $\left(S_{i}\right)$ seasonally. Although these adjustments may seem somewhat arbitrary, they can be justified for a number of reasons, and are the type of adjustments that have had to be made in previous Chesapeake Bay modeling studies (Xu and Hood, 2006). Moreover, they were set a priori and so were not used for any major tuning of the model. Mortality rates for phytoplankton were increased in the spring and fall to account for sinking and sedimentation following the spring bloom (Malone et al., 1996, 1988) and mixing of the water column associated with the fall overturn (Boicourt, 1992). Mortality rates for zooplankton were increased during the summer and early fall to reflect high seasonal predation by ctenophores (Stoecker et al., 1987) and the jellyfish Chrysaora quinquecirrah (Baird and Ulanowicz, 1989; Purcell, 1992). Atlantic menhaden, bay anchovies, other filter-feeding fish, and larval fish may also exert high predation pressure on both phytoplankton (mostly menhaden predation) and zooplankton at different times of the year (Baird and Ulanowicz, 1989; Hartman et al., 2004; Lewis and Peters, 1994). Furthermore, plankton may also experience predation by benthic or attached predators, who are more active during the warmer months of the year.

\subsection{Dissolved organic matter}

Dissolved organic matter has separate state variables for $\mathrm{C}$ and $\mathrm{N}$ which are divided into labile, semi-labile, and refractory pools following Anderson and Williams (1999) (see Appendix A.74-A.79). Dissolved organic matter is produced by phytoplankton excretion and leakage, zooplankton sloppy feeding, zooplankton excretion, viral lysis of phytoplankton and bacteria, plankton mortality, and detritus decay. Labile DOM is consumed directly by bacteria and phytoplankton. Semi-labile DOM requires ectoenzyme hydrolysis by bacteria to become available (labile) for consumption. A Michaelis-Menten kinetic formulation (Anderson and Williams, 1999) describes bacterial hydrolysis of semi-labile DOM, with semilabile DOM entering the labile and refractory DOM pools upon hydrolysis. Refractory DOM is considered unavailable for consumption by bacteria and phytoplankton.

Photochemical processes are assumed to be the only means of turnover for refractory material. These processes are included because research has shown that UV radiation tends to make terrestrially derived refractory material from coastal and estuarine environments more available for use by bacteria (Mopper and Kieber, 2002). Our formulation followed that of Anderson and Williams (1999) with this process occuring at a rate of $0.0015 \mu \mathrm{MC}$ or $\mathrm{N} \mathrm{d}^{-1}$. Photochemical processes are also responsible for the conversion of DOC to dissolved inorganic carbon, and the global average removal rate is estimated to be approximately $0.038 \mu \mathrm{MCd}^{-1}$, if all DOC is considered to be photoreactive (Miller and Zepp, 1995). As not all DOC is photoreactive or subjected to direct photochemical reactions and the exact removal rate is unknown, we formulated this conversion to occur at a lower rate of $0.004 \mu \mathrm{MCd}^{-1}$. Recent research (Koopmans and Bronk, 2002) has also shown that in humic-rich surface waters photochemical processes can release ammonium from more refractory DON. Unfortunately, the rate at which this reaction occurs is poorly understood so we allowed only small amounts of DON $\left(0.0005 \mu \mathrm{M} \mathrm{N} \mathrm{d}^{-1}\right)$ to be photooxidized to produce ammonium.

The amount of dissolved organic matter production that enters the labile, semi-labile, and refractory pools is difficult to estimate because it is poorly understood. Further complicating this partitioning is the fact that production, involving the same processes such as phytoplankton exudation, may be different for different species (i.e., the amount and lability of exuded DOM will not be the same for a diatom and a dinoflagellate). Previous modeling studies of DOM cycling have typically adjusted these parameters in order to achieve acceptable fits to the data (Christian and Anderson, 2002). We had to take a similar approach after trying to use partitioning parameters from previous models, which were for coastal and open ocean systems, and finding poor fits with station CB3.3.C data. However, our partitioning was not completely arbitrary. Partitioning of DOM to the labile fraction was based on work by Wetz et al. (2008) who measured a $41 \%$ average degradation of phytoplankton derived DOC after three days in coastal waters. Partition of DOM to the semi-labile fraction was based on a number of studies which have shown that a large fraction of freshly formed DOM is semi-labile and degraded over a period of weeks (Aluwihare and Repeta, 1999; Chen and Wangersky, 1996; Gobler and Sañudo-Wilhelmy, 2003; Meon and Kirchman, 2001). In addition, the Anderson and Williams (1998) modeling study also suggested that a large fraction of the DOC produced by primary producers was semi-labile in nature. Little is known about the production of refractory DOM, although it has been shown to be directly produced during blooms in mesocosm studies (Kragh and Søndergaard, 2009). Bacterially-mediated remineralization of DOM has also been shown to produce refractory DOC (Brophy and Carlson, 1989; Ogawa et al., 2001). However, only a small fraction of biologically produced DOM escapes remineralization (Benner, 2002) so we partitioned only a small amount to the refractory fraction. Thus, on this basis $40 \%$ of phytoplankton exudation and non-detrital zooplankton and phytoplankton mortality was partitioned to labile DOM, 59\% to semi-labile DOM, and the remaining $1 \%$ to refractory DOM. We also partitioned 53\% of DOM from sloppy feeding and bacterial mortality to labile DOM, 45\% to semilabile DOM, and the remaining 2\% to refractory DOM. DOM from viral lysis was partitioned so that it was split evenly between the labile and semi-labile pools with only a small amount $<1 \%$ entering the refractory pool. Extra DOC from viral lysis (to account for $\mathrm{C}: \mathrm{N}$ ratio differences) was partitioned so that $1 \%$ went to the labile pool, $89.6 \%$ went to the semi-labile pool, and the remaining amount went to the refractory pool. DOM from the decay of detritus was partitioned so that $50 \%$ went to labile DOM, $49 \%$ went to semi-labile DOM, and the remaining $1 \%$ went to refractory DOM.

The inflow of DOM to the system (see Section 2.2.1) was based on mean monthly DOC and DON concentrations from station CB3.2. As this data did not report on the bioavailability of the DOM we set the bioavailability during the tuning process. While this may seem somewhat arbitrary, there is very little data available on the biodegradability of DOM discharged by rivers into estuaries and the few studies that have reported on the bioavailability of this DOM have shown that it is highly variable (0-73\%) and dependent on hydrological processes in the watershed (Cauwet, 2002). In addition, it also appears that the estuarine turbidity maximum, which is upstream of station CB3.3C, can be a source of DOM, especially during the summer (Fisher et al., 1998) and thus may provide this station with "new" DOM that may be readily degradable by the unique communities of bacteria that develop in the middle of estuaries (Crump et al., 2004). Setting the bioavailability of inflowing DOM during the tuning process also allowed us to better constrain these parameters using the model results (i.e., inflowing DOM bioavailability must be near these values for the model to achieve a reasonable solution). Therefore, on this basis inflowing DON was partitioned between the labile (20\%), semi-labile (30\%), and refractory $(50 \%)$ pools and inflowing DOC was partitioned between the labile (19\%), semi-labile (30\%), and refractory pools (51\%). 


\subsection{DIC, DIN, and Detritus}

The production and uptake of DIC are discussed in the sections above. In order to avoid the complications of modeling $\mathrm{CO}_{2}$ air-sea interactions, and because this process was not a focus of our research, DIC inflow was set so that it balanced the uptake of DIC and kept the concentration of DIC at $2100 \mu \mathrm{MC}$. The biological production and consumption of ammonium and nitrate are discussed above. The inflow of ammonium and nitrate to the system (see Section 2.2.1) was based on monthly mean measurements from station CB3.2. In addition, we found during tuning that we had to add extra ammonium to the system in the summer (Table 3 ) to account for the nitrogen added to surface waters from below by wind induced mixing or tilting of the water column and phytoplankton migrating to or below the pycnocline to acquire nutrients. Vertical migration by phytoplankton is well documented (Beckmann and Hense, 2004; Ross and Sharples, 2008) and almost certainly occurs at this station in the summer because of the phytoplankton species present, high productivity, and high concentration of ammonium below the pycnocline (CBP data). It has also been hypothesized that wind-driven mixing and tilting of the pycnocline can increase the transport of ammonium from below the pycnocline to surface waters and stimulate high summer primary productivity (Yeager et al., 2005). The biological production and consumption of detritus is discussed in the sections above. In addition to these processes, detritus decayed to DOM following the formulation of Anderson and Pondaven (2003) with nitrogenous detritus breaking down slightly faster $\left(0.055 \mu \mathrm{M} \mathrm{N} \mathrm{d}^{-1}\right)$ than carbon detritus $\left(0.040 \mu \mathrm{MCd}^{-1}\right)$. The inflow of detritus to the system was based on particulate carbon and nitrogen (PC, PN) data from station CB3.2. In order to account for the presence of living biomass in the PC and PN data we subtracted the inflowing biomass of phytoplankton, zooplankton, and bacteria from it. We do not have specific loss terms to account for the loss of detritus due to sinking although we have partially accounted for some of this loss by directly exporting plankton biomass, that may have become detritus, out of the system using the mortality terms described in Section 2.3.5.

\section{Results}

In this section we present the results our main run solution, the model skill assessment, and selected parameter sensitivity studies. When possible, comparisons are made to mean monthly or bi-monthly (climatological) CBP station measurements from 1997 to 2007. The quantitative metrics that we used to assess the model skill (root mean squared error (RMSE), the correlation coefficient $(r)$, reliability index $(\mathrm{RI})$, average error bias $(\mathrm{AE})$, average absolute error (AAE), and modeling efficiency (MEF)) are as described in Stow et al. (2009).

\subsection{Main run results}

\subsubsection{Comparison with CBP station CB3.3C data}

In general the model results compare well with the available station data (Figs. 3 and 4 and Table 4). Simulated ammonium and nitrate concentrations both reproduce the observed seasonal patterns fairly well (Fig. 3a), although the modeled concentration of nitrate was slightly high in the winter, spring, and fall and a little low in the summer. The model also generally reproduced the peaks and patterns of observed chlorophyll $a$ (Fig. 3b). However, the model did not capture the timing of when the spring bloom begins. The modeled and observed DOC concentrations are also similar (Fig. 3c), although there was a tendency for the model to slightly underestimate the DOC concentration at certain times of the year. The modeled DON concentrations were within the range

\section{Table 4}

Model skill assessment quantitative metrics. Root mean squared error (RMSE), correlation coefficient $(r)$, reliability index (RI), average error bias (AE), absolute average error (AAE), and modeling efficiency (MEF).

\begin{tabular}{llcrrcr}
\hline & Nitrate & Ammonium & DON & \multicolumn{1}{c}{ DOC } & Chlorophyll $a$ & $K_{d}$ \\
\hline RMSE & 6.62 & 1.14 & 3.54 & 18.79 & 3.61 & 0.17 \\
$r$ & 0.97 & 0.79 & 0.25 & 0.81 & 0.89 & 0.62 \\
RI & 1.51 & 1.40 & 1.09 & 1.04 & 1.09 & 1.06 \\
AE & 1.55 & -0.14 & 0.50 & -12.97 & -0.34 & 0.11 \\
AAE & 5.83 & 0.93 & 2.95 & 15.31 & 2.40 & 0.18 \\
MEF & 0.88 & 0.59 & -0.40 & 0.02 & 0.79 & -0.26 \\
\hline
\end{tabular}

of DON observations and agreed reasonably well with the observations in the early summer and at a point in the fall (Fig. 3d). However, the model missed the timing of a peak in DON in the spring and produced this peak later when observed springtime DON had decreased. In addition, the model overestimated the concentration of DON in the late summer, producing a peak that then declined to below the observed DON concentration in the late fall and winter. Most of the variability in the modeled DOM concentrations was due to changes in the semi-labile pools of DOC and DON. While we do not have measurements of seasonal bioavailability at this station for comparison, this result is consistent with observations from various systems around that world, including Chesapeake Bay, which show that DOC, and sometimes DON, concentrations vary seasonally as a result of changes in the labile and/or semi-labile DOM pool (Bronk, 2002; Bronk et al., 1998; Carlson, 2002; Cauwet, 2002; Raymond and Bauer, 2001).

The empirical light model that we used was able to reproduce the observed pattern of $K_{d}$ values reasonably well (Fig. 4a), although there was a tendency for the model to overestimate $K_{d}$ in the spring. As Table 4 shows, the model output for $K_{d}$ compares well with the observations for some metrics, but does poorly for other metrics such as the correlation coefficient $(r)$ and the modeling efficiency (MEF). In Fig. 4b, which shows PAR at the surface and the average PAR in the mixed layer, it is interesting to note that even though the PAR input used by the model changed seasonally along with modeled $K_{d}$, the calculation of average PAR in the surface layer showed little change throughout the year.

\subsubsection{Biomass and detritus}

Phytoplankton biomass peaked twice, once in the spring, and once in the summer/early fall (Fig. 5a). The spring biomass peak was composed mostly of large phytoplankton, while the summer/early fall biomass peak was composed of a mix of large and small phytoplankton (Fig. 5c shows similar results in terms of chlorophyll). Since these results closely match the chlorophyll a concentrations reported at station CB3.3C (Fig. 3b) and the general patterns in phytoplankton composition and biomass reported for the Chesapeake Bay (Adolf et al., 2006; Malone et al., 1996) we believe that the model did a relatively good job of capturing the phytoplankton biomass dynamics at this station. The biomass of large zooplankton peaked in the spring following the springtime phytoplankton bloom and then leveled off with low biomass during the summer and very little biomass in the winter. These results are of a similar magnitude and consistent with the longterm trends in mesozooplankton abundance reported for the upper Chesapeake Bay (Kimmel and Roman, 2004) and with CBP data for station CB3.3C. The biomass of small zooplankton remained low (compared to other plankton) throughout the year with the highest biomass $(1.02 \mu \mathrm{MN})$ occurring in the summer. Our modeled maximum summer microzooplankton biomass was very similar to the maximum microzooplankton biomass reported at station CB3.3C in summer of 2000 by Johnson et al. (2003) who found that the heterotrophic and mixotrophic ciliate biomass was $4.16 \mu \mathrm{MC}$ $(0.75 \mu \mathrm{MN}$ using a microzooplankton C: $\mathrm{N}$ ratio of 5.5$)$ and the het- 

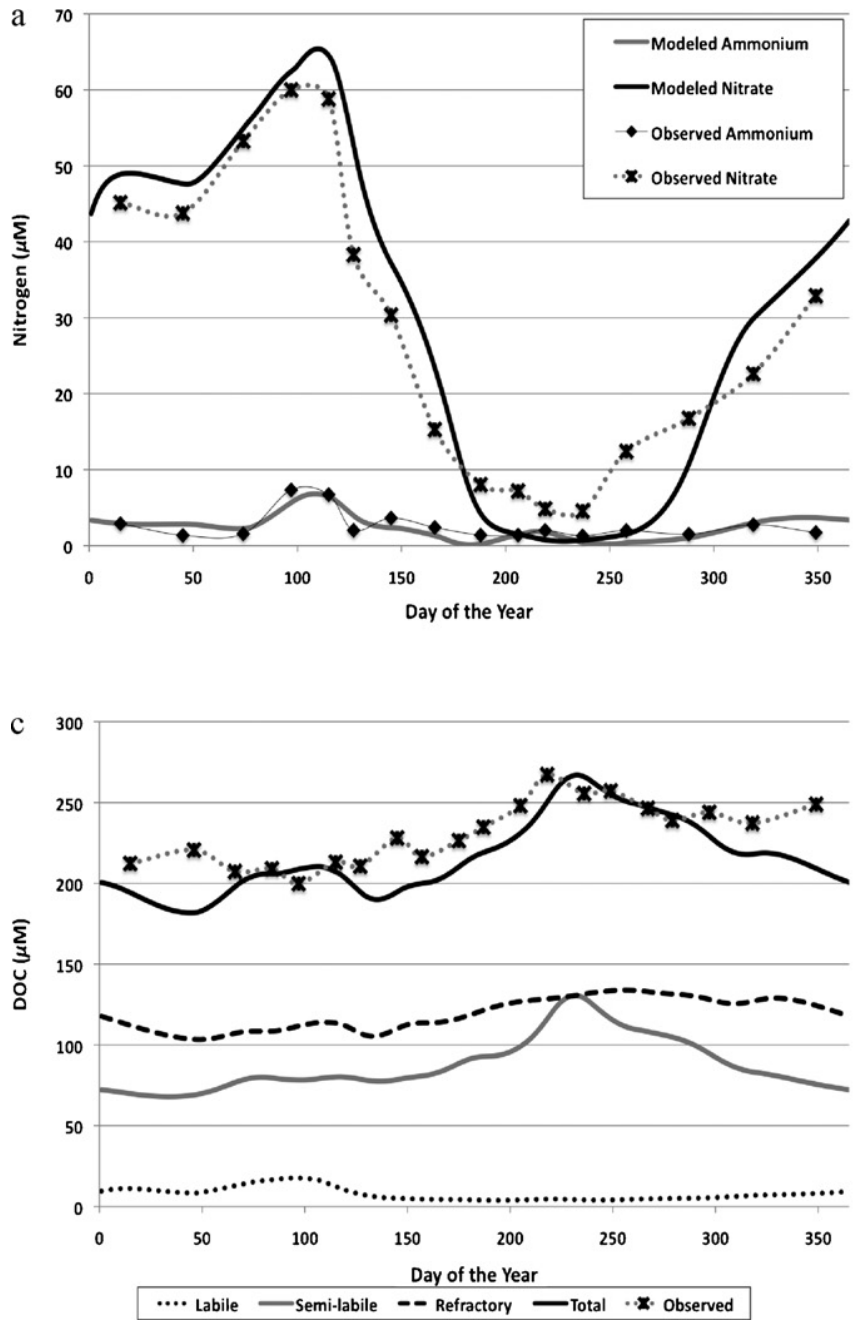

Fig. 3. The modeled and mean observed concentrations of (a) ammonium and nitrate; (b) chlorophyll $a$; (c) DOC; (d) DON at station CB3.3C.

erotrophic dinoflagellate biomass was $5.82 \mu \mathrm{MC}(1.01 \mu \mathrm{M} \mathrm{N}$ using a microzooplankton $\mathrm{C}: \mathrm{N}$ ratio of 5.5). A direct comparison with $\mathrm{CBP}$ station $\mathrm{CB} 3.3 \mathrm{C}$ microzooplankton data was not performed because this data was collected with a $44 \mu \mathrm{m}$ net, which may capture less than half of the total microzooplankton biomass (Brownlee and Jacobs, 1987). However, the trend in abundance showed a similar pattern to our modeled data with the highest abundance of microzooplankton occurring in the summer.

The biomass of bacteria was the highest in the summer and relatively constant throughout the spring, winter, and fall. Our results are consistent with a study of Chesapeake Bay bacterioplankton by Shiah and Ducklow (1994a) who found similar seasonal trends in abundance and biomass (range $0.49-9.86 \mu \mathrm{MN}$; annual average: upper bay $2.69 \mu \mathrm{MN}$, mid-bay $3.87 \mu \mathrm{MN}$ ). The biomass of viruses (Fig. 5b) generally followed the seasonal abundance of their hosts (Fig. 5a) and was therefore rather constant throughout the year for bacteriophages and showed two peaks, a small one in the spring and a larger one in the summer, for phytoplankton viruses. These results are within the range of virus abundance data (when converted to biomass) reported by Wommack et al. (1992) for the Chesapeake Bay (range 0.042-2.09 $\mu \mathrm{MN}$; annual mean $0.40 \mu \mathrm{MN}$ ) and show the same seasonal trend with the highest viral abundance (biomass) in the late summer and fall. Our results are also consistent with the limited MOVE virus data for station CB3.3C. The concentration of detritus (Fig. 5d) was highest in the late summer when plankton biomass was at its seasonal maximum and productivity was high.
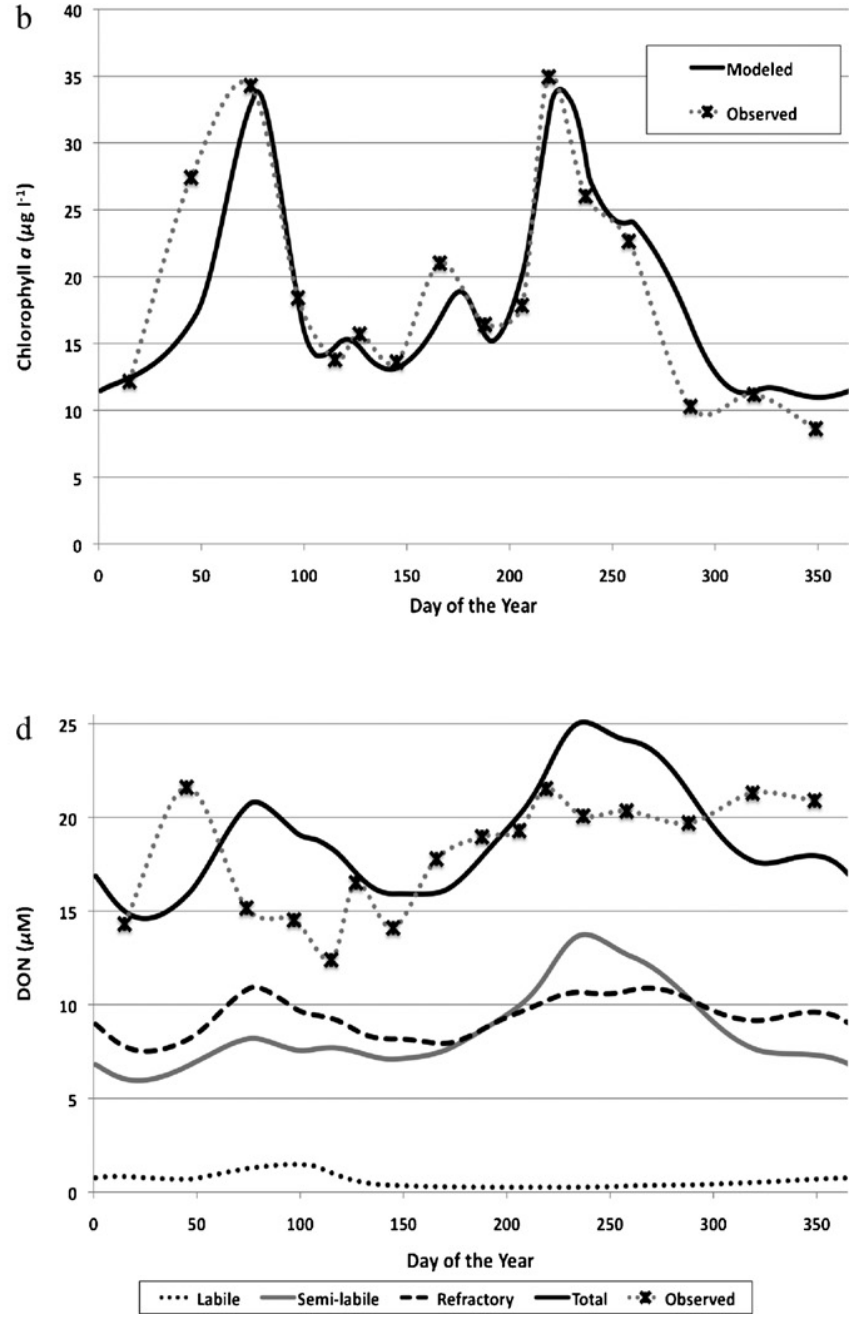

\subsubsection{Production}

Primary production (Fig. 6) was lowest in the winter and peaked in the spring and again in late summer. The contribution to total primary production by the different size classes of phytoplankton changed seasonally with large phytoplankton dominating production in the spring and small phytoplankton dominating production in the late summer, a result that is consistent with studies of this area of the bay (Adolf et al., 2006). In the spring and early summer primary production was fueled by the uptake of nitrate, which was abundant at this time of year (Fig. 3a), while in the late summer peak primary production was fueled by the uptake of ammonium (Supplemental Fig. 1). We were unable to directly compare our primary production rates with CBP data because of the methodology they used to measure primary production. However, we did compare trends, which show that our results are similar to the mean CBP primary production observations at station CB3.3C, with low winter productivity and peaks of nearly equal magnitude in the spring and late summer (comparisons not shown).

Modeled bacterial production fluctuated throughout the year between 0.4 and $0.7 \mu \mathrm{mol} \mathrm{Cd}^{-1}$ (average $0.53 \mu \mathrm{mol} \mathrm{Cd}^{-1}$ ) which compares well with the $0.5 \mu \mathrm{mol} \mathrm{Cd}^{-1}$ bacterial production measurements made by Raymond and Bauer (2001) during DOC consumption experiments in the nearby York River estuary, a subestuary of the Chesapeake Bay. The CBP does not collect bacterial production data so we were unable to make any direct comparisons to station data. 

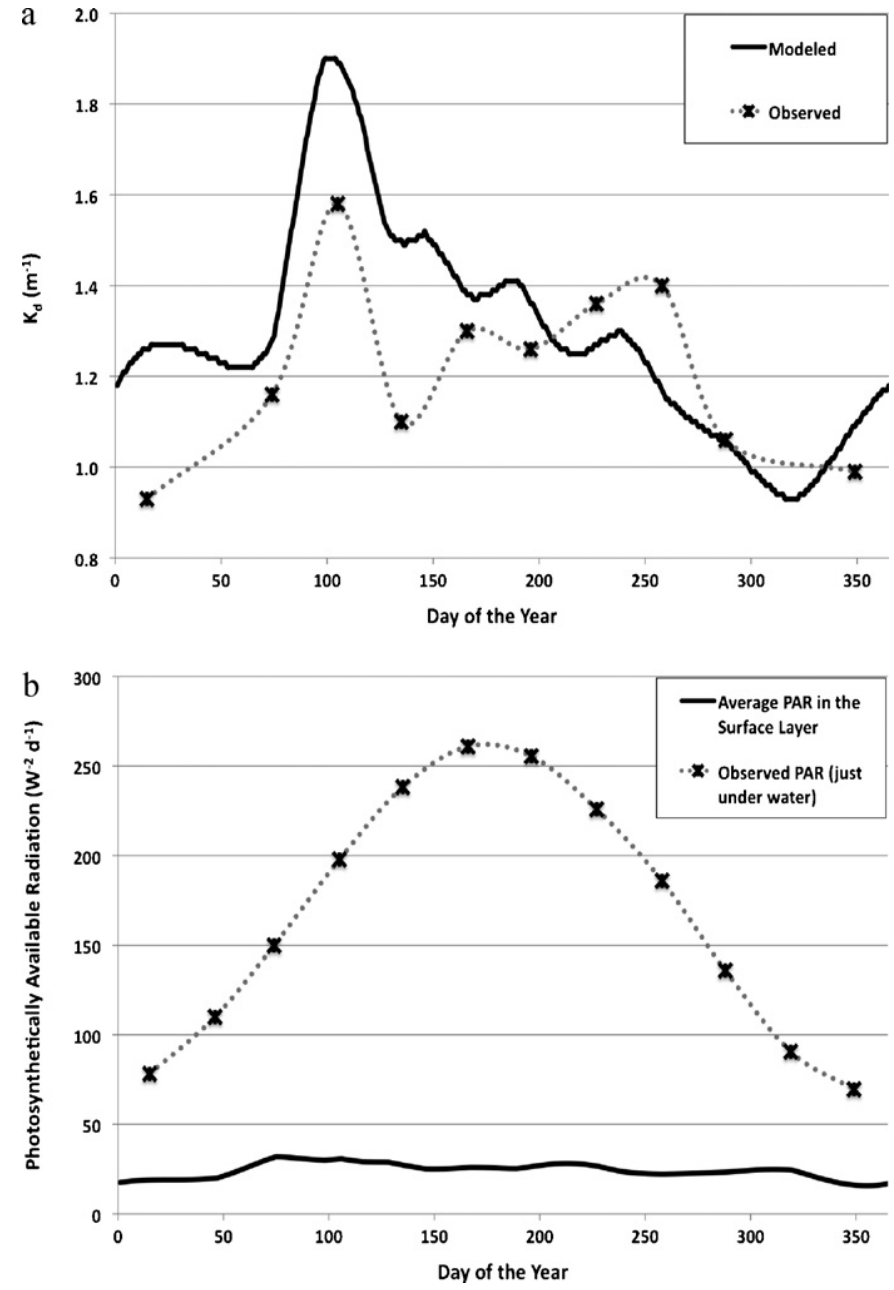

Fig. 4. Comparisons between: (a) the modeled and mean observed vertical light attenuation coefficient $\left(K_{d}\right)\left(\mathrm{m}^{-1}\right)$; (b) modeled photosynthetically available radiation (PAR) and the amount of PAR just below the water surface (95\% of PAR at the surface, $5 \%$ reflectance loss).

\subsubsection{Zooplankton grazing}

The sources of nitrogen in the diet of large zooplankton (Supplemental Fig. 2a) varied throughout the year, indicating a diverse diet, and reflecting the seasonal abundances of different food sources. The sources of nitrogen in the diet of small zooplankton (Supplemental Fig. 2b) were less varied, indicating a more selective diet, consisting of mostly phytoplankton and bacteria. The percentage of primary production lost to zooplankton grazing (Supplemental Fig. 2c) shows that zooplankton had the largest impact on primary production in the spring with large zooplankton consuming almost half of daily primary production. Measurements of primary production lost to zooplankton grazing in the mesohaline portion of Chesapeake Bay (south of station CB3.3C) show a similar trend with the highest consumption occurring in the spring during March (White and Roman, 1992).

\subsubsection{DOM sources and cycling}

The production of DOM (Fig. 7) peaked in the spring and the late summer, corresponding to the peaks in plankton biomass and productivity described in the sections above. It is interesting to note that peaks in DOC production (Fig. 7a) were of roughly the same magnitude ( 1.88 and $2.08 \mu \mathrm{MC}^{-1}$ ) while the springtime DON production (Fig. 7b) peak (159.5 $\left.\mathrm{nM} \mathrm{N} \mathrm{d}^{-1}\right)$ was much higher than the late summer peak $\left(98.7 \mathrm{nM} \mathrm{N} \mathrm{d}^{-1}\right)$. A more detailed examination of DOC production shows that phytoplankton exudation was the dominant source of DOC, averaging $63 \%$ of total DOC production throughout the year, except for a brief period during the spring when the production of DOC from sloppy feeding was high. Viral lysis was also an important source of DOC (averaging 14\% of total DOC production throughout the year), especially during the late summer and early fall. Mortality, the decay of detritus, zooplankton excretion, and sloppy feeding all produced minor amounts of DOC throughout the year, except for the noted peak in the production of DOC by sloppy feeding in the spring. The contribution of different sources of DON to total DON production varied much more seasonally than for DOC. In the spring sloppy feeding was the most important source of DON (up to $75 \%$ of total DON production). This result is consistent with a study by Bronk et al. (1998), which suggested that sloppy feeding contributed significantly to spring DON production. In the summer when DON production peaked again, the peak was due to increases in all DON sources with production from viral lysis $(36 \%)>$ phytoplankton exudation $(26 \%)>$ the decay of detritus $(18 \%)>$ mortality $(9 \%)>$ sloppy feeding $(7 \%)>$ zooplankton excretion (4\%). The decay of viruses (Fig. 5b) also transferred significant amounts of organic matter $\left(61.62-154.94 \mathrm{nM} \mathrm{N} \mathrm{d}^{-1}\right.$ and $0.20-0.51 \mu \mathrm{MC}^{-1}$ ) from viruses to the modeled pools of DOM.

A more detailed look at individual sources of DOM (Fig. 8) highlights the seasonal role that different groups of plankton play in DOM cycling. The release of DOM by phytoplankton (Fig. 8a) in the spring came mostly from large phytoplankton while in the late summer most of the DOM was produced by smaller phytoplankton. These seasonal patterns of phytoplankton DOM production correspond with the seasonal biomass and productivity patterns of phytoplankton. The production of DOM by sloppy feeding (Fig. 8b) peaked in the spring when the biomass (Fig. 5a) of large zooplankton was highest. Most of the DOM produced by this process came from large zooplankton feeding on other large zooplankton with lesser amounts coming from large zooplankton feeding on large phytoplankton and detritus. The production of DOM by viral lysis (Fig. 8c) peaked slightly in the spring and then reached a maximum rate in the late summer. Lysis of bacteria was the most important source of DOM throughout the year but the maximum amount of DOM produced by this process was from the lysis of small phytoplankton in the late summer. The production of DOM from mortality (individual sources not shown) and the breakdown of detritus (Fig. 7) track the mass of that source as it changes seasonally (i.e., the peak in large zooplankton biomass corresponds to a peak in DOM from the mortality of large zooplankton).

The transformation and C:N ratio of DOM is shown in Fig. 9. The rate of ectoenzyme hydrolysis of the semi-labile DOM pool (Fig. 9a) peaked in the summer when the concentration of semi-labile DOM and bacterial biomass were at their seasonal maxima. Due to the model formulation most (90\%) of this semi-labile DOM was transformed into labile DOM with only a small fraction becoming more refractory. Photochemical reactions were especially important for turning over the refractory pools of DOM. Photochemical processes (Fig. 9b) converted DOC to DIC at a mean rate of $0.029 \mu \mathrm{MCd}^{-1}$, DON to ammonium at a mean rate of $0.299 \mathrm{nM} \mathrm{N} \mathrm{d}^{-1}$, refractory DOC to labile DOC at a mean rate of $0.006 \mu \mathrm{MCd}^{-1}$, and refractory DON to labile DON at a mean rate of $0.467 \mathrm{nM} \mathrm{N} \mathrm{d}^{-1}$.

The primary consumers of DON were bacteria (Supplemental Fig. 3) with phytoplankton taking up minor amounts of DON when their biomass and productivity was highest. The maximum uptake of DON by bacteria occurred in the spring. High rates of DON uptake by bacteria did not occur in the summer because the $\mathrm{C}: \mathrm{N}$ ratio of labile DON (Fig. 9c) was high at this time of year causing them to become nitrogen limited and start taking up ammonium. The degree to which this actually occurs is unknown as DOM uptake by bacteria has not been measured seasonally at this station. However, previous studies (Apple et al., 2006; Shiah and Ducklow, 1994a,b) 

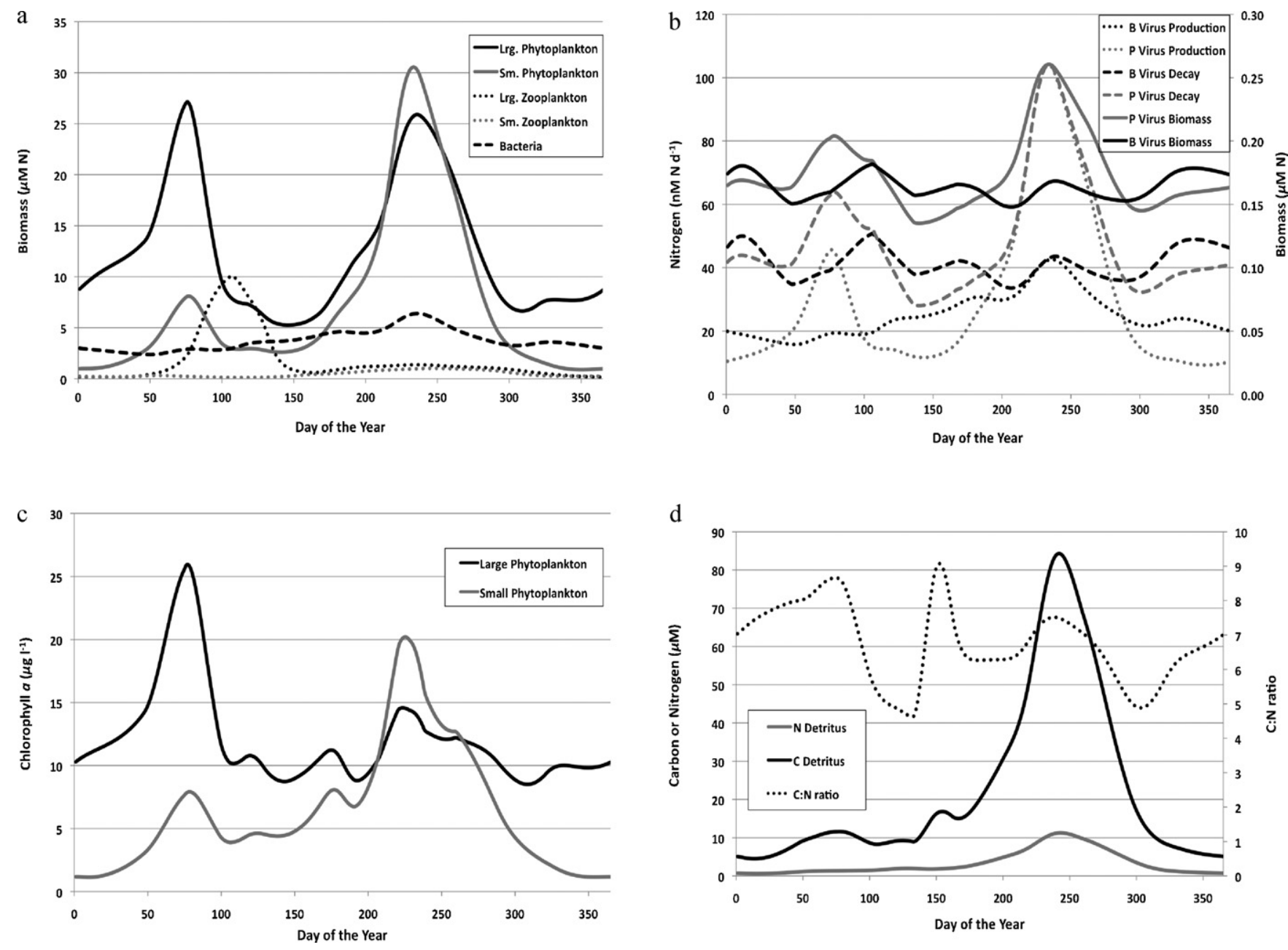

Fig. 5. Model output: (a) plankton biomass; (b) phytoplankton [P] and bacterial [B] virus biomass, production, and decay; (c) large and small phytoplankton chlorophyll a concentration; $(\mathrm{d})$ detritus mass and C:N ratio.

in the Bay have suggested that bacteria become substrate limited in the summer when the temperature exceeds $20^{\circ} \mathrm{C}$.

\subsection{Sensitivity analysis}

Model sensitivity to selected parameters (see Fig. 10) was assessed by varying each in turn $\pm 50 \%$ of their default value. The

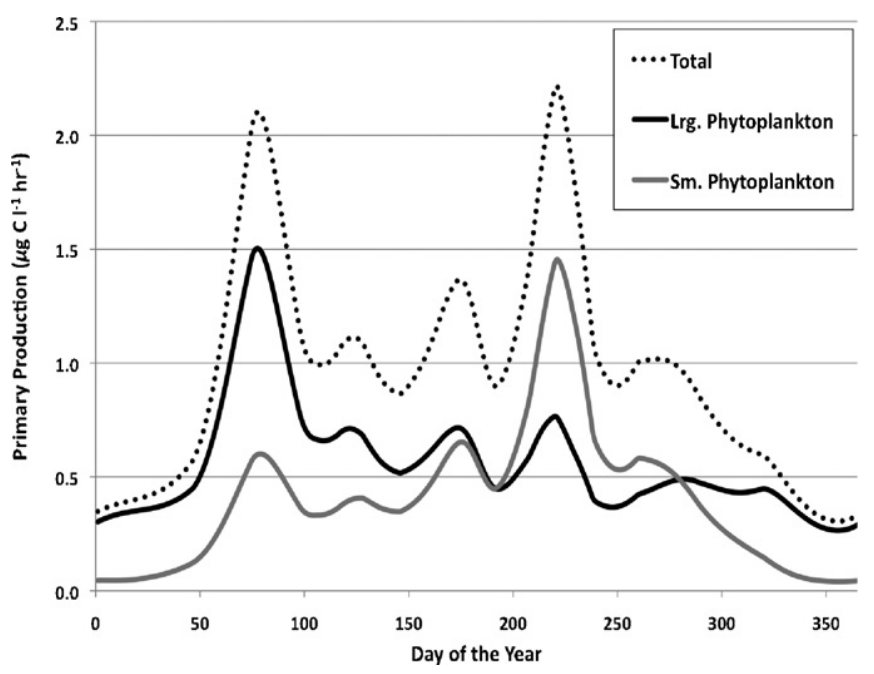

Fig. 6. Model output: primary production. affect of the parameter variations was then determined by comparing the adjusted model output to the main model run at times of the year when biomass and productivity were high, in the spring (day 90) and the late summer (day 225). The sensitivity of primary and bacterial production to these parameter variations is discussed below because of the key roles that these processes play in DOM production and cycling. Light limitation of phytoplankton growth was not addressed in this sensitivity analysis because the amount of light that phytoplankton received in the normal model run (Fig. 4b) was similar throughout the year and always somewhat limiting (i.e., phytoplankton growth would always be sensitive to changes in light availability).

An examination of the sensitivity of modeled primary production indicates that in addition to light limitation, spring (Fig. 10a) production was limited by the growth rate of phytoplankton, $\mu_{P}$, and their growth efficiency (in this case, $\alpha$, the amount of production not lost to DOM through leakage) with the availability of nitrogen not being an issue, as indicated by a lack of sensitivity to changes in the phytoplankton $\mathrm{C}: \mathrm{N}$ ratio, $\lambda_{P}$. In the summer (Fig. 10b) primary production was limited more by nitrogen (and light availability) than anything else (indicated by sensitivity to gge $_{B}$, which affects nitrogen remineralization by bacteria, and $\lambda_{P}$ ). These results are in agreement with an analysis by Malone et al. (1996), which suggest that Chesapeake Bay phytoplankton growth in this region is nutrient saturated in the spring and nitrogen limited in the summer. Phytoplankton biomass was similarly sensitive (data not shown) to the parameters that affected production at 

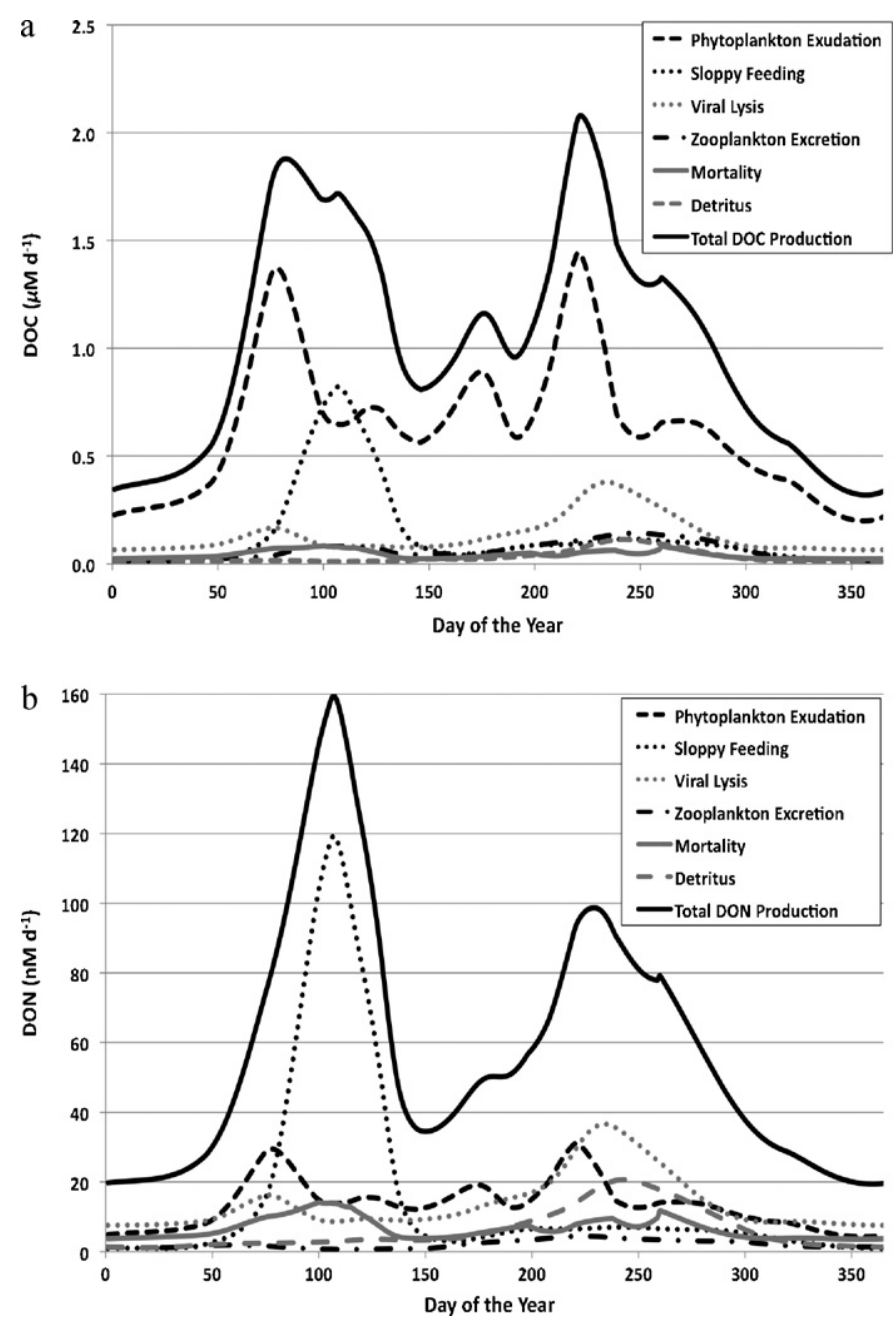

Fig. 7. Modeled DOM production for (a) DOC and (b) DON.

different times of the year. However, unlike primary production sensitivity, phytoplankton biomass was also sensitive in the spring to variations in their $\mathrm{C}: \mathrm{N}$ ratio, $\lambda_{P}$, because of the affect it had on zooplankton biomass and grazing mortality for phytoplankton (data not shown). Small phytoplankton biomass also showed a greater magnitude of sensitivity in the summer (2-fold change in biomass compared to spring). In addition, it was evident that competition was occurring between large and small phytoplankton, as their biomass and productivity was inversely sensitive to parameter variations that affected the other either negatively or positively.

Bacterial production in the spring (Fig. $10 \mathrm{c}$ ) was most sensitive to factors that affect growth $\left(\mu_{B}, g g e_{B}, K_{L_{C}}\right)$, with only a slight indication of any nutrient (DOM) limitation (sensitivity to $\zeta$ and phytoplankton exudation parameters). In the summer, bacterial production was sensitive to parameter variations that increased the amount of available DOM $\left(\alpha, \chi_{D_{N}}, \zeta, \lambda_{P}, \varpi_{2}, K_{S}\right)$ and their growth efficiency (Fig. 10d). In addition, summer nutrient limitation was also indicated by bacterial production not being sensitive to variations in their growth rate, $\mu_{B}$. Bacterial biomass was sensitive (data not shown) to the same parameter variations as production (Fig. 10c and d) with the only difference being a greater magnitude of sensitivity in the summer (2-fold change in biomass compared to spring).

The biomass of large and small zooplankton was sensitive in both the spring and summer (data not shown) to parameter variations in their growth coefficients $\left(g e_{Z_{L}}\right.$ and $\left.g e_{Z_{L}}\right)$ and the phyto- plankton C: $\mathrm{N}$ ratio, $\lambda_{P}$. And except for small zooplankton biomass in the spring, they were sensitive to variations in their mortality rates, $m Z_{\mathrm{L}}$ and $m Z_{\mathrm{S}}$. Large zooplankton were also sensitive to variations in the sloppy feeding parameters, $\omega_{Z_{L}}, \omega_{P_{L}}, \omega_{D}$ (which are essentially assimilation terms), and to variations that affected phytoplankton growth, with sensitivity to changes in the phytoplankton growth rate, $\mu_{P}$, and efficiency, $\alpha$.

Total DOC and DON concentrations were much more sensitive to parameter variations in the summer than they were in the spring (Fig. 11, note differences in the $x$-axis scales). Most of this sensitivity was in the semi-labile pools of DOM as the refractory pools were rather insensitive to parameter variations and the labile DOM pools actually exhibited the opposite behavior and were more sensitive in the spring than in the summer (data not shown). The labile DOM pools were for the most part sensitive only to parameter variations that affected bacterial growth and uptake of DOM. The semi-labile DOM pools were sensitive to parameters that controlled the production of DOM, with the semi-labile DOC pool being especially sensitive to phytoplankton DOC exudation, as well as the transformation of DOM (i.e., hydrolysis of semi-labile DOM). The model was also particularly sensitive to parameter variations that affected phytoplankton (i.e., C:N ratio, exudation, growth rate) which is not surprising since primary production ultimately provides the organic matter that is cycled through the various DOM pools.

These results of the sensitivity analysis indicate that DOM cycling is intricately tied to the biomass and production of zooplankton, phytoplankton, and bacteria with the relative magnitude of sources and sinks of DOM dependant on the relationships between these groups (i.e., high phytoplankton biomass and productivity results in increases in DOM exudation which then provides a substrate to fuel bacterial growth, resulting in more DOM release from bacterial viral lysis and so on). These results are in agreement with a previous sensitivity analysis of this model which examined, in detail, how sensitive the production, transformation, and uptake of DOM was to parameter variations at steady-state under eutrophic, mesotrophic, and oligotrohic nutrient conditions (Keller and Hood, 2011).

\section{Discussion}

\subsection{Model formulation}

Dissolved organic matter cycling is very complex because it involves numerous biological, chemical, and physical processes. This complexity creates a problem when trying to understand and model DOM cycling because complex models, with many state variables and parameters, often do not perform better than simpler ones (Anderson, 2005; Arhonditsis et al., 2006; Freidrichs et al., 2007; Hood et al., 2006). However, since the cycling of DOM is so complex, it cannot be adequately described using the simple modeling approach of aggregating species into all-encompassing functional groups (as in NPZ models) and adding a DOM pool. Therefore, when DOM is included in a model the purpose and goals of the research must be carefully considered during model development. In the study presented here the objective of this research was to simulate the autochthonous production of DOM from processes that are thought to be important in the Chesapeake Bay. In order to do this we decided that it was necessary to explicitly include the sources (and sinks) of this DOM as state variables. In addition, DOM had to be adequately described. Our justification for adding state variables to previous model formulations of DOM cycling (i.e., Anderson and Williams (1998)) is presented below.

Describing DOM has always been problematic and a number of approaches have been taken in modeling studies. Many early models, like the one of Anderson and Williams (1998), included only the 
a
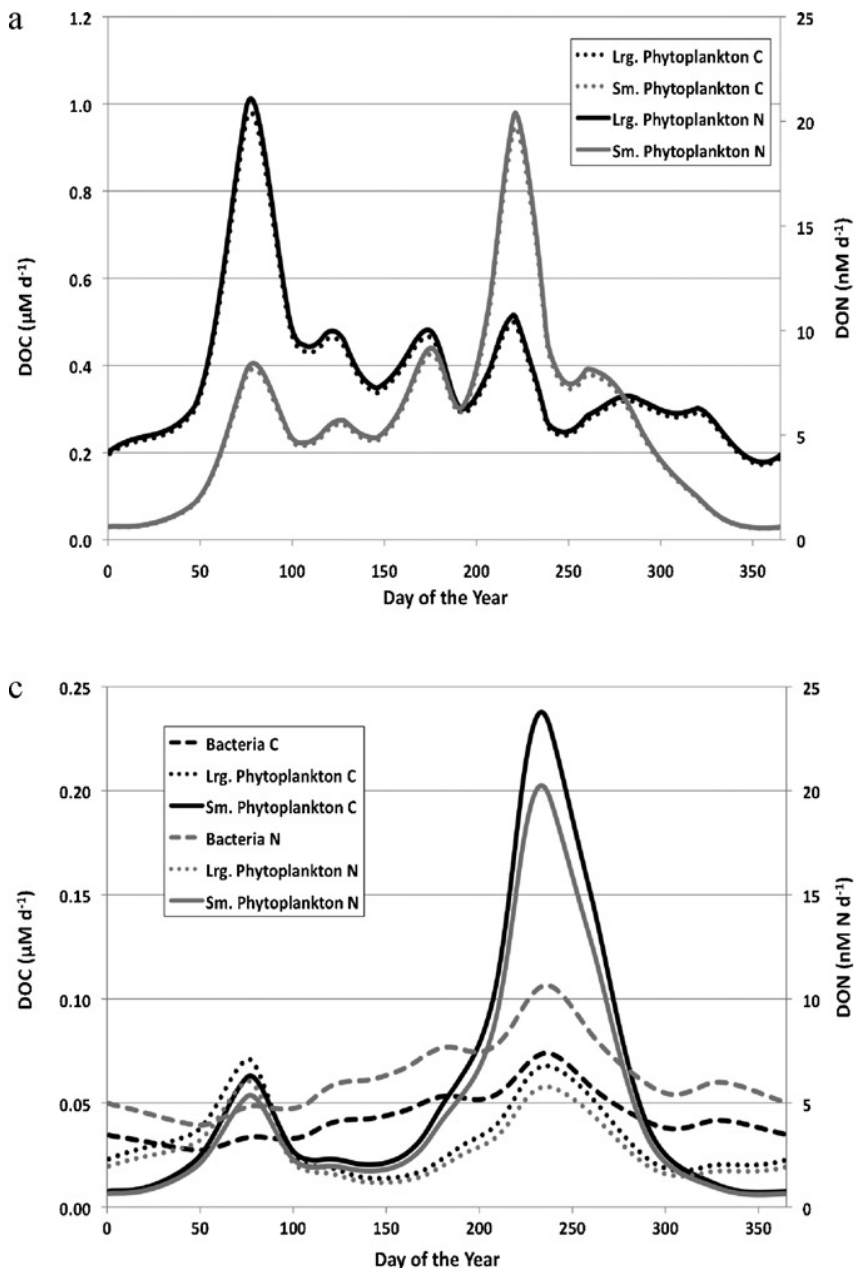

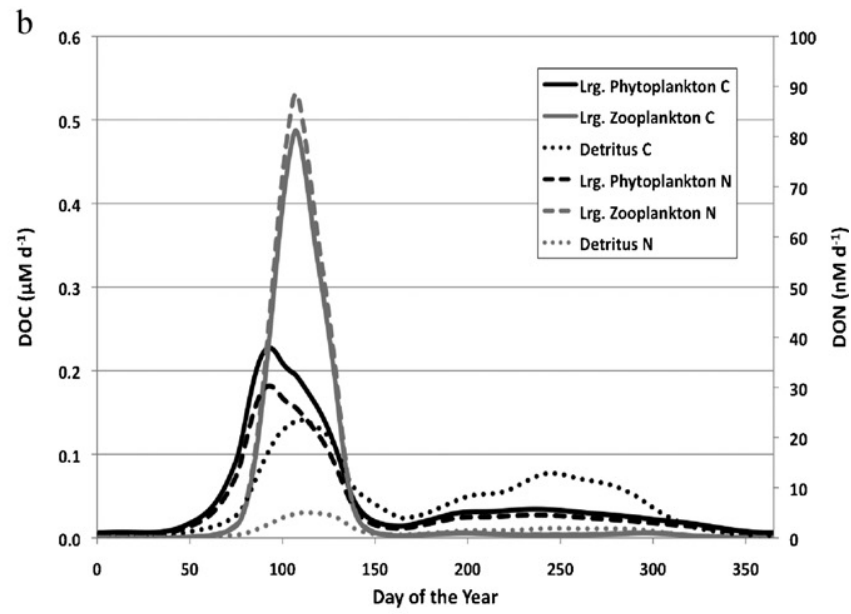

Fig. 8. Modeled individual sources of DOM: (a) phytoplankton exudation; (b) sloppy feeding; (c) viral lysis.

portions of the DOM pool that turned over quickly due to biological consumption (i.e., labile and semi-labile DOM), while ignoring the large "refractory" portion of the pool (Christian and Anderson, 2002). However, recent studies have shown that the "refractory" DOM pool may be more dynamic than previously thought. Photochemical reactions are now know to convert refractory DOM into DIC, ammonium, or more labile forms on short time scales (Mopper and Kieber, 2002). In addition, refractory DOM is also thought to be produced through biological processes or photochemical reactions (Mopper and Kieber, 2002; Ogawa et al., 2001). Photochemistry may be especially important in Chesapeake Bay DOM cycling as a significant amount of allochthonous DOM from tidal marshes undergoes photochemical oxidation (Tzortziou et al., 2008, 2007) and, thus, may be an important source of labile DOM in the main stem of the bay. Therefore, following a few other models of DOM cycling (Anderson and Williams, 1999; Pahlow et al., 2008), we included a refractory DOM pool.

Two size classes of phytoplankton and zooplankton were included in the model to account for seasonal changes in the size structure of these Chesapeake Bay communities (Kimmel and Roman, 2004; Malone, 1980). Allowing the size structure of the planktonic community to seasonally change was especially important for modeling the production of DOM from large crustacean zooplankton sloppy feeding because it is a size based processes (Møller, 2005; Møller and Nielsen, 2001). In addition, there are differences in the utilization of nutrients and the growth rates of different phytoplankton size classes that need to be accounted for as this can affect the amount of DOM phytoplankon exude.
There are also important differences in growth rates, feeding preferences, assimilation-, and production-efficiencies of large (macro) and small (micro) zooplankton that we wanted to account for as some of these differences may play an important role in DOM cycling (i.e., microzooplankton are important predators of freeliving bacteria, while larger zooplankton are not).

Viruses were explicitly included in the model for a number of reasons. First, they were included to account for the role of viral decay in DOM cycling. Second, they were included because they are small enough that they are operationally considered to part of the DOM pool and thus their biomass must be accounted for, especially if DOM is classified according to bioavailability. Third, by having viruses as a state variable the processes of viral lysis becomes more dynamic and realistic (i.e., dependent on virus density/biomass) and is not just a fixed rate as in an implicit scheme.

Phosphorus $(\mathrm{P})$ was not included in the model for a number of reasons. First, in the Chesapeake Bay the annual cycles of phytoplankton growth and productivity are principally a function of light-limited growth (Malone et al., 1996). Although there is some evidence from bioassay experiments that phytoplankton in the Bay can be P-limited in the spring, Malone et al. (1996) report that even though phytoplankton may respond to P additions, they appear to be at, or near, their maximum light-limited growth rates during this period. Second, Malone et al. (1996) concluded that the production of phytoplankton biomass on the seasonal scale of the bay as a whole is limited by nitrogen. Third, there is not as much $P$ data, especially for dissolved organic phosphorus, to parameterize, force, and validate the model. Thus, the results of a P inclusive 

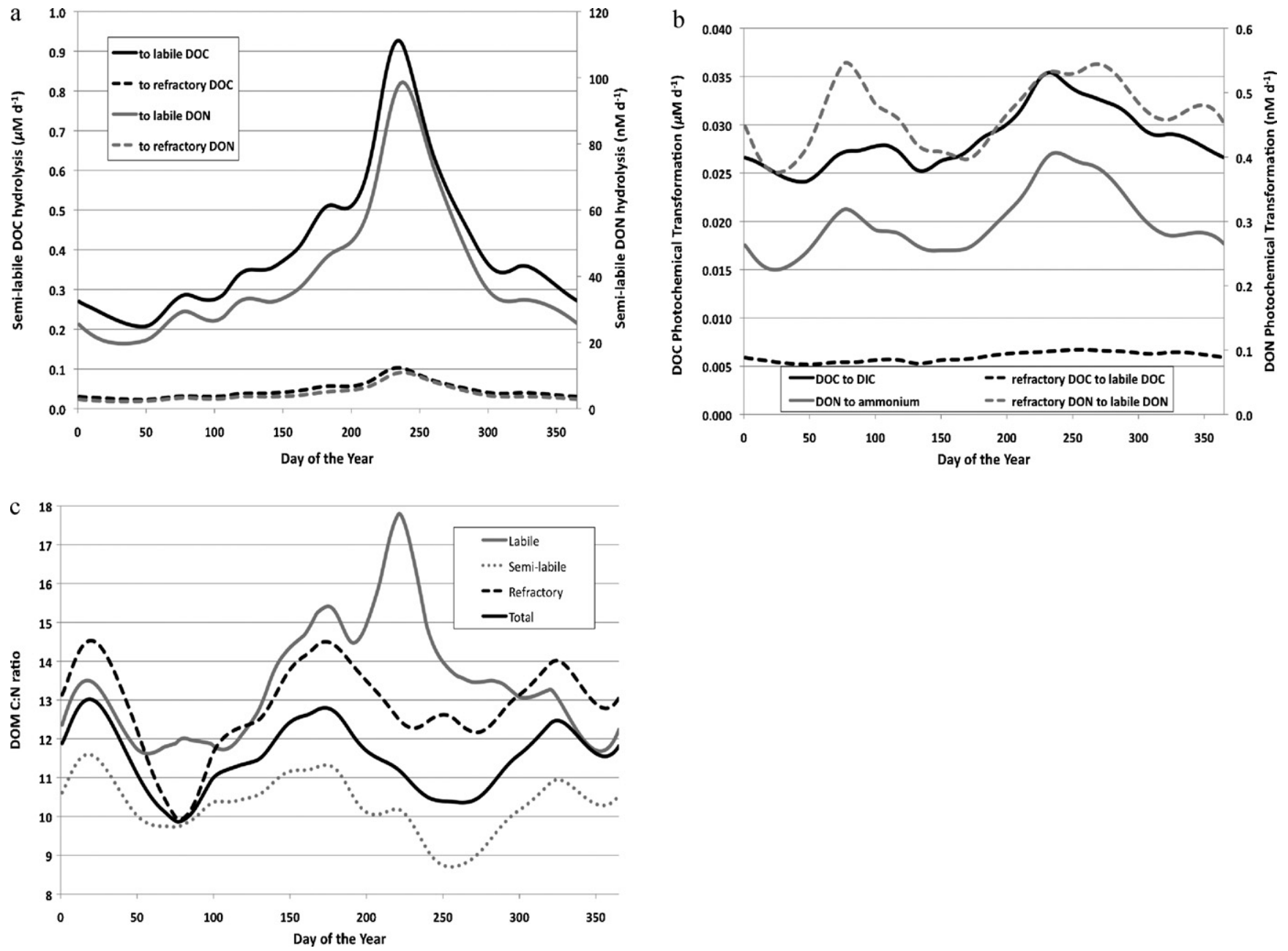

Fig. 9. Model output: (a) rate of semi-labile DOM hydrolysis; (b) rate of photochemical DOM transformation; (c) DOM C:N ratio.

model would be less robust. Finally, including P would have made the model much more complex.

\subsection{Model performance}

Since many of the processes involved in DOM cycling are poorly constrained it was important to reproduce the observed patterns in biomass, productivity, nutrients, and DOM at this station before we could be confident that our model could simulate the flow of carbon and nitrogen between plankton, nutrients, detritus, and DOM. In general the model results compare well with the available station data (Figs. 3 and 4 and Table 4). Simulated ammonium, nitrate, and chlorophyll $a$ concentrations all reproduce the observed seasonal patterns fairly well. However, the model did not capture the timing of when the spring bloom begins (Fig. 3b). This may be due to a phenomenon unique to Chesapeake Bay where dinoflagellates are transported in the bottom layer from near the mouth of the bay to the general area around this station where they surface and often cause late winter or early spring "blooms" (Tyler and Seliger, 1978, 1981). As our model was not embedded in a hydrodynamic model of the whole bay we could not easily reproduce this phenomenon and were therefore more reliant on temperature and light to trigger a spring bloom. In addition, our model did not account for the ability of mixotrophic species, which can be present at this station in high concentrations during the spring (Adolf et al., 2006; Keller, personal observation in 2007 and 2008), to supplement their photosynthetic growth with grazing and, thus, grow better than strict phototrophs at low spring temperatures and light levels. The exponential temperature function that we used to set the maximum attainable daily growth rate of phytoplankton may have also contributed to the delay in the beginning of the spring bloom as it has often led models to underestimate primary production at lower temperatures (Brush et al., 2002; Cerco and Noel, 2004).

The modeled concentration of DOC also compares well with the available station data (Fig. 3c). However, for DON (Fig. 3d), the model missed the timing of a peak in DON in the spring and produced this peak later when observed springtime DON had decreased. This may be due to the model missing the timing of the spring bloom (see above) and the production of DOM that goes along with it. In addition, the model overestimated the concentration of DON in the late summer, producing a peak that then declined to below the observed DON concentration in the late fall and winter. This result indicates that the model may either be overestimating the production of DON in the summer or underestimating its consumption. However, we should also note that there is a discrepancy in the station data as the mean DON observations at the end of the year are much higher than the mean DON observations at beginning of year. This indicates that DON either decreases rapidly at some point during the winter or that there is a problem with the data, in which case our model results may not be that inaccurate.

In the model the average PAR in the surface layer showed little change throughout the year (Fig. 4b). This occurred because the mean depth of the surface layer changed throughout the year (CBP data not shown) and was at its deepest during the summer when 
a
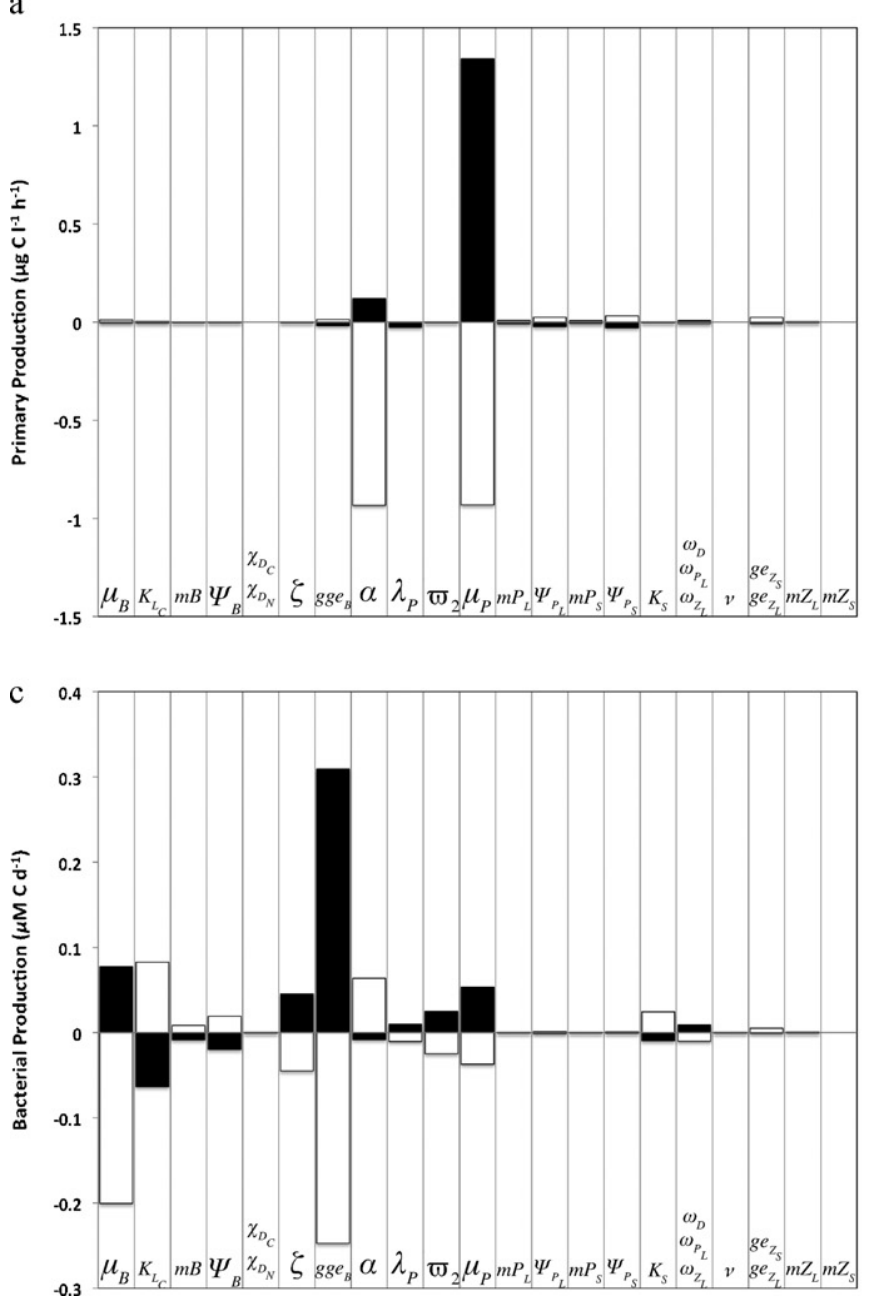

b

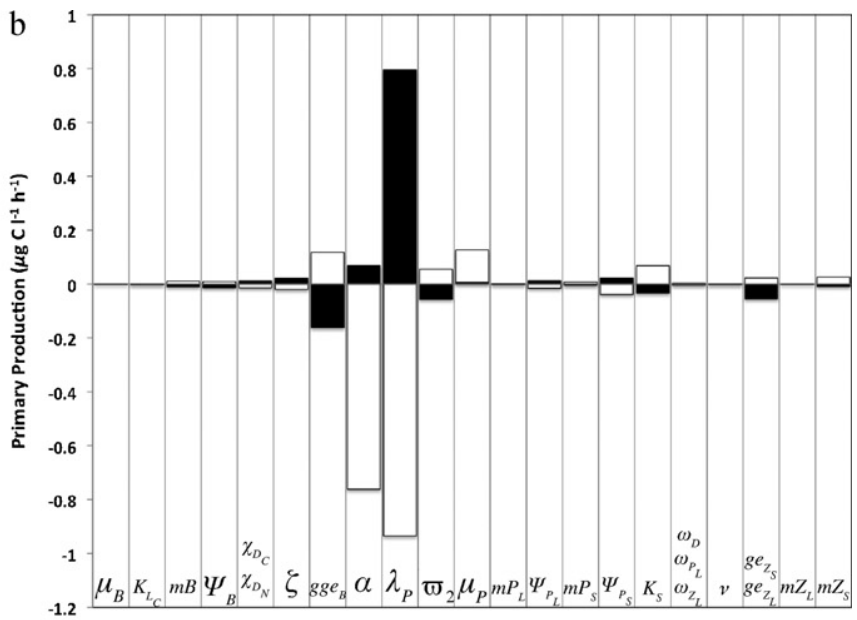

Fig. 10. Results of a sensitivity analysis for parameter variations of $\pm 50 \%$. Day 90 : (a) primary production; (c) bacterial production. Day 225 : (b) primary production; (c) bacterial production. Parameter increases are in black ( $\square)$ and parameter decreases are in white ( $\square)$.

surface PAR values were highest. Thus indicating that phytoplankton growth at this station may be more dependent on temperature than light, unless the species present are able to regulate their buoyancy and remain mostly at the surface where light levels are highest.

Ecosystem properties that were not directly comparable to station data compare reasonably well with other measurements from this area of the Bay. The model successfully reproduced the mean seasonal peaks in zooplankton, phytoplankton, bacteria, and viral biomass that have been observed in this area of the Bay. The model also simulated the general magnitude and pattern of primary and bacterial productivity that have been measured in this region of the Bay. In addition, the simulated diets of zooplankton and amount of primary production lost to grazing compare well to studies of these processes.

\subsection{Dissolved organic matter production}

In our model autochthonous DOM production (Fig. 7) peaked in the spring and late summer when plankton biomass, productivity, and trophic interactions were highest. However, even though the production of DOM peaked twice, the dominant sources of DOM, especially for DON, were not always the same. Very little is reported in the literature about which individual sources of DOM are important on a seasonal basis so we can make few comparisons. However, since our model performs reasonably well when compared to other seasonal ecosystem measurements (i.e., nutrients, biomass, etc.), we are confident that the model simulates the general seasonal autochthonous production of DOM. In the model phytoplankton exudation was almost always the dominant source of DOC. However, our results also indicate that sloppy feeding can be an important source of DOC in the spring. During the late summer and fall, our results suggest that, in addition to phytoplankton exudation, viral lysis can be an important source of DOC. For DON, our results indicate that sloppy feeding was the most important source in the spring and that viral lysis, phytoplankton exudation, and the decay of detritus were important in the summer and early fall. Our spring DON production results are consistent with a study by Bronk et al. (1998), which suggested that sloppy feeding contributed significantly to spring DON production. Unfortunately, we could find no comparable Chesapeake Bay studies of DON sources in the summer and early fall.

In our simulations the important sources of DOM, phytoplankton exudation, sloppy feeding, viral lysis, and the decay of detritus, all had seasonal patterns that reflected the seasonal planktonic dynamics of the system. For phytoplankton DOM production this meant the DOM production corresponded with their seasonal biomass and productivity patterns. While our formulation for the release of DOM by phytoplankton is relatively simple (i.e., a fixed rate), compared to Flynn et al.'s (2008) models of DOM release, and does not take important factors such as the nutritional status or growth rate of phytoplankton into account, we feel that 

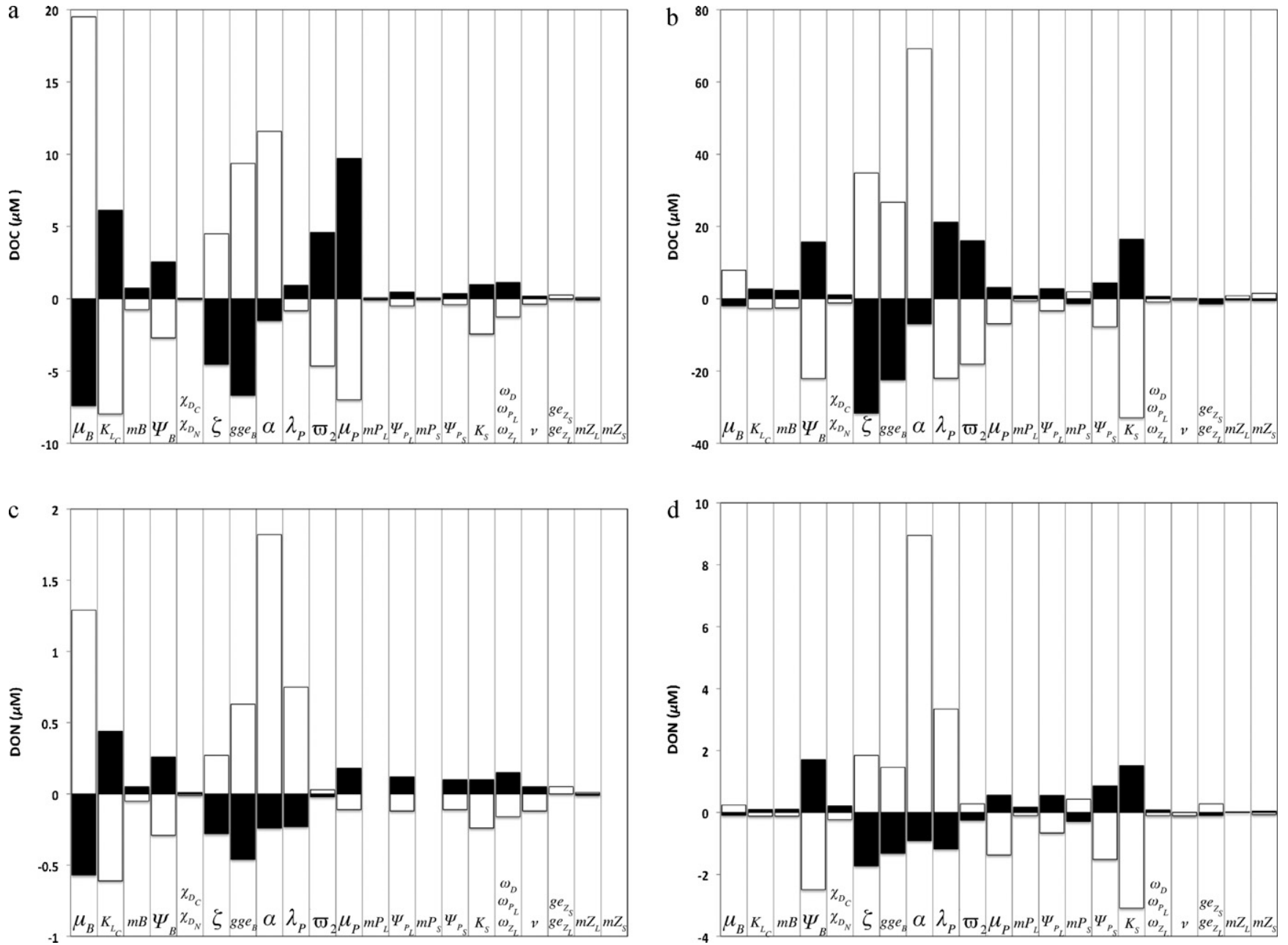

Fig. 11. Results of a sensitivity analysis for parameter variations of $\pm 50 \%$. Day 90: (a) DOC; (c) DON. Day 225: (b) DOC; (d)DON. Parameter increases are in black (匹) and parameter decreases are in white $(\square)$

our model provides a reasonable description of seasonal DOM production by phytoplankton (i.e., high phytoplankton biomass and productivity at certain times of the year should result in increases in DOM exudation by phytoplankton at those times of the year).

The production of DOM from sloppy feeding was highest in the spring when large zooplankton and phytoplankton were the most abundant. This is not surprising because the release of DOM by sloppy feeding is a size dependent process that occurs when large zooplankton (copepods) feed (Møller, 2005, 2007; Møller and Nielsen, 2001). Our finding that viral lysis was important in the summer seems reasonable given that viruses tend to show a seasonal trend in abundance with peak abundance occurring in the late summer and early fall (Wommack et al., 1992). This high abundance of viruses indicates that virus production is also high at this time of year. And because viral production (i.e., lysis) also produces DOM it is reasonable to assume that DOM production by viral lysis is high when viral production is high. Since most virioplankton are thought to be bacteriophages (Weinbauer, 2004; Wommack and Colwell, 2000) and because bacteria are very abundant and productive in Chesapeake Bay, it was not surprising that our results show that seasonally most of the DOM from viral lysis comes from the lysis of bacteria. The peaks in DOM production from viral lysis of phytoplankton were because more DOM is produced when a phytoplankton cell lyses (i.e., the larger the cell lysed the more DOM produced), not because more phytoplankton than bacteria underwent lysis.
The production of DOM from mortality (individual sources not shown) and the breakdown of detritus (Fig. 7) were formulated so that a fixed percentage of the state variable mass enters the DOM pool on a daily basis. Consequently, the amount of DOM produced by mortality and the breakdown of detritus tracks the mass of that source as it changes seasonally (i.e., the peak in large zooplankton biomass corresponds to a peak in DOM from the mortality of large zooplankton). These processes are not well understood and there is very little information in the literature to parameterize the rates at which they occur or to make comparisons with. Therefore, it is difficult to conclude that our model, or any other ecosystem model, adequately simulates the true magnitude of the production of DOM from mortality and the breakdown of detritus. However, it is logical to assume that when the mass and/or productivity of plankton and detritus are high the amount of DOM produced by their mortality or breakdown will be higher than when their mass and/or productivity is low. This gives us some confidence that our model at least captures the seasonal trends in DOM production from these sources.

The results of the sensitivity analysis support our conclusion that the magnitudes of autochthonous sources of DOM change in response to the seasonal dynamics of planktonic community. Perturbations during the sensitivity analysis that changed the structure and productivity of the ecosystem changed the magnitude of DOM sources in a manner similar to seasonal ecosystem changes. Furthermore, the sensitivity analysis highlighted the interconnectedness of plankton, inorganic nutrients, detritus, and 
DOM by demonstrating how changing a key parameter involved in DOM production could affect the flow of $C$ and $N$ between all of the other state variables.

In addition to showing how the autochthonous sources of DOM change seasonally, our results also indicate that viral decay may be an important source of DOM at all times of the year (Fig. 5b). We did not include this in our figures of DOM production because viruses are small enough that they are considered to be DOM. However, from a DOM bioavailability perspective infective viruses are unavailable for uptake by bacteria or phytoplankton and thus their decay represents the production of "new" potentially bioavailable DOM. The amount of DOM, especially DON, produced by viral decay is high compared to other sources of DOM and is a source of DOM that has generally been overlooked by the scientific community. Even if we overestimated viral production or the decay rate and the amount of DOM produced by viral decay is half of what we calculated, this would still represent a significant source of potentially bioavailable DOM.

\subsection{Future modeling challenges}

The development and implementation of this model has revealed important gaps in our general and local knowledge of DOM cycling that need to be addressed in future research efforts. Obtaining more data to force and validate certain aspects of the model is particularly important as we lacked seasonal measurements of some key variables and processes in this study, despite choosing a location in a well-studied estuary.

Improving equations that simulate a number of ecosystem processes is also important as our research indicates that some formulations do not adequately describe certain biological or chemical processes. Here we specifically highlight areas for future research that play in an important role in DOM cycling and need to be better understood. First, there was no adequate data on the biodegradability of DOM inputs from upstream sources. Second, data to fully constrain interactions with the benthos and adjacent terrestrial environments, such as tidal marshes, was unavailable. Third, some of the model parameters, especially those related to mortality and viral infection and decay, had to be estimated using assumptions that may not be valid. Fourth some processes, such as photochemical effects and the decay of detritus are modeled using simple linear equations that may not adequately describe these processes. Fifth, physical processes such as sorption/desorption and flocculation that may alter the concentration and chemical structure of DOM and influence its bioavailability as it is transported through the estuary are also poorly understood, especially in estuaries with steep salinity gradients, and we did not include them in the model. Finally, parameters describing the partitioning of freshly produced DOM to labile, semi-labile, and refractory pools were poorly constrained (see Section 2.4). Hopefully, our study increases awareness of these issues and can be used to guide future research on DOM cycling.

\section{Summary and conclusions}

In this paper we describe a new model formulation that is designed to simulate and investigate DOM cycling in pelagic marine systems. This model includes a representation of DOM in terms of refractory, semi-labile and labile constituents for both DON and DOC. In addition, sources and sinks for DOM from multiple phytoplankton and zooplankton size classes and bacteria are included in the model, along with an explicit representation of the impacts of viruses and viral infection. The effects of light on DOM lability are also included.
Table 5

Seasonally important sources of DOM

\begin{tabular}{|c|c|c|c|}
\hline \multicolumn{2}{|l|}{ Spring } & \multicolumn{2}{|l|}{ Late Summer } \\
\hline $\mathrm{DOC}$ & DON & DOC & DON \\
\hline \multirow[t]{2}{*}{$\begin{array}{l}\text { Phytoplankton } \\
\text { exudation } \\
\text { (Lrg. Phytoplankton) }\end{array}$} & & $\begin{array}{l}\text { Phytoplankton } \\
\text { exudation } \\
\text { (Sm. Phytoplankton) }\end{array}$ & Viral lysis \\
\hline & $\begin{array}{l}\text { Sloppy } \\
\text { feeding }\end{array}$ & & $\begin{array}{l}\text { Phytoplankton } \\
\text { exudation }\end{array}$ \\
\hline Sloppy Feeding & & Viral lysis & Decay of detritus \\
\hline & & Viral decay? & \\
\hline
\end{tabular}

The model was tuned, parameterized, and physically forced with the explicit goal of describing the general seasonal production of DOM in the surface layer at station CB3.3C in Chesapeake Bay. Because many of the processes involved in DOM cycling are poorly constrained it was important to reproduce the observed patterns in biomass, productivity, nutrients, and DOM at this station before we could be confident that our model could simulate the interactions between plankton, nutrients, detritus, and DOM. Our results show that we successfully reproduced the mean seasonal peaks in zooplankton, phytoplankton, bacteria, and viral biomass that have been observed at or near this station. The model also did a reasonable job of reproducing the observed seasonal concentrations of nitrate, ammonium, DOC, and DON.

According to our model, autochthonous DOM production and cycling was strongly influenced by seasonal changes in the planktonic community. The degree to which different groups of plankton influenced DOM production was strongly related to their biomass and productivity in relation to that of the other groups of plankton. Thus, in the spring DOM production and cycling was mostly controlled by interactions between large phytoplankton, large zooplankton, and bacteria. While in the summer, DOM production and cycling was mostly controlled by interactions between small phytoplankton, small zooplankton, viruses, and bacteria. The production of DOM peaked twice, in the spring and late summer, in correspondence with the peak productivity of the spring and summer plankton communities. Table 5 summarizes the most important processes involved in peak DOM production. Our results also indicate that viral decay may represent an important, and often overlooked, source of "new" potentially bioavailable DOM from within the DOM pool. Bacteria were the most important consumers of DOM throughout the year with phytoplankton consuming a small but significant amount of DOM in the spring and late summer. Furthermore, bacteria played an important role in hydrolyzing the semi-labile DOM that accumulated as a result of spring and summer productivity. Photochemical, chemical, and physical processes such as the decay of detritus and the transformation of refractory DOM to labile DOM also played an important role in DOM cycling at this station, and were especially important in turning over the refractory pools of DOM.

In general, our simulations of DOM cycling appear to agree with the current scientific understanding of DOM biogeochemistry. However, we cannot validate some of the model results because we lack the data to do so. Thus, many of our model-generated results about certain aspects of DOM cycling are predictions that need to be tested. These predictions can help guide future research. Moreover, this modeling effort has synthesized a large body of recent DOM literature and provided a means to look at the simultaneous flow of carbon and nitrogen throughout the whole ecosystem and compare the importance of various processes over a long time scale, something that is technically and economically unfeasible to do experimentally. Finally, the development of this model has 
highlighted important gaps in our knowledge of key processes that influence DOM cycling in marine waters.

\section{Acknowledgements}

This research was supported by grants from the National Science Foundation sponsored DOMINO (OCE-0221825) and BITMAXII (OCE-0453905) programs. We would also like to thank the MOVE virus group for providing us with data.

\section{Appendix A.}

\section{A.1. Model calculation}

The model was solved numerically using a fourth order Runge-Kutta method (Press et al., 1992). A thirty-second time step was used because we found that numerical errors occurred with larger time steps.

\section{A.2. Model equations}

\section{A.2.1. Physical forcing}

The inflow and outflow ( $\mu \mathrm{MN}$ or $\mathrm{Cs}^{-1}$ ) of state variables is calculated as:

inflow $=h i^{o}$

outflow $=h i$

where $h$ is the rate $\left(\mathrm{s}^{-1}\right)$ of flow, $i^{0}$ is the upstream state variable mass (interpolated from station CB3.2 data), and $i$ is the model state variable mass. The rate of flow, $h$, was based on Susquehanna river flow and the volume (analogous to turbidostat vessel volume) of the surface layer in a selected area around station CB3.3C:

$h=\frac{F_{\text {river }}}{Z C_{\text {area }}}$

where $F_{\text {river }}\left(\mathrm{m}^{3} \mathrm{~s}^{-1}\right)$ is interpolated from Susquehanna river flow data, $Z$ is interpolated surface layer depth $(\mathrm{m})$, and $C_{\text {area }}$ is a $5.56 \mathrm{~km}$ (width of the bay) by $5 \mathrm{~km}$ area $\left(27,780,000 \mathrm{~m}^{2}\right)$ around station CB3.3C. Susquehanna river flow data was used because the Susquehanna river contributes approximately $87 \%$ of all freshwater that enters the upper bay and thus controls the circulation pattern in the main body of the upper bay (Schubel and Pritchard, 1986). $C_{\text {area }}$ was chosen so that the flow of water was constrained by the width of the bay at station CB3.3C. This formulation gave us a seaward surface flow past station CB3.3C that ranged from 1.2 to $10.2 \mathrm{~cm} \mathrm{~s}^{-1}$ which is similar in magnitude to a 27-day record taken in the spring from nearby Thomas Point light that measured a mean surface flow of $8 \mathrm{~cm} \mathrm{~s}^{-1}$ (Beardsley and Boicourt, 1981).

\section{A.2.2. Light attenuation}

To calculate the underwater light field we used a simple model to derive the average irradiance of the surface layer:

$I=\left(\frac{I_{\text {surface }}}{Z}\right)\left(\frac{1}{K_{d}}\right) \exp \left(-K_{d} Z-1\right)$

where $I_{\text {surface }}$ is the interpolated PAR just below the surface of the water ( $95 \%$ of PAR at the surface, $5 \%$ reflectance loss), $Z$ is interpolated surface layer depth, and $K_{d}$ is the diffuse attenuation coefficient. $K_{d}$ was calculated using a simple empirical optical model that was derived specifically for the Chesapeake Bay (Xu et al., 2005). In this model the specific attenuation coefficients for chlorophyll, total suspended solids (TSS), and salinity (used as a proxy for colored dissolved organic matter (CDOM)) are used to determine $K_{d}$ as follows:

$K_{d}=1.80-0.0044 C h l+0.0673$ TSS $-0.096 S$

Salinity $(S)$ data were from station CB3.3C measurements. The chlorophyll values $(\mathrm{Chl})$ that we used in these calculations were obtained by converting the modeled biomass of phytoplankton $(\mu \mathrm{MN})$ to chlorophyll a $\left(\mu \mathrm{gl}^{-1}\right)$ (see Eq. (A.18)). TSS was calculated by adding the modeled biomass of plankton and detritus (both carbon and nitrogen values converted to $\mathrm{mgl}^{-1}$ ) to the mean TSS measurements from station CB3.3C. Using data output from the biological model to calculate chlorophyll and TSS thus allowed us to provide a feedback mechanism between the optical model and the biological model (i.e., high concentrations of phytoplankton or biologically derived TSS can decrease light penetration).

\section{A.2.3. Phytoplankton}

The equation for large phytoplankton is:

$\frac{\partial P_{L}}{\partial t}=\alpha J_{P_{L}} Q_{P_{L}} P_{L}+h P_{L}^{o}-S_{P_{L}} P_{L}-G_{Z_{L} P_{L}}-G_{Z_{S} P_{L}}-\Psi_{P_{L}} V_{P} P_{L}-h P_{L}$

The equation for small phytoplankton is:

$\frac{\partial P_{S}}{\partial t}=\alpha J_{P_{S}} Q_{P_{S}} P_{S}+h P_{S}^{o}-S_{P_{S}} P_{S}-G_{Z_{L} P_{S}}-G_{Z_{S} P_{S}}-\Psi_{P_{S}} V_{P} P_{S}-h P_{S}$

In both of the above equations the first two terms represent growth and inflowing biomass. The remaining terms represent losses due to mortality, large zooplankton grazing, small zooplankton grazing, viral lysis, and ecosystem outflow.

The maximum growth rate of phytoplankton is:

$\mu_{P}=0.81 e^{(0.0631 T)}$

Temperature data from station $\mathrm{CB} 3.3 \mathrm{C}$ were interpolated into the model for $T$.

Large phytoplankton light limited growth in (A.6) is:

$J_{P_{L}}=\mu_{P}\left(1-e^{-I / I_{P}}\right)\left(e^{-I / I_{\beta}}\right)$

with nitrogen uptake described as:

$Q_{P_{L}}=Q_{P_{L}}^{1}+Q_{P_{L}}^{2}+Q_{P_{L}}^{3}$

Small phytoplankton light limited growth in (A.7) is:

$J_{P_{S}}=1.3 \mu_{P}\left(1-e^{-I / I_{P}}\right)\left(e^{-I / I_{\beta}}\right)$

with nitrogen uptake described as:

$Q_{P_{S}}=Q_{P_{S}}^{1}+Q_{P_{S}}^{2}+Q_{P_{S}}^{3}$

The uptake of nitrogen by phytoplankton, $Q_{P_{L \text { or }} \text {, is designed so }}$ that the uptake of nitrate, $Q_{P_{L \text { or }}}^{3}$, is inhibited if the nitrogen requirements are met by the uptake of ammonium, $Q_{P_{L \text { or }}}^{1}$, and labile DON, $Q_{P_{\text {Lor } S}}^{2}$. Where

$Q_{P_{\text {Lor } S}}^{1}=\frac{A}{K_{P_{L \text { or } S} A}+A}$

$Q_{P_{\text {Lor } S}}^{2}=\frac{L_{N}}{K_{P_{\text {Lor } S} L_{N}}+L_{N}}$

and if $Q_{P_{L \text { or } S}}^{1}+Q_{P_{L \text { or } S}}^{2}$ is less than one then

$Q_{P_{\text {Lor } S}}^{3}=\frac{N_{n}}{K_{P_{\text {Lor } S} N_{n}}+N_{n}}\left(1-\left(Q_{P_{\text {Lor } S}}^{1}+Q_{P_{\text {Lor } S}}^{2}\right)\right)$. 
Else

$Q_{P_{\text {Lor } S}}^{3}=0$.

In addition to the leakage of DOM from the cell, represented as $(1-\alpha) J_{P_{L \text { or } S}} Q_{P_{L \text { or } S}} P_{L \text { or } S}$ (see DOM equations), phytoplankton also release "extra carbon" due to metabolic instabilities caused by shifts in environmental conditions (light, nutrients, salinity, etc.). This is modeled by transferring carbon from DIC to DOC in proportion, $\varpi_{2}$, to total phytoplankton growth:

$E_{P_{\text {Lor } S}}=\varpi_{2} \lambda_{P} J_{P_{\text {Lor } S}} Q_{P_{L \text { or } S}} P_{L \text { or } S}$.

The Chl $a: C$ ratio is:

Chl : $C=0.003+0.0154 e^{(0.050 T)} e^{(-0.0591 I)} Q_{P_{L \text { or } S}}$

Temperature data from station $\mathrm{CB} 3.3 \mathrm{C}$ were interpolated into the model for $T$.

\section{A.2.4. Zooplankton}

The equation for large zooplankton is:

$\frac{\partial Z_{L}}{\partial t}=F_{Z_{L}}+h Z_{L}^{o}-G_{Z_{L} Z_{L}}-S_{Z_{L}} Z_{L}^{2}-h Z_{L}$

In this equations the first two terms represent growth and inflowing biomass. The remaining terms represent losses due to self predation, mortality, and ecosystem outflow.

Large zooplankton production, $F_{Z_{L}}\left(\right.$ mmoles $\left.\mathrm{N} \mathrm{m}^{-3} \mathrm{~d}^{-1}\right)$, is calculated according to the stoichiometric model of Anderson and Hessen (1995). This model operates on the basis of a food threshold elemental ratio, $\theta_{f_{Z_{L}}}^{*}\left(\mathrm{~mol} \mathrm{C} \mathrm{mol}^{-1} \mathrm{~N}\right)$, below which $\mathrm{C}$ limits growth and above which $\mathrm{N}$ limits growth. This ratio is described as:

$\theta_{f_{Z_{L}}}^{*}=\frac{\beta_{\mathrm{N}_{Z}} \lambda_{Z}}{\beta_{\mathrm{C}_{Z}} g e_{Z_{L}}}$

where $\beta_{\mathrm{N}_{Z}}$ and $\beta_{\mathrm{C}_{Z}}$ are assimilation efficiencies for $\mathrm{N}$ and $\mathrm{C}, \lambda_{Z}$ is the zooplankton $\mathrm{C} / \mathrm{N}$ ratio and $g e_{Z_{L}}$ is $C$ production efficiency (fraction assimilated $\mathrm{C}$ allocated to production, remainder respired). Intakes of $\mathrm{N}$ and $\mathrm{C}, I_{\mathrm{N}_{Z_{L}}}, I_{\mathrm{C}_{Z_{L}}}\left(\mathrm{mmol} \mathrm{m}^{-3} \mathrm{~d}^{-1}\right)$ are the sum of large zooplankton grazing on large and small phytoplankton, large and small zooplankton, bacteria, and detritus less "sloppy feeding" losses:

$I_{\mathrm{N}_{L}}=\left(1-\omega_{P_{L}}\right) G_{Z_{L} P_{L}}+G_{Z_{L} P_{S}}+\left(1-\omega_{D_{N}}\right) G_{Z_{L} D_{N}}+G_{Z_{L} B}$

$$
+\left(1-\omega_{Z_{L}}\right) G_{Z_{L} Z_{L}}+G_{Z_{L} Z_{S}}
$$

$$
\begin{aligned}
I_{\mathrm{C}_{Z_{L}}} & =\left(1-\omega_{P_{L}}\right) \lambda_{P} G_{Z_{L} P_{L}}+\lambda_{P} G_{Z_{L} P_{S}}+\left(1-\omega_{D_{N}}\right) G_{Z_{L} D_{N}}+\lambda_{P} G_{Z_{L} B} \\
& +\left(1-\omega_{Z_{L}}\right) \lambda_{Z} G_{Z_{L} Z_{L}}+\lambda_{Z} G_{Z_{L} Z_{S}}
\end{aligned}
$$

where the coefficient $\left(1-\omega_{i}\right)$ represents prey that is ingested and not lost to sloppy feeding and

$$
\begin{aligned}
& G_{Z_{L} P_{L}}=m_{P_{L}} Z_{L} C_{Z_{L}} P_{L} \\
& G_{Z_{L} P_{S}}=m_{P_{S}} Z_{L} C_{Z_{L}} P_{S} \\
& G_{Z_{L} D_{N}}=m_{D} Z_{L} C_{Z_{L}} D_{N} \\
& G_{Z_{L} Z_{L}}=m_{Z_{L}} C_{Z_{L}} Z_{L}^{2} \\
& G_{Z_{L} B}=m_{B} Z_{L} C_{Z_{L}} B \\
& G_{Z_{L} D_{C}}=m_{D} Z_{L} C_{Z_{L}} D_{C} \\
& G_{Z_{L} Z_{S}}=m_{Z_{S}} Z_{L} C_{Z_{L}} Z_{S} .
\end{aligned}
$$

The coefficient $C_{Z_{L}}$ is the maximum large zooplankton consumption rate and

$m_{P_{L}}=\frac{\Phi_{P_{L}}}{\Theta}$

$$
\begin{aligned}
& m_{P_{S}}=\frac{\Phi_{P_{S}}}{\Theta} \\
& m_{D}=\frac{\Phi_{D}}{\Theta} \\
& m_{Z_{L}}=\frac{\Phi_{Z_{L}}}{\Theta} \\
& m_{B}=\frac{\Phi_{B}}{\Theta} \\
& m_{Z_{S}}=\frac{\Phi_{Z_{S}}}{\Theta}
\end{aligned}
$$

with

$\Theta=\Phi_{P_{L}} P_{L}+\Phi_{P_{S}} P_{S}+\Phi_{D} D_{N}+\Phi_{Z_{L}} Z_{L+} \Phi_{B} B+\Phi_{Z_{S}} Z_{S}+K_{Z}$.

This formulation allows assignment of "preferences" for the different forms of organic nitrogen (Fasham et al., 1990; McCreary et al., 1996). For simplicity, the half-saturation constant $K_{Z}$, is assumed to be the same for all substrates.

The following equations from Anderson and Hessen (1995) describe how if the $\mathrm{C} / \mathrm{N}$ ratio of ingested food:

$\theta_{f_{Z_{L}}}=\frac{I_{C_{Z_{L}}}}{I_{N_{Z_{L}}}}$

is greater than $\theta_{f_{Z_{L}}}^{*}$ then $N$ limits production, excretion of $N$ $\left(E_{Z_{L}}, \mathrm{mmol} \mathrm{m} \mathrm{m}^{-3} \mathrm{~d}^{-1}\right)$ is zero, and $F_{Z_{L}}$ is:

$F_{Z_{L}}=\beta_{N_{Z}} I_{N_{L}}$

whereas if $\theta_{f_{Z_{L}}}<\theta_{f_{Z_{L}}}^{*}$ then $C$ limits production and the equations for $F_{Z_{L}}$ and $E_{Z_{L}}$ are:

$F_{Z_{L}}=\frac{\beta_{C} g e_{Z_{L}} I_{C_{Z_{L}}}}{\lambda_{Z_{L}}}$

$E_{Z_{L}}=I_{C}\left(\frac{\beta_{N}}{\theta_{f_{L}}}-\frac{\beta_{C} g e_{Z_{L}}}{\lambda_{Z_{L}}}\right)$

Large zooplankton respiration, $R_{Z_{L}}\left(\mathrm{mmol} \mathrm{Cm}^{-3} \mathrm{~d}^{-1}\right)$, is:

$R_{Z_{L}}=\beta_{C_{Z}} I_{C_{Z_{L}}}-\lambda_{Z} F_{Z_{L}}$

The equation for small zooplankton is:

$\frac{\partial Z_{S}}{\partial t}=F_{Z_{S}}+h Z_{S}^{o}-G_{Z_{L} Z_{S}}-G_{Z_{S} Z_{S}}-S_{Z_{S}} Z_{S}^{2}-h Z_{S}$

In this equation the first two terms represent growth and inflowing biomass. The remaining terms represent losses due to large zooplankton predation, self predation, mortality, and ecosystem outflow. Small zooplankton production, $F_{Z_{S}}\left(\right.$ mmoles $\mathrm{N} \mathrm{m}^{-3} \mathrm{~d}^{-1}$ ), is calculated according to the stoichiometric model of Anderson and Hessen (1995) described above. However, there are notable differences between the small and large zooplankton grazing formulations such as no grazing by small zooplankton on large zooplankton and no losses due to "sloppy feeding" during small zooplankton grazing. Thus, the equations for small zooplankton growth are the same as for large zooplankton (substituting the appropriate subscripts) except for the following:

$I_{N_{Z_{S}}}=G_{Z_{S} P_{L}}+G_{Z_{S} P_{S}}+G_{Z_{S} D_{N}}+G_{Z_{S} B}+G_{Z_{S} Z_{S}}$

$I_{Z_{Z_{S}}}=\lambda_{P} G_{Z_{S} P_{L}}+\lambda_{P} G_{Z_{S} P_{S}}+G_{Z_{S} D_{C}}+\lambda_{B} G_{Z_{S} B}+\lambda_{Z} G_{Z_{S} Z_{S}}$

where

$G_{Z_{S} P_{L}}=n_{P_{L}} Z_{S} C_{Z_{S}} P_{L}$

$G_{Z_{S} P_{S}}=n_{P_{S}} Z_{S} C_{Z_{S}} P_{S}$ 
$G_{Z_{S} D_{N}}=n_{D} Z_{S} C_{Z_{S}} D_{N}$

$G_{Z_{S} Z_{S}}=n_{Z_{S}} C_{Z_{S}} Z_{S}^{2}$

$G_{Z_{S} B}=n_{B} Z_{S} C_{Z_{S}} B$

$G_{Z_{S} D_{C}}=n_{D} Z_{S} C_{Z_{S}} D_{C}$

The coefficient $C_{Z_{S}}$ is the maximum small zooplankton consumption rate and

$n_{P_{L}}=\frac{\varphi_{P_{L}}}{\sigma}$

$n_{P_{S}}=\frac{\varphi_{P_{S}}}{\sigma}$

$n_{D}=\frac{\varphi_{D}}{\sigma}$

$n_{Z_{S}}=\frac{\varphi_{Z_{S}}}{\sigma}$

$n_{B}=\frac{\varphi_{B}}{\sigma}$

with

$\sigma=\varphi_{P_{L}} P_{L}+\varphi_{P_{S}} P_{S}+\varphi_{D} D_{N}+\varphi_{Z_{S}} Z_{S}+\varphi_{B} B+K_{Z}$

The production of DOM and detritus as a result of large zooplankton sloppy feeding is based on a predator-to-prey size ratio that determines the amount of DOM and detritus produced. Based on research by Møller (2005) sloppy feeding is calculated using the following equation:

$Q=0.714-0.013\left(\frac{E S D_{\text {copepod }}}{E S D_{\text {prey }}}\right)$

where $Q$ is the fraction of prey carbon removed from suspension and lost as DOC and detritus during feeding and ESD is the equivalent spherical diameter. This equation was only used for predator-to-prey ratios of <55; sloppy feeding was assumed not to occur at higher ratios. Therefore, we estimated the average ESD of large zooplankton to be $484 \mu \mathrm{M}$ and the average ESD of large phytoplankton to be $13.8 \mu \mathrm{M}$ based on work by Møller (2005), which gives a $Q$ value of $0.26\left(\omega_{P_{L}}\right)$ for large zooplankton feeding on large phytoplankton. For large zooplankton feeding on other large zooplankton, an ESD of $484 \mu \mathrm{M}$ was estimated for the predator and an ESD of $304 \mu \mathrm{M}$ was used for the prey, simulating an average copepod feeding on an average copepodite, which gives a $Q$ value of $0.69\left(\omega_{Z_{L}}\right)$. For large zooplankton feeding on detritus the predator-to-prey ratio was assumed to be $18: 1$, the optimal copepod predator-to-prey size ratio (Hansen et al., 1994), which gives a $Q$ value of 0.48 . However, as detritus is non-living it likely contains less DOM that can be released when sloppy feeding occurs, so we assume that DOM production from large zooplankton feeding on detritus is less and set the $Q$ value to equal $0.24\left(\omega_{D}\right)$. We could not find any data that reported how much detritus is produced as a result of sloppy feeding, so we assumed that the amount of detritus produced is $25 \%$ of the $Q$ value calculated above.

\section{A.2.5. Bacteria}

The equation for bacteria is:

$\frac{\partial B}{\partial t}=B_{\text {growth }}+h B^{o}-G_{Z_{L} B}-G_{Z_{S} B}-S_{B} B-\Psi_{B} V_{B} B-h B$

In this equation the first two terms represent bacterial growth and inflowing biomass. The remaining terms represent losses due to large zooplankton grazing, small zooplankton grazing, mortality, viral lysis, and ecosystem outflow.
Bacterial growth, excretion, and respiration $\left(B_{\text {growth }}, b_{\chi}\right.$, and $\left.R_{B}\right)$ are calculated from elemental stoichiometry. This formulation follows that of Anderson and Williams (1998) and assumes that labile DOC and DON are the primary growth substrates, with ammonium supplementing DOM when the $\mathrm{C} / \mathrm{N}$ of DOM is high. Uptake rates of labile DOC and DON, $U_{\mathrm{C}}$ and $U_{\mathrm{N}}$, and the potential (uptake only occurs if required) uptake of ammonium, $U_{A}^{*}$, are:

$U_{C}=\lambda_{B} B \mu_{B}\left(\frac{L_{C}}{K_{L_{C}}+L_{C}}\right)$,

$U_{N}=\frac{U_{C} L_{N}}{L_{C}}$,

and

$U_{A}^{*}=\frac{\mu_{B} B A}{K_{B A}+A}$.

If potential ammonium and labile DON uptake is sufficient to ensure complete utilization of DOC, then bacterial growth, excretion, and respiration $\left(B_{\text {growth }}, b_{\chi}\right.$, and $\left.R_{B}\right)$ are:

$B_{\text {growth }}=\frac{\operatorname{gge}_{B} U_{C}}{\lambda_{B}}$,

$R_{B}=U_{C}\left(1-g g e_{B}\right)$

and

$b_{\chi}=U_{C}\left(\frac{U_{N}}{U_{C}}-\frac{g g e_{B}}{\lambda_{B}}\right)$.

The realized uptake of ammonium, $U_{A}$, is then zero for $b_{\chi}>0$, and $-b_{\chi}$ for $b_{\chi}<0$. If labile DON and ammonium uptake cannot deliver enough nitrogen for bacteria to utilize all available labile DOC, excess consumed DOC is respired and the uptake of ammonium equals $U_{A}^{*}$. In this case the equations for $\mathrm{B}_{\text {growth }}, b_{\chi}$, and $R_{B}$ are:

$B_{\text {growth }}=U_{N}+U_{A}$,

$R_{B}=\lambda_{B} B_{\text {growth }}\left(\frac{1}{g g e_{B}-1}\right)$,

and

$b_{\chi}=-U_{A}$.

\section{A.2.6. Detritus}

Changes in nitrogenous detritus (mmoles $\mathrm{N} \mathrm{m}^{-3}$ ) are modeled as:

$$
\begin{aligned}
\frac{d D_{N}}{d t}= & \left(1-\beta_{N_{Z}}\right)\left(I_{N_{Z_{L}}}+I_{N_{Z_{S}}}\right)+\rho_{D}\left(\omega_{P_{L}} G_{Z_{L} P_{L}}+\omega_{P_{D}} G_{Z_{L} D_{N}}+\omega_{Z_{L}} G_{Z_{L} Z_{L}}+m B\right) \\
& +\beta_{1}\left(m P_{L}+m P_{S}+m Z_{L}^{2}+m Z_{S}^{2}\right)+\varepsilon_{D}\left(\Psi_{P_{L}} V_{P} P_{L}+\Psi_{P_{S}} V_{P} P_{S}+\Psi_{B} V_{B} B\right) \\
& \chi_{D_{N}} D_{N}-G_{Z_{L} D_{N}}-G_{Z_{S} D_{N}}-h D_{N}+h D_{N}^{o}
\end{aligned}
$$

Changes in carbon detritus (mmoles $\mathrm{Cm}^{-3}$ ) are modeled as:

$$
\begin{aligned}
\frac{d D_{C}}{d t}= & \left(1-\beta_{C_{Z}}\right)\left(I_{C_{Z_{L}}}+I_{C_{Z_{S}}}\right)+\rho_{D}\left(\omega_{P_{L}} \lambda_{P} G_{Z_{L} P_{L}}+\omega_{D} \lambda_{D} G_{Z_{L} D_{C}}+\omega_{Z_{L}} \lambda_{Z} G_{Z_{L} Z_{L}}+m \lambda_{B} B\right) \\
& +\beta_{1}\left(m \lambda_{P} P_{L}+m \lambda_{P} P_{S}+m \lambda_{Z} Z_{L}^{2}+m \lambda_{Z} Z_{S}^{2}\right)+\beta_{5} \varepsilon_{V}\left(\Psi_{P_{L}} V_{P}\left(\lambda_{P}-\lambda_{V P}\right) P_{L}\right. \\
& \left.+\Psi_{P_{S}} V_{P}\left(\lambda_{P}-\lambda_{V P}\right) P_{S}+\Psi_{B} V_{B}\left(\lambda_{B}-\lambda_{V B}\right) B\right)+\varepsilon_{D}\left(\Psi_{P_{L}} V_{P} \lambda_{P} P_{L}+\Psi_{P_{S}} V_{P} \lambda_{P} P_{S}\right. \\
& \left.+\Psi_{B} V_{B} \lambda_{B} B\right)-\chi_{D_{C}} D_{C}-G_{Z_{L} D_{C}}-G_{Z_{S} D_{C}}-h D_{C}+h D_{C}^{o}
\end{aligned}
$$

In these equations the positive terms represent the production of detritus from zooplankton fecal pellet production or egestion, sloppy feeding, plankton mortality (see Section 2.3.5 and Eq. (A.8)), viral lysis (two terms for $D_{C}$ ) and detritus inflow (last term). The negative terms represent the loss of detritus due to photooxidation, large zooplankton grazing, small zooplankton grazing, and ecosystem outflow. 
A.2.7. Dissolved inorganic carbon

The equation for DIC is:

$$
\begin{aligned}
\frac{d D I C}{d t}= & -J_{P_{L}} Q_{P_{L}} P_{L} \lambda_{P}-J_{P_{S}} Q_{P_{S}} P_{S} \lambda_{P}-E_{P_{L}}-E_{P_{S}}+\sigma_{Z}\left(R_{Z_{L}}+R_{Z_{S}}\right) \\
& +R_{B}+\chi_{U V_{C}}\left(L_{C}+S_{C}+R_{C}\right)
\end{aligned}
$$

In this equation the four loss terms represent phytoplankton uptake of DIC for during growth. The positive terms represent the production of DIC from zooplankton respiration, bacterial respiration, and the photooxidation of DOC.

\section{A.2.8. Nutrients}

The equation for nitrate is:

$$
\frac{d N_{n}}{d t}=-J_{P_{L}} Q_{P_{L}}^{3} P_{L}-J_{P_{S}} Q_{P_{S}}^{3} P_{S}+\varpi_{1} A+h N_{n}^{o}-h N_{n} .
$$

In this equation the first two terms represent the uptake of nitrate by phytoplankton. The remaining terms represent the nitrification of ammonium to nitrate and the inflow and outflow of nitrate from the ecosystem. Light inhibited nitrification was formulated following Martin and Pondaven (2006):

$\varpi_{1}=0.16\left(\frac{1-I}{I_{\text {surface }}}\right)$

where 0.16 is the maximum nitrification rate $\left(\mathrm{d}^{-1}\right)$ which is based on rates reported by Horrigan et al. (1990) for the Chesapeake Bay.

The equation for ammonium is:

$$
\begin{aligned}
\frac{d A}{d t}= & \kappa_{Z}\left(E_{Z_{L}}+E_{Z_{S}}\right)+b_{\chi}+\chi_{U V_{N}}\left(S_{N}+R_{N}\right)+h A^{o} \\
& -J_{P_{L}} Q_{P_{L}}^{1} P_{L}-J_{P_{S}} Q_{P_{S}}^{1} P_{S}-U_{A}-\varpi_{1} A-h A
\end{aligned}
$$

In this equation the positive terms represent the production or addition of ammonium from zooplankton excretion, bacterial excretion, the photooxidation of DON, and ecosystem inflow. The negative terms represent a loss of ammonium due to phytoplankton and bacterial uptake, nitrification, and ecosystem outflow.

\section{A.2.9. Dissolved organic matter}

Equations for labile $\left(L_{C}\right.$ and $\left.L_{N}\right)$, semi-labile $\left(S_{C}\right.$ and $\left.S_{N}\right)$, and refractory $\left(R_{C}\right.$ and $\left.R_{N}\right)$ DOM are:

$$
\begin{aligned}
\frac{d L_{N}}{d t}= & \left.o_{L}\left((1-\alpha) J_{P_{L}} Q_{P_{L}} P_{L}+J_{P_{S}} Q_{P_{S}} P_{S}\right)+\left(1-\beta_{1}\right)\left(m P_{L}+m P_{S}+m Z_{L}^{2}+m Z_{S}^{2}\right)\right) \\
& +o_{Z}\left(\left(1-\kappa_{Z}\right)\left(E_{Z_{L}}+E_{Z_{S}}\right)\right)+\rho_{L}\left(\omega_{P_{L}} G_{Z_{L} P_{L}}+\omega_{D} G_{Z_{L} D_{N}}+\omega_{Z_{L}} G_{Z_{L} Z_{L}}+m B\right) \\
& +\delta_{1} \chi_{D_{N}} D_{N}+\eta v\left(V_{P}^{2}+V_{B}^{2}\right)+\varepsilon_{L}\left(\Psi_{P_{L}} V_{P} P_{L}+\Psi_{P_{S}} V_{P} P_{S}+\Psi_{B} V_{B} B\right)+\tau \frac{\mu_{S} S_{N} \lambda_{B} B}{K_{S}+S_{C}} \\
& -U_{N}-J_{P_{L}} Q_{P_{L}}^{2} P_{L}-J_{P_{S}} Q_{P_{S}}^{2} P_{S}+\zeta R_{N}+h L_{N}^{o}-h L_{N}
\end{aligned}
$$

$$
\begin{aligned}
\frac{d L_{C}}{d t}= & o_{L}\left((1-\alpha) \lambda_{P}\left(J_{P_{L}} Q_{P_{L}} P_{L}+J_{P_{S}} Q_{P_{S}} P_{S}\right)+E_{P_{L}}+E_{P_{S}}+\left(1-\beta_{1}\right)\left(m \lambda_{P} P_{L}\right.\right. \\
& \left.\left.+m \lambda_{P} P_{S}+m \lambda_{Z} Z_{L}^{2}+m \lambda_{Z} Z_{S}^{2}\right)\right)+\rho_{L}\left(\omega_{P_{L}} \lambda_{P} G_{Z_{L} P_{L}}+\omega_{D} G_{Z_{L} D_{C}}\right. \\
& \left.+\omega_{Z_{L}} \lambda_{Z} G_{Z_{L} Z_{L}}+m \lambda_{B} B\right)+\delta_{1} \chi_{D_{C}} D_{C}+\eta v \lambda_{V}\left(V_{P}^{2}+V_{B}^{2}\right)+\varepsilon_{L}\left(\Psi_{P_{L}} V_{P} \lambda_{P} P_{L}\right. \\
& \left.+\Psi_{P_{S}} V_{P} \lambda_{P} P_{S}+\Psi_{B} V_{B} \lambda_{B} B\right)+\beta_{2} \varepsilon_{V}\left(\Psi_{P_{L}} V_{P}\left(\lambda_{P}-\lambda_{V}\right) P_{L}+\Psi_{P_{S}} V_{P}\left(\lambda_{P}-\lambda_{V}\right) P_{S}\right. \\
& \left.+\Psi_{B} V_{B}\left(\lambda_{B}-\lambda_{V}\right) B\right)+\tau \frac{\mu_{S} S_{C} \lambda_{B} B}{K_{S}+S_{C}}-\lambda_{B} B_{\text {growth }}-R_{B}+o_{Z}\left(1-\sigma_{Z}\right)\left(R_{Z_{L}}+R_{Z_{S}}\right) \\
& -\chi_{U V_{C}} L_{C}+\zeta R_{C}+h L_{N}^{o}-h L_{N}
\end{aligned}
$$

$$
\begin{aligned}
\frac{d S_{N}}{d t} & =o_{S}\left((1-\alpha)\left(J_{P_{L}} Q_{P_{L}} P_{L}+J_{P_{S}} Q_{P_{S}} P_{S}\right)+\left(1-\beta_{1}\right)\left(m P_{L}+m P_{S}+m Z_{L}^{2}+m Z_{S}^{2}\right)\right) \\
& +\left(1-o_{Z}\right)\left(1-\kappa_{Z}\right)\left(E_{Z_{L}}+E_{Z_{S}}\right)+\rho_{S}\left(\omega_{P_{L}} G_{Z_{L} P_{L}}+\omega_{D} G_{Z_{L} D_{N}}+\omega_{Z_{L}} G_{Z_{L} Z_{L}}+m B\right) \\
& +\delta_{2} \chi_{D_{N}} D_{N}+\varepsilon_{S}\left(\Psi_{P_{L}} V_{P} P_{L}+\Psi_{P_{S}} V_{P} P_{S}+\Psi_{B} V_{B} B\right)+(1-\eta) v\left(V_{P}^{2}+V_{B}^{2}\right)-\chi_{U V_{N}} S_{N} \\
& -\frac{\mu_{S} S_{N} \lambda_{B} B}{K_{S}+S_{C}}+h S_{N}^{o}-h S_{N}
\end{aligned}
$$

$$
\begin{aligned}
& \frac{d S_{C}}{d t}=o_{S}\left((1-\alpha) \lambda_{p}\left(J_{P_{L}} Q_{P_{L}} P_{L}+J_{P_{S}} Q_{P_{S}} P_{S}\right)+E_{P_{L}}+E_{P_{L}}+\left(1-\beta_{1}\right)\left(m \lambda_{P} P_{L}\right.\right. \\
& \left.\left.+m \lambda_{P} P_{S}+m \lambda_{Z} Z_{L}^{2}+m \lambda_{Z} Z_{S}^{2}\right)\right)+\left(1-o_{Z}\right)\left(1-\sigma_{Z}\right)\left(R_{Z_{L}}+R_{Z_{S}}\right) \\
& +(1-\eta) v \lambda_{V}\left(V_{P}^{2}+V_{B}^{2}\right)+\rho_{S}\left(\omega_{P_{L}} \lambda_{P} G_{Z_{L} P_{L}}+\omega_{D} G_{Z_{L} D_{C}}+\omega_{Z_{L}} \lambda_{Z} G_{Z_{L} Z_{L}}\right. \\
& \left.+m \lambda_{B} B\right)+\varepsilon_{S}\left(\Psi_{P_{L}} V_{P} \lambda_{P} P_{L}+\Psi_{P_{S}} V_{P} \lambda_{P} P_{S}+\Psi_{B} V_{B} \lambda_{B} B\right) \\
& \left.+\beta_{3} \varepsilon_{V}\left(\Psi_{P_{L}} V_{P}\left(\lambda_{P}-\lambda_{V}\right) P_{L}+\Psi_{P_{S}} V_{P}\left(\lambda_{P}-\lambda_{V}\right) P_{S}\right)+\Psi_{B} V_{B}\left(\lambda_{B}-\lambda_{V}\right) B\right) \\
& +\delta_{2} \chi_{D_{C}} D_{C}-\frac{\mu_{S} S_{C} \lambda_{B} B}{K_{S}+S_{C}}-\chi_{U V_{C}} S_{C}+h S_{N}^{o}-h S_{N} \\
& \frac{d R_{N}}{d t}=o_{R}\left((1-\alpha)\left(J_{P_{L}} Q_{P_{L}} P_{L}+J_{P_{S}} Q_{P_{S}} P_{S}\right)+\left(1-\beta_{1}\right)\left(m_{P_{L}}+m P_{S}+m Z_{L}^{2}+m Z_{s}^{2}\right)\right) \\
& +\rho_{R}\left(\omega_{P_{L}} G_{Z_{L} P_{L}}+\omega_{D} G_{Z_{L} D_{N}}+\omega_{Z_{L}} G_{Z_{L} Z_{L}}+m B\right)+\delta_{3} \chi_{D_{N}} D_{N}-\zeta R_{N} \\
& +\varepsilon_{R}\left(\Psi_{P_{L}} V_{P} P_{L}+\Psi_{P_{S}} V_{P} P_{S}+\Psi_{B} V_{B} B\right)+(1-\tau)\left(\frac{\mu_{S} S_{N} \lambda_{B} B}{K_{S}+S_{C}}\right)-\chi_{U V_{N}} R_{N} \\
& h R_{N}^{o}-h R_{N} \\
& \frac{d R_{C}}{d t}=o_{R}\left((1-\alpha) \lambda_{p}\left(J_{P_{L}} Q_{P_{L}} P_{L}+J_{P_{S}} Q_{P_{S}} P_{S}\right)+E_{P_{L}}+E_{P_{S}}+\left(1-\beta_{1}\right)\left(m \lambda_{P} P_{L}+m \lambda_{P} P_{S}\right.\right. \\
& \left.\left.+m \lambda_{Z} Z_{L}^{2}+m \lambda_{Z} Z_{S}^{2}\right)\right)+\rho_{R}\left(\omega_{P_{L}} \lambda_{P} G_{Z_{L} P_{L}}+\omega_{D} G_{Z_{L} D_{C}}+\omega_{Z_{L}} \lambda_{Z} G_{Z_{L} Z_{L}}+m \lambda_{B} B\right) \\
& +\beta_{4} \varepsilon_{V}\left(\Psi_{P_{L}} V_{P}\left(\lambda_{P}-\lambda_{V P}\right) P_{L}+\Psi_{P_{S}} V_{P}\left(\lambda_{P}-\lambda_{V P}\right) P_{S}+\Psi_{B} V_{B}\left(\lambda_{B}-\lambda_{V B}\right) B\right) \\
& +\delta_{3} \chi_{D_{C}} D_{C}+\varepsilon_{R}\left(\Psi_{P_{L}} V_{P} \lambda_{P} P_{L}+\Psi_{P_{S}} V_{P} \lambda_{P} P_{S}+\Psi_{B} V_{B} \lambda_{B} B\right)-\zeta R_{C} \\
& +(1-\tau)\left(\frac{\mu_{S} S_{C} \lambda_{B} B}{K_{S}+S_{C}}\right)-\chi_{U V_{C}} R_{C}+h R_{C}^{o}-h R_{C}
\end{aligned}
$$

Dissolved organic matter is produced by phytoplankton excretion and leakage, zooplankton sloppy feeding, zooplankton excretion, viral lysis of phytoplankton and bacteria, viral decay, plankton mortality, and detritus decay. The partitioning of freshly produced DOM is described in Section 2.4. Labile DOM can be consumed directly by bacteria and phytoplankton. Semi-labile DOM requires ectoenzyme hydrolysis by bacteria to become available (labile) for consumption. Bacterial hydrolysis of semi-labile DOM transforms it into either labile or refractory DOM upon hydrolysis. Photochemical processes are responsible for the conversion of some refractory DOM into labile DOM. Photochemical processes also convert some DOC into DIC and DON into ammonium. DOM also flows into and out of the ecosystem (last two terms).

\section{A.2.10. Viruses}

The equation for bacterial viruses is:

$\frac{\partial V_{B}}{\partial t}=\varepsilon_{V} \Psi_{B} V_{B} B-v V_{B}^{2}+h V_{B}^{o}-h V_{B}$.

The equation for phytoplankton viruses is:

$\frac{\partial V_{B}}{\partial t}=\varepsilon_{V}\left(\Psi_{P_{L}} P_{L}+\Psi_{P_{S}} V_{P} P_{S}\right)-v V_{P}^{2}+h V_{P}^{o}-h V_{P}$.

In these equations the first term represents the production of viruses during viral lysis. The next term represents the decay of viruses, and the final terms represent the inflow and outflow of viruses from the ecosystem.

The viral infection rates for bacteria and phytoplankton are calculated by dividing a fixed daily infection rate by the host-specific virus biomass:

$\Psi_{B}=\frac{0.40}{V_{B}}$

$\Psi_{P_{S}}=\frac{0.07}{0.44 V_{P}}$

$\Psi_{P_{L}}=\frac{0.03}{0.56 V_{P}}$

Since there is only one state variable for phytoplankton viruses it was estimated that $44 \%$ of them were small phytoplankton viruses and $56 \%$ of them were large phytoplankton viruses. 


\section{A.2.11. Mortality}

The formulation used to determine $m$ was:

$m=S_{i}-\left(S_{i}-0.02\right.$ or 0.01$)$

where $S_{i}$ is the mortality rate $\left(\mathrm{d}^{-1}\right)$ for state variable $i$. If $S_{i}$ was less than 0.02 or $0.01\left(\mathrm{~d}^{-1}\right)$ no export occurred. In addition, zooplankton mortality was calculated using a power function to provide additional closure and stabilize the model (Steele and Henderson, 1992).

\section{Appendix B. Supplementary data}

Supplementary data associated with this article can be found, in the online version, at doi:10.1016/j.ecolmodel.2010.12.014.

\section{References}

Adolf, J.E., Yeager, C.L.J., Miller, W.D., Mallonee, M.E., Harding, L.W., 2006. Environmental forcing of phytoplankton floral composition, biomass, and primary productivity in Chesapeake Bay, USA. Estuarine, Coastal and Shelf Science 67, $108-122$.

Aluwihare, L.I., Repeta, D.J., 1999. A comparison of the chemical characteristics of oceanic DOM and extracellular DOM produced by marine algae. Marine Ecology Progress Series 186, 105-117.

Anderson, T.R., 2005. Plankton functional type modelling: running before we can walk? Journal of Plankton Research 27, 1073-1081.

Anderson, T.R., Hessen, D.O., 1995. Carbon or nitrogen limitation of marine copepods? Journal of Plankton Research 17, 317-331.

Anderson, T.R., Pondaven, P., 2003. Non-redfield carbon and nitrogen cycling in the Sargasso Sea: pelagic imbalances and export flux. Deep-Sea Research I 50, 573-591.

Anderson, T.R., Ryabchenko, V.A., Fasham, M.J.R., Gorchakov, V.A., 2007. Denitrification in the Arabian Sea: a 3D ecosystem modelling study. Deep-Sea Research 1 54, 2082-2119.

Anderson, T.R., Williams, P.J.l.B., 1998. modelling the seasonal cycle of dissolved organic carbon at station e1 in the english channel. Estuarine, Coastal and Shelf Science 46, 93-109.

Anderson, T.R., Williams, P.J.I.B., 1999. A one-dimensional model of dissolved organic carbon cycling in the water column incorporating combined biological-photochemical decomposition. Global Biogeochemical Cycles 13 , 337-349.

Apple, J.K., del Giorgio, P.A., Kemp, M., 2006. Temperature regulation of bacterial production, respiration, and growth efficiency in a temperate salt-marsh estuary. Aquatic Microbial Ecology 43, 243-254.

Arhonditsis, G.B., Adams-Vanharan, B.A., Nielsen, L., Stow, C.A., Reckhow, K.H., 2006 Evaluation of the current state of mechanistic aquatic biogeochemical modeling: citation analysis and future perspectives. Environmental Science \& Technology 40, 6547-6554.

Aumont, O., Maier-Reimer, E., Blain, S., Monfray, P., 2003. An ecosystem model of the global ocean including Fe, Si, P colimitations. Global Biogeochemical Cycles $17,1060$.

Baird, D., Ulanowicz, R., 1989. The seasonal dynamics of the Chesapeake Bay ecosystem. Ecological Monographs 59, 329-364.

Baklouti, M., Diaz, F., Pinazo, C., Faure, V., Quéguiner, 2006a. Investigation of mechanistic formulations depicting phytoplankton dynamics for models of marine pelagic ecosystems and description of a new model. Progress in Oceanography 71, 1-33.

Baklouti, M., Faure, V., Pawlowski, L., Sciandra, A., 2006b. Investigation and sensitivity analysis of a mechanistic phytoplankton model implemented in a new modular numerical tool (Eco3M) dedicated to biogeochemical modelling. Progress in Oceanography 71, 34-58.

Beardsley, R.C., Boicourt, W.C., 1981. On estuarine and continental shelf circulation in the Middle Atlantic Bight. In: Warren, B.A., Wunsch, C. (Eds.), Evolution of Physical Oceanography. The MIT Press, Cambridge, MA, pp. 198-233.

Beckmann, A., Hense, I., 2004. Torn between extremes: the ups and downs of phytoplankton. Ocean Dynamics 54, 581-592.

Benner, R., 2002. Chemical composition and reactivity. In: Hansell, D.A., Carlson, C.A (Eds.), Biogeochemistry of Marine Dissolved Organic Matter. Elsevier Science, USA, pp. 59-90.

Berman, T., Bronk, D.A., 2003. Dissolved organic nitrogen: a dynamic participant in aquatic ecosystems. Aquatic Microbial Ecology 31, 279-305.

Bissinger, J.E., Montagnes, D.J.S., Sharples, J., Atkinson, D., 2008. Predicting marine phytoplankton maximum growth rates from temperature: improving on the Eppley curve using quantile regression. Limnology and Oceanography 53 487-493.

Boenigk, J., Arndt, H., 2002. Bacterivory by heterotrophic flagellates: community structure and feeding strategies. Antonie van Leeuwenhoek 81, 465-480.

Boicourt, W.C., 1992. Influence of circulation processes on dissolved oxygen in the Chesapeake Bay. In: Smith, D., Leffler, M., Mackiernan, G. (Eds.), Oxygen Dynamics in Chesapeake Bay: A Synthesis of Research. University of Maryland Sea Grant, pp. 7-53.
Børsheim, K.Y., Bratbak, G., 1987. Cell volume to cell carbon conversion factors for bacterivorous Monas sp. enriched from seawater. Marine Ecology Progress Series $36,171-175$.

Bronk, D.A., 2002. Dynamics of DON. In: Hansell, D.A., Carlson, C.A. (Eds.), Biogeochemistry of Marine Dissolved Organic Matter. Elsevier Science, USA, pp. $153-247$.

Bronk, D.A., Glibert, P.M., Malone, T.C., Banahan, S., Sahlsten, E., 1998. Inorganic and organic nitrogen cycling in Chesapeake Bay: autotrophic versus heterotrophic processes and relationships to carbon flux. Aquatic Microbial Ecology 15, 177-189.

Bronk, D.A., Glibert, P.M., Ward, B.B., 1994. Nitrogen uptake, dissolved organic nitrogen release, and new production. Science 265, 1843-1846.

Brophy, J.E., Carlson, D.J., 1989. Production of biologically refractory dissolved organic carbon by natural seawater microbial populations. Deep-Sea Research A 36, 497-507.

Brownlee, D., Jacobs, F., 1987. Mesozooplankton and microzooplankton in the Chesapeake Bay. In: Majumdar, S., Hall, L., Austin, H. (Eds.), Contaminant Problems and Management of Living Chesapeake Bay Resources. Pennsylvania Academy of Science, Philadelphia, PA, pp. 217-269.

Brush, M.J., Brawley, J.W., Nixon, S.W., Kremer, J.N., 2002. Modeling phytoplankton production: problems with the Epply curve and an emperical alternative. Marine Ecology Progress Series 238, 31-45.

Burdige, D.J., Zheng, S., 1998. The biogeochemical cycling of dissolved organic nitrogen in estuarine sediments. Limnology and Oceanography 43, 1796-1813.

Calbet, A., Landry, M.R., 2004. Phytoplankton growth, microzooplankton grazing, and carbon cycling in marine systems. Limnology and Oceanography 49 , 51-57.

Carlson, C.A., 2002. Production and removal processes. In: Hansell, D.A., Carlson, C.A (Eds.), Biogeochemistry of Marine Dissolved Organic Matter. Elsevier Science, USA, pp. 91-151.

Caron, D.A., Goldman, J.C., Fenchel, T., 1990. Protozoan respiration and metabolism. In: Capriulo, G.M. (Ed.), Ecology of marine protozoa. Oxford University Press, pp. 307-322.

Cauwet, G., 2002. DOM in the coastal zone. In: Hansell, D.A., Carlson, C.A. (Eds.), Biogeochemistry of Marine Dissolved Organic Matter. Elsevier Science, USA, pp. 579-609.

CBP, online database. www.chesapeakebay.net/data/index.htm.

Cerco, C.F., Noel, M.R., 2004. Process-based primary production modeling in Chesapeake Bay. Marine Ecology Progress Series 282, 45-58.

Chen, W., Wangersky, P.J., 1996. Rates of microbial degradation of dissolved organic carbon from phytoplankton cultures. Journal of Plankton Research 18 1521-1533.

Christian, J.R., Anderson, T.R., 2002. Modeling DOM biogeochemistry. In: Hansell, D.A., Carlson, C.A. (Eds.), Biogeochemistry of Marine Dissolved Organic Matter. Elsevier Science, USA, pp. 717-755.

Christian, J.R., Verschell, M.A., Murtugudde, R., Busalacchi, A.J., McClain, C.R., 2002. Biogeochemical modelling of the tropical Pacific Ocean. I. Seasonal and interannual variability. Deep-Sea Research II 49, 509-543.

Cloern, J.E., Grenz, C., Lucas, L.V., 1995. An empirical model of the phytoplankton chlorophyll: carbon ratio - the conversion factor between productivity and growth rate. Limnology and Oceanography 40, 1313-1321.

Collos, Y., Vaquer, A., Souchu, P., 2005. Acclimation of nitrate uptake by phytoplankton to high substrate levels. Journal of Phycology 41, 466-478.

Connolly, J.P., Coffin, R.B., Landeck, R.E., 1992. Modeling carbon utilization by bacteria in natural water systems. In: Hurst, C.J. (Ed.), Modeling the Metabolic and Physiologic Activities of Micro-organisms. John Wiley, New York, pp. 249-276.

Crump, B.C., Hopkinson, C.S., Sogin, M.L., Hobbie, J.E., 2004. Microbial biogeography along an estuarine salinity gradient: the combined influences of bacterial growth and residence time. Applied Environmental Microbiology 70, 1494-1505.

del Giorgio, P.A., Cole, J.J., 1998. Bacterial growth efficiency in natural aquatic systems. Annual Review of Ecology and Systematics 29, 503-541.

Dolan, J.R., Coats, D.W., 1990. Seasonal abundances of planktonic ciliates and microflagellages in Mesohaline Chesapeake Bay Waters. Estuarine, Coastal and Shelf Science 31, 157-175.

Druon, J.N., Mannino, A., Signorini, S., McClain, C., Friedrichs, M.A.M., Wilkin, J., Fennel, K., 2010. Modeling the dynamics and export of dissolved organic matter in the Northeastern U.S. continental shelf. Estuarine, Coastal and Shelf Science 88 488-507.

Eppley, R.W., 1972. Temperature and phytoplankton growth in the sea. Fisheries Bulletin 70, 1063-1085.

Eppley, R.W., Rogers, J.N., McCarthy, J.J., 1969. Half-saturation constants for uptake of nitrate and ammonium by marine phytoplankton. Limnology and Oceanography 14, 912-920.

Fan, C., Glibert, P.M., Alexander, J., Lomas, M.W., 2003. Characterization of urease activity in three marine phytoplankton species, Aureococcus anophagefferens, Protocentrum minimum, and Thalassiosira weissflogii. Marine Biology 142 , 949-958.

Fasham, M.J.R., Ducklow, H.W., McKelvie, S.M., 1990. A nitrogen-based model of plankton dynamics in the oceanic mixed layer. Journal of Marine Research 48 591-639.

Faure, V., Pinazo, C., Torréton, J.-P., Douillet, P., 2006. Relevence of various formulations of phytoplankton chlrophyll $a$ : carbon ratio in a 3D marine ecosystem model. Comptes Rendus Biologies 329, 813-822.

Fischer, U.R., Weisz, W., Wieltschnig, C., Kirschner, A.K.T., Velimirov, B., 2004. Benthic and pelagic viral decay experiments: a model-based analysis and its applicability. Applied \& Environmental Microbiology 70, 6706-6713. 
Fisher, T.R., Gustafson, A.B., Radcliffe, G.M., Sundberg, K.L., Stevenson, J.C., 2003. A long-term record of photosynthetically available radiation (PAR) and total solar energy at $38.6^{\circ} \mathrm{N}, 78.2^{\circ} \mathrm{W}$. Estuaries $26,1450-1460$.

Fisher, T.R., Hagy, J.D., Rochelle-Newall, E.J., 1998. Dissolved and particulate organic carbon in Chesapeake Bay. Estuaries 21, 215-229.

Flynn, K.J., Clark, D.R., Xue, Y., 2008. Modeling the release of dissolved organic matter by phytoplankton. Journal of Phycology 44, 1171-1187.

Freidrichs, M.A.M., Dusenberry, J.A., Anderson, L.A., Armstrong, R.A., Chai, F., Christian, J.R., Doney, S.C., Dunne, J., Fujii, M., Hood, R.R., McGillicuddy Jr., D.J., Moore, J.K., Schartau, M., Spitz, Y.H., Wiggert, J.D., 2007. Assessment of skill and portability in regional marine biogeochemical models: role of multiple planktonic groups. Journal of Geophysical Research-Oceans 112, C08001.

Fuhrman, J.A., 1999. Marine viruses and their biogeochemical and ecological effects. Nature 399, 541-548

Fukuda, R., Ogawa, H., Nagata, T., Koike, I., 1998. Direct determination of carbon and nitrogen contents of natural bacterial assemblages in marine environments. Applied \& Environmental Microbiology 64, 3352-3358.

Gobler, C.J., Sañudo-Wilhelmy, S.A., 2003. Cycling of colloidal organic carbon and nitrogen during an estuarine phytoplankton bloom. Limnology and Oceanography $48,2314-2320$.

Grégoire, M., Soetaert, K., 2010. Carbon, nitrogen, oxygen and sulfide budgets in the Black Sea: a biogeochemical model of the whole water column coupling the oxic and anoxic parts. Ecological Modelling 221, 2287-2301.

Hansen, B., Bjornsen, P.K., Hansen, P.J., 1994. The Size Ratio Between Planktonic Predators and Their Prey. Limnology and Oceanography 39, 395-403.

Harrison, W.G., Harris, L.R., Irwin, B.D., 1996. The kinetics of nitrogen utilization in the oceanic mixed layer: nitrate and ammonium interactions at nanomolar concentrations. Limnology and Oceanography 41, 16-32.

Hartman, K.J., Howell, J., Sweka, J.A., 2004. Diet and daily ration of bay anchovy in the Hudson River, New York. Transactions of the American Fisheries Society 133, 762-771.

Hood, R.R., Bates, N.R., Capone, D.G., Olson, D.B., 2001. Modeling the effect of nitrogen fixation on carbon and nitrogen fluxes at BATS. Deep-Sea Research II 48 1609-1648.

Hood, R.R., Laws, E.A., Armstrong, R.A., Bates, N.R., Brown, C.W., Carlson, C.A., Chai, F., Doney, S.C., Falkowski, P.G., Feely, R.A., Freidrichs, M.A.M., Landry, M.R., Moore, J.K., Nelson, D.M., Richardson, T.L., Salihoglu, B., Schartau, M., Toole, D.A., Wiggert, J.D., 2006. Pelagic functional group modeling: progress, challenges and prospects. Deep-Sea Research Part II-Topical Studies in Oceanography 53, 459-512.

Horrigan, S.G., Montoya, J.P., Nevins, J.L., McCarthy, J.J., Ducklow, H., Goericke, R., Malone, T.C., 1990. Nitrogenous nutrient transformations in the spring and fall in the Chesapeake Bay. Estuarine, Coastal and Shelf Science 30, 369-391.

Huntley, M.E., Lopez, M.D.G., 1992. Temperature-dependent production of marine copepods - a global synthesis. American Nature 140, 210-242

Johnson, M.D., Rome, M., Stoecker, D.K., 2003. Microzooplankton grazing on Prorocentrum minimum and Karlodinium micrum in Chesapeake Bay. Limnology and Oceanography $48,238-248$

Jonas, R.B., Tuttle, J.H., 1990. Bacterioplankton and organic carbon dynamics in the lower Mesohaline Chesapeake Bay. Applied \& Environmental Microbiology 56, 747-757.

Keller, D.P., personal observation in 2007 and 2008.

Keller, D.P., Hood, R.R., 2011. A steady-state comparative simulation of dissolved organic matter cycling in idealized oceanic, coastal, and estuarine surface waters: the role of the planktonic community structure. Journal of Marine Systems, in preparation.

Kimmel, D.G., Roman, M.R., 2004. Long-term trends in mesozooplankton abundance in Chesapeake Bay USA: influence of freshwater input. Marine Ecology Progress Series 267, 71-83.

Kiørboe, T., Møhlenberg, F., Hamburger, K., 1985. Bioenergetics of the planktonic copepod Acartia tonsa: relation between feeding, egg production and respiration, and composition of specific dynamic action. Marine Ecology Progress Series 26, 85-97.

Kleppel, G.S., 1993. On the diets of calanoid copepods. Marine Ecology Progress Series 99, 183-195.

Koopmans, D.J., Bronk, D.A., 2002. Photochemical production of dissolved inorganic nitrogen and primary amines from dissolved organic nitrogen in waters of two estuaries and adjacent surficial groundwaters. Aquatic Microbial Ecology 26 295-304.

Kragh, T., Søndergaard, M., 2009. Production and decomposition of new DOC by marine plankton communities: carbohydrates, refractory components and nutrient limitation. Biogeochemistry 96, 177-187.

Lewis, V.P., Peters, D.S., 1994. Diet of juvenile and adult atlantic menhaden in estuarine and coastal habitats. Transactions of the American Fisheries Society 123, 803-810.

Llebot, C., Spitz, Y.H., Solé, J., Estrada, M., 2010. The role of inorganic nutrients and dissolved organic phosphorus in the phytoplankton dynamics of a Mediterranean bay. Journal of Marine Systems 83, 192-209.

Loh, A.N., Bauer, J.E., Canuel, E.A., 2006. Dissolved and particulate organic matter source-age characterization in the upper and lower Chesapeake Bay: a combined isotope and biochemical approach. Limnology and Oceanography 51, 1421-1431.

Lomas, M.W., Trice, T.M., Glibert, P.M., Bronk, D.A., McCarthy, J.J., 2002. Temporal and spatial dynamics of urea uptake and regeneration rates and concentrations in Chesapeake Bay. Estuaries 25, 469-482.
Luo, Y.-W., Friedrichs, M.A.M., Doney, S.C. Church, M., Ducklow, H., 2010. Oceanic heterotrophic bacterial nutrition by semilabile DOM as revealed by data assimilative modeling. Aquatic Microbial Ecology 60, 273-287.

Malone, T.C., 1980. Size-fractionated primary productivity of marine phytoplankton. In: Falkowski, P.G. (Ed.), Primary Productivity in the Sea. Plenum Press, New York, pp. 301-319.

Malone, T.C., Conley, D.J., Fisher, T.R., Glibert, P.M., Harding, L.W., 1996. Scales of nutrient-limited phytoplankton productivity in Chesapeake Bay. Estuaries 19, 371-385.

Malone, T.C., Crocker, L.H., Pike, S.E., Wendler, B.W., 1988. Influences of river flow in the dynamics of phytoplankton production in a partially stratified estuary. Marine Ecology Progress Series 48, 235-249.

Malone, T.C., Ducklow, H.W., Peele, E.R., Pike, S.E., 1991. Picoplankton carbon flux in Chesapeake Bay. Marine Ecology Progress Series 78, 11-22.

Mannino, A., Harvey, H.R., 2000. Biochemical composition of particles and dissolved organic matter along an estuarine gradient: sources and implications for DOM reactivity. Limnology and Oceanography 45, 775-788.

Martin, A.P., Pondaven, P., 2006. New primary production and nitrification in the western subtropical North Atlantic: a modeling study. Global Biogeochemical Cycles 20, GB4014.

Mazzone, H.M., 1998. CRC Handbook of Viruses: Mass-molecular Weight Values and Related Properties. CRC Press.

McCreary Jr., J.P., Kohler, K.E., Hood, R.R., Olson, D.B., 1996. A four-component ecosystem model of biological activity in the Arabian Sea. Progress in Oceanography $37,193-240$

Meon, B., Kirchman, D.L., 2001. Dynamics and molecular composition of dissolved organic material during experimental phytoplankton blooms. Marine Chemistry 75, 185-199.

Miller, W.L., Zepp, R.G., 1995. Photochemical production of dissolved inorganic carbon from terrestrial organic matter: significance to the oceanic carbon cycle. Geophysical Research Letters 22, 417-420.

Møller, E.F., 2005. Sloppy feeding in marine copepods: prey-size-dependent production of dissolved organic carbon. Journal of Plankton Research 27, $27-35$.

Møller, E.F., 2007. Production of dissolved organic carbon by sloppy feeding in the copepods Acartia tonsa, Centropages typicus, and Temora longicornis. Limnology and Oceanography $52,79-84$

Møller, E.F., Nielsen, T.G., 2001. Production of bacterial substrate by marine copepods: effect of phytoplankton biomass and cell size. Journal of Plankton Research $23,527-536$

Mopper, K., Kieber, D.J., 2002. Photochemistry and the cycling of carbon, sulfur, nitrogen and phosphorus. In: Hansell, D.A., Carlson, C.A. (Eds.), Biogeochemistry of Marine Dissolved Organic Matter. Elsevier Science, USA, pp. 455-508.

MOVE, Microbial Observatory for Virioplankton Ecology website, www.dbi.udel.edu/MOVE/MO_index.htm.

Mulholland, M.R., Gobler, C.J., Lee, C., 2002. Peptide hydrolysis, amino acid oxidation, and nitrogen uptake in communities seasonally dominated by Aureococcus anophagefferens. Limnology and Oceanography 47, 1094-1108.

Mulholland, M.R., Lee, C., Glibert, P.M., 2003. Extracellular enzyme activity and uptake of carbon and nitrogen along an estuarine salinity and nutrient gradient. Marine Ecology Progress Series 258, 3-17.

Müller, H., Geller, W., 1993. Maximum growth rates of aquatic ciliated protozoa: the dependence on body size and temperature reconsidered. Archives of Hydrobiology $126,315-327$.

Nagata, T., 2000. Production mechanisms of dissolved organic matter. In: Kirchman, D.L. (Ed.), Microbial Ecology of the Oceans. Wiley-Liss, Inc., pp. 121-152.

Nakata, K., Doi, T., 2006. Estimation of primary production in the ocean using a physical-biological coupled ocean carbon cycle model. Environmental Modelling \& Software 21, 204-228.

Ogawa, H., Amagai, Y., Koike, I., Kaiser, K., Benner, R., 2001. Production of refractory dissolved organic matter by bacteria. Science 292, 917-920.

Pahlow, M., Vézina, A.F., 2003. Adaptive model of DOM dynamics in the surface ocean. Journal of Marine Research 61, 127-146.

Pahlow, M., Vézina, A.F., Casault, B., Maas, H., Malloch, L., Wright, D.G., Lu, Y., 2008. Adaptive model of plankton dynamics for the North Atlantic. Progress in Oceanography 76, 151-191.

Platt, T., Gallegos, C.J., Harrison, W.G., 1980. Photoinhibiton of photosynthesis in natural assemblages of marine phytoplankton. Journal of Marine Research 38, 678-701.

Polimene, L., Allen, J.I., Zavatarelli, M., 2006. Model of interactions between dissolved organic carbon and bacteria in marine systems. Aquatic Microbial Ecology 43 , 127-138.

Polimene, L., Pinardi, N., Zavatarelli, M., Allen, J.I., Giani, M., Vichi, M., 2007. A numerical simulation study of dissolved organic carbon accumulation in the northern Adriatic Sea. Journal of Geophysical Research 112, C03S20.

Press, W.H., Teukolsky, S.A., Vetterling, W.T., Flannery, B.P., 1992. Numerical Recipes in FORTRAN: The Art of Scientific Computing, 2nd ed. Cambridge University Press, Cambridge, New York.

Purcell, J.E., 1992. Effects of predation by the scyphomedusan Chrysaora quinquecirrha on zooplankton populations in Chesapeake Bay, USA. Marine Ecology Progress Series 87, 65-76.

Raven, J.A., Kübler, J.E., 2002. New light on the scaling of metabolic rate within the size of algae. Journal of Phycology 38, 11-16.

Raymond, P.A., Bauer, J.E., 2001. DOC cycling in a temperate estuary: A mass balance approach using natural C-14 and C-13 isotopes. Limnology and Oceanography $46,655-667$. 
Rochelle-Newall, E.J., Fisher, T.R., 2002. Chromophoric dissolved organic matter and dissolved organic carbon in Chesapeake Bay. Marine Chemistry 77, 23-41.

Ross, O.N., Sharples, J., 2008. Swimming for survival: a role of phytoplankton motility in a stratified turbulent environment. Journal of Marine Systems 70, 248-262.

Ruardij, P., Veldhuis, M.J.W., Brussaard, C.P.D., 2005. Modeling the bloom dynamics of the polymorphic phytoplankter Phaeocystis globosa: impact of grazers and viruses. Harmful Algae 4, 941-963.

Salihoglu, B., Garçon, V., Oschlies, A., Lomas, D.A., 2008. Influence of nutrient utilization and remineralization stoichiometry on phytoplankton species and carbon export: a modeling study at BATS. Deep-Sea Research I 55, 73-107.

Santschi, P.H., Guo, L.D., Baskaran, M., Trumbore, S., Southon, J., Bianchi, T.S., Honeyman, B., Cifuentes, L., 1995. Isotopic evidence for the contemporary origin of high-molecular-weight organic-matter in oceanic environments. Geochmica et Cosmochimica Acta 59, 625-631.

Schmittner, A., Oschlies, A., Giraud, X., Eby, M., Simmons, H.L., 2005. A global mode of the marine ecosystem for long-term simulations: sensitivity to ocean mixing buoyancy forcing, particle sinking, and dissolved organic matter cycling. Globa Biogeochemical Cycles, 19

Schubel, J.R., Pritchard, D.W., 1986. Responses of Upper Chesapeake Bay to variations in discharge of the Susquehanna River. Estuaries 9, 236-249.

Seitzinger, S.P., Sanders, R.W., 1999. Atmospheric inputs of dissolved organic nitrogen simulate estuarine bacteria and phytoplankton. Limnology and Oceanography 44, 721-730.

Shiah, F.-K., Ducklow, H.W., 1994a. Temperature and substrate regulation of bacterial abundance, production and specific growth rate in Chesapeake Bay, USA. Marine Ecology Progress Series 103, 297-308.

Shiah, F.-K., Ducklow, H.W., 1994b. Temperature regulation of heterotrophic bacterioplankton abundance, production, and specific growth rate in Chesapeake Bay. Limnology and Oceanography 39, 1243-1258.

Steele, J.H., Henderson, E.W., 1992. The role of predation in plankton models. Journa of Plankton Research 14, 157-172.

Steinberg, D.K., Carlson, C.A., Bates, N.R., Goldthwait, S.A., Madin, L.P., Michaels, A.F., 2000. Zooplankton vertical migration and the active transport of dissolved organic and inorganic carbon in the Sargasso Sea. Deep-Sea Research I, 47.

Steinberg, D.K., Goldthwait, S.A., Hansell, D.A., 2002. Zooplankton vertical migration and the active transport of dissolved organic and inorganic nitrogen in the Sargasso Sea. Deep-Sea Research I, 49.

Stoecker, D.K., Michaels, A.E., Davis, L.H., 1987. Grazing by the jellyfish, Aurelia aurita on microzooplankton. Journal of Plankton Research 9, 901-915.

Stolte, W., McCollin, T., Noordeloos, A.A.M., Reigman, R., 1994. Effect of nitrogen source on the size distribution within marine phytoplankton populations. Journal of Experimental Marine Biology and Ecology 184, 83-97.

Stow, C.A., Jolliff, J., McGillicuddy Jr., D.J., Doney, S.C., Allen, J.I., Friedrichs, M.A.M., Rose, K.A., Wallhead, P., 2009. Skill assessment for coupled biological/physical models of marine systems. Journal of Marine Systems 76 $4-15$
Szybalski, W., 1974. Genetic and Molecular Map of Escherichia coli Bacteriophage Lambda, Handbook of Microbiology. CRC Press, Inc., USA.

Tillmann, U., 2004. Interactions between Planktonic Microalgae and Protozoan Grazers. Journal of Eukaryotic Microbiology 51, 156-168.

Tyler, M.A., Seliger, H.H., 1978. Annual subsurface transport of a red tide dinoflagellate to its bloom area: water circulation patterns and organism distributions in the Chesapeake Bay. Limnology and Oceanography 23, 227-246.

Tyler, M.A., Seliger, H.H., 1981. Selection for a red tide organism: physiological responses to the physical environment. Limnology and Oceanography 26, 310-324.

Tzortziou, M., Neale, P.J., Osburn, C.L., Megonigal, J.P., Maie, N., Jaffé, R., 2008 Tidal marshes as a source of optically and chemically distinctive colored dissolved organic matter in the Chesapeake Bay. Limnology and Oceanography 53 148-159.

Tzortziou, M., Osburn, C.L., Neale, P.J., 2007. Photobleaching of dissolved organic material from a tidal marsh-estuarine system of the Chesapeake Bay. Photochemistry and Photobiology 83, 782-792.

U.S.G.S., http://va.water.usgs.gov/chesbay/RIMP/adaps.html. streamflow database.

Verdugo, P., Alldredge, A.L., Azam, F., Kirchman, D.L. Passow, U., Santschi, P.H. 2004. The oceanic gel phase: a bridge in the DOM-POM continuum. Marine Chemistry $92,67-85$.

Vichi, M., Pinardi, N., Masina, S., 2007. A generalized model of pelagic biogeochemistry for the global ocean ecosystem. Part I. Theory. Journal of Marine Systems 64, 89-109.

Weinbauer, M.G., 2004. Ecology of prokaryotic viruses. FEMS Microbiology Reviews $28,127-181$.

Wetz, M.S., Hales, B., Wheeler, P.A., 2008. Degradation of phytoplankton-derived organic matter: implications for carbon and nitrogen biogeochemistry in coastal ecosystems. Estuarine Coastal And Shelf Science 77, 422-432.

White, J.R., Roman, M.R., 1992. Seasonal study of grazing by metazoan zooplankton in the mesohaline Chesapeake Bay. Marine Ecology Progress Series 86, 251-261.

Wommack, E.K., Colwell, R.R., 2000. Virioplankton: viruses in aquatic ecosystems. Microbiology and Molecular Biology Reviews 64, 69-114.

Wommack, E.K., Hill, R.T., Kessel, M., Russek-Cohen, E., Colwell, R.R., 1992. Distribution of viruses in the Chesapeake Bay. Applied \& Environmental Microbiology 58, 2965-2970.

Xu, J., Hood, R.R., 2006. Modeling biogeochemical cycles in Chesapeake Bay with a coupled physical-biological model. Estuarine, Coastal and Shelf Science 69 19-46.

Xu, J.T., Hood, R.R., Chao, S.Y., 2005. A simple empirical optical model for simulating light attenuation variability in a partially mixed estuary. Estuaries 28, 572-580.

Yeager, C.L.J., Harding, L.W., Mallonee, M.E., 2005. Phytoplankton production, biomass and community structure following a summer nutrient pulse in Chesapeake Bay. Aquatic Ecology 39, 135-149.

Zhang, X., Roman, M.R., Kimmel, D., McGilliard, C., Boicourt, W., 2006. Spatial variability in planktonic biomass and hydrographic variables along an axial transect in Chesapeake Bay. Journal of Geophysical Research, 111. 